\title{
Segmentação de Seqüências de Imagens por Morfologia Matemática
}

\author{
Franklin César Flores
}

\author{
DISSERTAÇÃO APRESENTADA \\ $\mathrm{AO}$ \\ INSTITUTO DE MATEMÁTICA E ESTATÍSTICA \\ DA \\ UNIVERSIDADE DE SÃO PAULO \\ PARA OBTENÇÃO DO GRAU DE MESTRE \\ EM \\ CIÊNCIA DA COMPUTAÇÃO
}

Área de Concentração : Ciência da Computação

Orientador : Prof. Dr. Junior Barrera

- São Paulo, Outubro de 2000 - 


\title{
Segmentação de Seqüências de Imagens
}

\author{
por \\ Morfologia Matemática
}

Este exemplar corresponde à redação

final da dissertação devidamente corrigida e apresentada por Franklin César Flores e aprovada pela Comissão Julgadora.

São Paulo, 4 de outubro de 2000

Banca Examinadora :

- Prof. Dr. Junior Barrera (orientador) - IME-USP

- Prof. Dr. Roberto Marcondes Cesar Junior - IME-USP

- Prof. Dr. Luiz Velho - IMPA 
aos meus pais Geraldo e Irene e ao meu irmão Walace todo o carinho que houver neste mundo... 
Que a arte nos aponte uma resposta, mesmo que ela não saiba $E$ que ninguém a tente complicar porque é preciso simplicidade para fazê - la florescer Porque metade de mim é a platéia, e a outra metade é canção E que a minha loucura seja perdoada,

Porque metade de mim é amor, e a outra metade... também.

Oswaldo Montenegro "Metade" 


\section{Agradecimentos}

Quando terminei este trabalho, pude perceber o quão afortunado sou. É muito gratificante saber que eu vim pra São Paulo em busca deste trabalho e que estou voltando com muitas outras coisas também preciosas em minha bagagem. Agradecer a Deus a cada minuto de minha vida por tudo que recebi ainda seria pouco diante da extensão de Sua GENEROSIDADE.

Devo a realização deste trabalho a muitas pessoas, alias, muitos AMIGOS. São tantos nomes que eu pensei em criar um único capítulo para acomodar todos os nomes. A todos, sou mais que grato pela companhia, pelo apoio e pelo carinho recebido. Agradeco:

Ao professor e orientador Junior Barrera pela inestimável oportunidade de trabalhar com ele, por todos os seus conselhos e ensinamentos, por sua amizade e pela parcela com que contribuiu para a minha maturação como cientista.

Aos colegas de trabalho, ou melhor, amigos de trabalho do Laboratório de Processamento de Imagens, membros do Non-Linear Image Processing Research Group e do Creativision: Caetano, Daniel, Heraldo, Marcel, Nina, Rogério, Teo e Walter. Agradeço especialmente a Roberto Hirata Jr. pela oportunidade de trabalharmos juntos e por ter permitido com que eu desfrutasse de seu trabalho de doutorado, tanto o material publicado quanto as toolboxes que desenvolvera, em especial a de operadores aperture, imprescindível para o desenvolvimento deste trabalho.

Ao professor Roberto Marcondes Cesar Junior pelas contribuições a este trabalho, através de aulas, sugestões e discussões. Ah, e também por ser um grande cara!

Ao professor Roberto de Alencar Lotufo, não só pelas várias contribuições a este trabalho, mas também pela inestimável oportunidade de podermos trabalhar juntos. Agradeco também por ter cedido as toolboxes que utilizei no desenvolvimento deste trabalho, bem como a seqüência do Jogador de Tênis de Mesa.

À Teresa Labarre por ter cedido a seqüência Mãos em Movimento.

À FAPESP por ter cedido suporte financeiro durante o desenvolvimento deste trabalho, através do processo 98/00311-4.

A todos (eu disse TODOS) os amigos mestres e doutores, mestrandos e doutorandos, que me fizeram companhia durante esta minha breve estada no IME. São muitos os nomes que deveriam ser citados aqui, mas por temer deixar alguém de fora desta, prefiro proclamar a minha admiração e o meu carinho que tenho por TODOS. Agradeço por tudo que me foi dado nesses últimos trinta e um meses, os ensinamentos, o carinho, os sorrisos, as noites mal dormidas, o pranto, a vitória, as festas, 
os ombros, o chá das seis, o futebol, as cervejadas, os shows, os amigos secretos, as broncas, os bandejões. Aqueles que merecem menção aqui por tudo isto e muito mais sabem disto no silêncio de seus corações.

A todos os amigos que encontrei entre os professores, funcionários e alunos da graduação. Muito obrigado pelo carinho e pela atenciosidade.

Em JESUS CRISTO Somos Mais Que Vencedores! Agradeço a todos os membros da Secretaria Lucas da Cidade de São Paulo pelo maravilhoso trabalho de evangelização e difusão do Amor de Deus por esta cidade. Agradeço a Deus por ter conduzido os meus passos em vossas direções e por tudo que Ele realizou em minha vida enquanto estivemos juntos. Obrigado por vocês terem sido veículos da Graça do Senhor. E pelo vosso despojar diante Dele para que a obra Dele se realize em todas as universidades de São Paulo (Que nós diminuamos para que ELE cresça).

Aos demais amigos que fiz em São Paulo, grandes responsáveis por eu aprender a amar esta cidade. Obrigado pelo amor que me foi dado e por terem aberto para mim as portas de suas casas e de seus corações. Agradecimentos especiais ao casal José e Tânia Ferreira, do Embu, por terem me dado a conhecer seus grandes corações. Agradecimentos MAIS que especiais ao casal Judite e Wlhem Caran, por terem me adotado como filho durante o tempo que fomos vizinhos. A todos vocês, meus maiores sentimentos de gratidão e amor.

Como está escrito num ímã da minha geladeira, "Friends are the family we choose for ourselves". Agradeço imensamente a Deus pela família que ele criou a partir do que era, inicialmente, uma república. Agradeço a Leandro Romero, Silvana Vicente e Teófilo E. Campos por terem deixado de serem meus amigos para se tornarem meus irmãos. Muito obrigado pela vossa paciência, carinho, alegria, e por terem segurado a minha barra por milhares de vezes. Pudesse eu não deixar esta república que tanto amo. Mas cada um dos momentos que passei em nossa (espaçosa) casa ficará para sempre gravado no meu coração.

Agradeco ao meu hiper-amigo, professor Airton Marco Polidório por ter apostado em mim e confiado em que eu pudesse chegar onde cheguei. Obrigado por tudo Airton, grande parte da culpa de eu ter terminado este trabalho é SUA. Que Deus te abençoe e permita que trabalhemos juntos um dia.

A todos os amigos que deixei em Mandaguari e Maringá que me recebem de braços abertos toda vez que retorno ao lar. Obrigado por nunca se esquecerem de mim e me darem seu carinho mesmo distantes. Agradecimentos MAIS que especiais ao bom e velho amigo Gilmar Lopes dos Santos, o mundialmente conhecido Magú, por ter sido o melhor dos amigos, fiel desde a minha chegada em Mandaguari até o momento de entrar no ônibus para voltar para Sampa. A você, meu amigo, e a todos, meu muito obrigado.

Especialmente à Tia Marlene, ao Tio Narciso e às primas Eliana, Silvana e Adriana, por terem sido a extensão de minha casa aqui em São Paulo. Obrigado por tudo o que vocês me deram! Que o Senhor possa lhes dar em dobro tudo o que recebi de vocês. 
Finalmente, e mais que especialmente, agradeço aos meus pais Geraldo Flores e Irene Gomes Flores por terem dado tudo de si para que eu chegasse onde eu cheguei, e ao meu irmão Walace Fabiano Flores por ser muito daquilo que eu queria ser. Vocês são a maior preciosidade que eu tenho. Obrigado por tudo! Este trabalho e tudo o que vem com ele também é de vocês. Que Deus continue nos abençoando sempre e sempre! 


\section{Resumo}

Dentre as técnicas aplicadas em produção de vídeo digital estão as aplicadas para combinação de vídeos. Estas técnicas consistem na substituição de objetos em uma seqüência de vídeo através do recorte desses objetos e da colagem dos mesmos em uma outra seqüência. Um dos problemas apresentados por técnicas convencionais de combinação de vídeos é o número de cuidados a priori que devem ser tomados na produção do vídeo que será processado. Outro problema relacionado a combinação de vídeos ocorre quando se deseja editar um vídeo que não foi produzido com cuidados a priori. Neste caso, os objetos são recortados manualmente, o que pode se tornar inviável, devido a grande quantidade de quadros da seqüência.

O objetivo deste trabalho é propôr uma ferramenta computacional que faça combinação de vídeos, sem as desvantagens apresentadas acima. Os objetos de interesse são segmentados através da aplicação do Paradigma de Beucher-Meyer, uma técnica aplicada em segmentação de imagens que provê a detecção exata das bordas dos objetos a partir de um conjunto de marcadores, reduzindo o problema de segmentação ao problema de se encontrar marcadores para os objetos a serem segmentados. Estes marcadores são encontrados através da aplicação de operadores aperture, projetados por técnicas de aprendizado computacional.

Após a introdução, seguem um capítulo sobre fundamentos da Morfologia Matemática e um capítulo sobre segmentação morfológica e filtros conexos, onde o Paradigma de Beucher-Meyer será apresentado. Em seguida, são apresentados os operadores aperture, bem como o projeto destes operadores por aprendizado computacional. É apresentada, então, a metodologia proposta para segmentação de seqüências de imagens, bem como alguns resultados da aplicação desta metodologia em seqüências de imagens em níveis de cinza e em seqüências de imagens coloridas. 


\section{Abstract}

Among the techniques applied to digital video edition are the video mixing ones. These techniques consist in the substitution of objects in a video sequence by cutting these objects and pasting them in another sequence. One problem related to usual video mixing techniques is the number of special cares supposed when the sequence is filmed. Another problem related to video mixing occurs when the edition of a sequence filmed without a priori cares is desired. In this case, the objects are cut manually, and this task can be impracticable, due the excessive number of frames in the sequence.

The goal of this work is to propose a computational tool to make video mixing, without the disadvantage pointed above. The desired objects are segmented through the Beucher-Meyer Paradigm application, a technique used in image segmentation to provide an exact border detection of the objects, given a set of markers, reducing the segmentation problem to the finding markers one. These markers are found through application of aperture operators, design by computational learning.

Following the introduction, are a chapter about the Mathematical Morphology basis and another chapter about morphological segmentation and connected filters. The Beucher-Meyer will be presented in this chapter. The next two chapters introduce the aperture operator and its design by computational learning. Finally, the proposed methodology is introduced, as well some results of application of this methodology in both grayscale and color image sequences. 


\section{Sumário}

1 Introdução 1

2 Fundamentos da Morfologia Matemática 5

2.1 Definições Preliminares . . . . . . . . . . . . . . . . . . . . . . . . 5

2.2 Operadores Elementares da Morfologia Matemática . . . . . . . . . . . . . . . 6

2.3 Operadores Morfológicos . . . . . . . . . . . . . . . . . . . . . 10

2.4 Morfologia Matemática para Imagens Multibanda . . . . . . . . . . . . . . . . . 13

2.4.1 Gradiente Colorido . . . . . . . . . . . . . . . . . . . . . . . . . . . . . 14

3 Filtros Conexos e Segmentação Morfológica 19

3.1 Definições Preliminares . . . . . . . . . . . . . . . . . . . . . . . . . . 20

3.2 Filtros Conexos . . . . . . . . . . . . . . . . . . . . . . . 21

$3.2 .1 \quad$ Filtragem Homotópica . . . . . . . . . . . . . . . . . . . . 22

$3.2 .2 \quad$ Levelings . . . . . . . . . . . . . . . . . . . . . . . . . 23

3.2 .3 Area Opening . . . . . . . . . . . . . . . . . . . . 26

$3.2 .4 \quad$ Area Merging . . . . . . . . . . . . . . . . . . 27

3.3 Linha de Partição de Águas (Watershed) $\quad \ldots \ldots$. . . . . . . . . . . . . 31

3.4 Paradigma de Beucher-Meyer . . . . . . . . . . . . . . . . . 33

3.5 Filtros Conexos Multibanda e Segmentação Colorida . . . . . . . . . . . . . . . 34

3.5.1 Area Opening . . . . . . . . . . . . . . . . . . . . 35

3.5.2 Area Merging . . . . . . . . . . . . . . . . . . . . . 35

3.5.3 Paradigma de Beucher-Meyer . . . . . . . . . . . . . . . . 36

4 Operadores Aperture $\quad 37$ 
$4.1 \quad$ Níveis de Cinza . . . . . . . . . . . . . . . . . . . . . . . . . . 37

4.2 Imagens Multibanda . . . . . . . . . . . . . . . . . . . . 41

5 Projeto de Operadores por Aprendizado Computacional 43

5.1 Projeto de Apertures . . . . . . . . . . . . . . . . . . . . . . . . . . 43

5.2 Projeto de Apertures Multibanda . . . . . . . . . . . . . . . . . . 48

6 Segmentação Morfológica de Seqüências de Imagens $\quad 51$

6.1 Metodologia Proposta . . . . . . . . . . . . . . . . . . . . . . . 51

6.2 Aplicação em uma Seqüência Sintética . . . . . . . . . . . . . . . . . . . 56

6.3 Comparação de Performance entre Multiclassificadores . . . . . . . . . . . . . . . 58

6.3 .1 Multiclassificação . . . . . . . . . . . . . . . . . . . . . 58

6.3 .2 Multiclassificação por Correlação . . . . . . . . . . . . . . . . . 59

6.3 .3 Multiclassificação por Módulo da Diferença . . . . . . . . . . . . . . 60

6.3 .4 Experimentos Realizados . . . . . . . . . . . . . . . . . . . 61

7 Aplicações $\quad 73$

7.1 Seqüência Real : Jogador de Tênis de Mesa . . . . . . . . . . . . . . . . . . 73

7.1 .1 Segmentação da Bola . . . . . . . . . . . . . . . . . . . . . . . 74

7.1 .2 Segmentação da Raquete . . . . . . . . . . . . . . . . . . . . . . . 74

7.2 Segmentação de Seqüências de Imagens Coloridas . . . . . . . . . . . . . . . . . 76

7.2.1 Metodologia Aplicada em Seqüências de Imagens Coloridas . . . . . . . . 78

7.2.2 Estudo Comparativo Entre os Gradientes Coloridos Propostos . . . . . . 80

7.3 Seqüência Real : Bolas de Bilhar . . . . . . . . . . . . . . . . . . . . 82

7.4 Seqüência Real : Mãos em Movimento . . . . . . . . . . . . . . . . . . . . 83

8 Conclusão $\quad 89$

A Abordagem Clássica $\quad 93$

A.1 Chroma Key . . . . . . . . . . . . . . . . . . . . . . . . . 93

A.2 Segmentação Hierárquica Baseada em Contorno . . . . . . . . . . . . . . . . . . 94

A.3 Segmentação Morfológica Hierárquica para Codificação . . . . . . . . . . . . . . . 96

A.4 Algoritmos Occam para Estimação de Movimento . . . . . . . . . . . . . . . . . . 97 
A.5 Perseguição de Alvo por Comparação de Características . . . . . . . . . . . . . . 99

A.6 Informação Vetorial e Critérios de Similaridade . . . . . . . . . . . . . . . . . . 100

B Notação Utilizada 103

C Artigos Publicados 109 


\section{Lista de Figuras}

1.1 Aplicação de Chroma Key em Forrest Gump . . . . . . . . . . . . . . . . 2

1.2 Etapas do Paradigma de Beucher-Meyer. (a) Imagem Original. (b) Imagem com Bordas Realçadas. (c) Marcadores. (d) Imagem Filtrada. (e) Bordas Detectadas. (f) Composição das Bordas Detectadas com a Imagem Original. . . . . . . . . . . 3

1.3 Projeto Automático de Operadores Aperture. Imagens de Observação e respectivas Imagens Ideais. . . . . . . . . . . . . . . . . . . . . . 4

2.1 (a) Imagem Original. (b) Dilatação. (c) Erosão. . . . . . . . . . . . . . . . . . . . 8

2.2 (a) Imagem Original. (b) Dilatação. (c) Erosão. . . . . . . . . . . . . . . . . . . . 9

2.3 (a) Imagem Original. (b) Abertura. (c) Fechamento. . . . . . . . . . . . . . . . 10

2.4 (a) Imagem Original. (b) Abertura. (c) Fechamento. . . . . . . . . . . . . . . . . 11

2.5 Resultados da Aplicação dos Gradientes Coloridos Apresentados. . . . . . . . . . 17

2.6 Resultados da Aplicação dos Gradientes Coloridos Apresentados. . . . . . . . . . 17

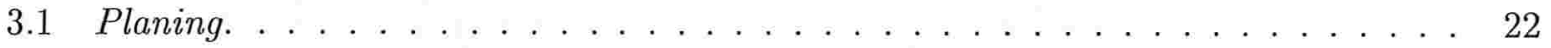

3.2 Filtragem Homotópica. (a) Gradiente. (b) Marcadores. (c) Gradiente Filtrado. . 22

3.3 Filtragem Homotópica: Somente os Mínimos Regionais são Alterados. … . . . 23

3.4 Flattening. . . . . . . . . . . . . . . . . . . . . . 24

3.5 Leveling. . . . . . . . . . . . . . . . . . . . . . . . 25

3.6 Construção de um Leveling para uma função $f$ utilizando-se uma Função Marcadora $g . g^{\prime}$ é um Leveling de $f \ldots \ldots \ldots . \ldots \ldots$

3.7 Função Marcadora obtida por um Filtro Alternado Seqüencial. (a) Imagem Original. (b) Função Marcadora. (c) Leveling. . . . . . . . . . . . . . . . . . . . . . 26

3.8 Area Opening. (a) Imagem Original. (b) Resultado da Filtragem. (c) Resíduo da Filtragem. . . . . . . . . . . . . . . . . . . . 27

3.9 Area Merging. (a) Imagem Original. (b) Resultado da Filtragem. . . . . . . . . . 30 
3.10 Bacias de Captação. (a) Inundação das Bacias a partir dos Mínimos Regionais. (b) Construção do Muro (Linha de Partição de Águas) que impede que duas Bacias se unam. . . . . . . . . . . . . . . . . . . . . . 32

3.11 Watershed. (a) Imagem Original. (b) Gradiente. (c) Watershed do Gradiente. . . 32

3.12 Supersegmentação. (a) Imagem Original. (b) Supersegmentação. . . . . . . . . . . 33

3.13 Etapas do Paradigma de Beucher-Meyer. (a) Imagem Original. (b) Gradiente. (c) Marcadores. (d) Filtragem Homótopica. (e) Watershed. (f) Composição do Watershed com a Imagem Original. . . . . . . . . . . . . . . . . . . . . . 34

3.14 Area Merging. (a) Imagem Original. (b) Resultado da Filtragem. . . . . . . . . . 35

4.1 Operador Localmente Definido. . . . . . . . . . . . . . . . . . . . 38

4.2 Operador Invariante por Translação. . . . . . . . . . . . . . . . . . . . 39

4.3 Enjanelamento nos Níveis de Cinza. . . . . . . . . . . . . . . . . . . 39

4.4 Exemplo de Aplicação do Aperture . . . . . . . . . . . . . . . . . . . . . 41

5.1 Etapas de Treinamento. . . . . . . . . . . . . . . . . . 45

5.2 Par de Treinamento. (a) Imagem de Observação. (b) Imagem Ideal. . . . . . . . 45

5.3 Particionamento de $\mathcal{M} \ldots \ldots \ldots \ldots \ldots \ldots \ldots \ldots$

5.4 Par (S,I) de Imagens de Treinamento (a) Imagem de Observação S. (b) Imagem

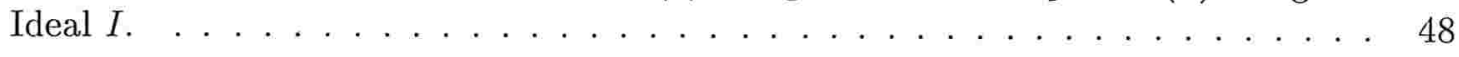

5.5 (a) Imagem Colorida. (b-d) Posicionamento das janelas $W_{1}, W_{2}$ e $W_{3}$ em suas respectivas bandas no ponto $(x, y) \ldots \ldots \ldots \ldots$. . . . . . . . . 49

6.1 Pares de Treinamento. Coluna da Esquerda: Imagens de Observação. Coluna da Direita: Imagens Ideais. . . . . . . . . . . . . . . . . . . 53

6.2 Aplicação do Operador Aperture. (a) $M_{i}$ calculada em função de $f_{i}$ (o objeto que lembra uma impressão digital), em composição com o quadro $i$. (b) Resultado do Operador Aperture restrito em $M_{i} \ldots \ldots \ldots \ldots \ldots$. . . . . . 54

6.3 Filtragem do Marcador. (a) Resultado do Aperture. (b) Marcadores Filtrados. (c) Composição com quadro. . . . . . . . . . . . . . . . . . 54

6.4 Diagrama de Blocos com as Principais Etapas da Metodologia Proposta. . . . . . 55

6.5 Segmentação de uma Partícula. quadros 35-46 da seqüência. . . . . . . . . . 57

6.6 Resultados do Algoritmo de Watershed. (a) Resultado Apropriado. (b) Resultado Não Apropriado. . . . . . . . . . . . . . . . . . . . . . . . . . 62 
6.7 Resultados dos Multiclassicadores: (a) Marcadores gerados pelo Aperture. (b) Composição dos Marcadores gerados pelo Aperture com Imagem Original. (c) Marcadores gerados por Correlação. (d) Composição dos Marcadores gerados por Correlação com Imagem Original.

6.8 Resultados dos Multiclassicadores: (a) Marcadores gerados pelo Aperture. (b) Composição dos Marcadores gerados pelo Aperture com Imagem Original. (c) Marcadores gerados por Correlação. (d) Composição dos Marcadores gerados por Correlação com Imagem Original.

6.9 Resultados de Segmentação. (a) Segmentação Correta (b) Erro do Algoritmo de Watershed (c) Redução do Erro do Algoritmo de Watershed (d) Invasão da Linha de Partição de Águas (e) Segmentação de Duas Partículas (f) Perda da Partícula

6.10 Segmentação da Partícula Fragmentada. (a) Segmentação Total. (b-c) Segmentação Parcial. . . . . . . . . . . . . . . . . . . . . . . . . .

7.1 Bola Segmentada na Seqüência Jogador de Tênis de Mesa. quadros 8-16 da seqüência. . . . . . . . . . . . . . . . . . . . . 75

7.2 (a) Raquete com Borda Não Definida. (b) Segmentação da Raquete. . . . . . . . 76

7.3 Raquete Segmentada na Seqüência Jogador de Tênis de Mesa. quadros 8-16 da seqüência. . . . . . . . . . . . . . . . . 77

7.4 Comparação da Redução de Zonas Planas Após Filtragem. (a) Sem Filtragem. (b) Abertura e Fechamento Coloridos. (c) Area Merging Colorido. (d) Composição de Abertura e Fechamento Coloridos com Area Merging Colorido. . . . . 79

7.5 Aplicação do Operador Aperture. (a) quadro $f_{i}$. (b) Restrição $M_{i}$. (c) Resultado da aplicação do Operador. . . . . . . . . . . . . . . . . . . . 80

7.6 Aplicação do Paradigma de Beucher-Meyer. (a) Gradiente do quadro Colorido. (b) Marcadores. (c) Objeto Segmentado (Watershed). (d) Composição do Watershed com o quadro. . . . . . . . . . . . . . . . . . . . . . . 81

7.7 Resultados do Primeiro Experimento de Comparação entre os Gradientes Coloridos. 81

7.8 Resultados do Segundo Experimento de Comparação entre os Gradientes Coloridos. 82

7.9 Seqüência Bolas de Bilhar Segmentada . . . . . . . . . . . . . . . . . . 84

7.10 Mãos em Movimento. (a) Quadro da Seqüência. (b) Imagem Filtrada. . . . . . . 85

7.11 Segmentação da Mão. (a) Marcadores. (b) Linha de Partição de Águas. . . . . . 85

7.12 Seqüência Mãos em Movimento Segmentada. . . . . . . . . . . . . . . . 87

8.1 Combinação de Vídeo realizado após Segmentação das Mãos. (a-b) Imagens a serem mixadas $(\mathrm{c}-\mathrm{d})$ Combinação de Vídeo. . . . . . . . . . . . . . . . . . 90

A.1 Estúdio de filmagem para seqüências onde será aplicada a Chroma Key . . . . . 94 
viii

A.2 Resultado de aplicação de Chroma Key. . . . . . . . . . . . . . . . . 95 


\section{Capítulo 1}

\section{Introdução}

Hoje vai passar um filme na TV

Que eu já vi no cinema

Epa!? Mutilaram o filme,

Cortaram uma cena

Ultraje a Rigor "Sexo!!"

Há pouco mais de um século os irmãos Lumière criaram o cinématographe [1]. Desde então, o mundo acompanha extasiado a evolução do cinema, onde cada novo filme apresenta efeitos especiais cada vez mais realistas.

Nos dias de hoje, alguns destes efeitos especiais são criados por inovadoras técnicas de edição de vídeo. Algumas destas técnicas, conhecidas como "combinação de vídeos", têm por finalidade combinar partes de vários vídeos de modo a criar um novo vídeo. Através da aplicação de tais técnicas podemos, por exemplo, utilizar um vídeo onde uma mesa esteja na cena e outro que apresente uma bailarina dançando, e criar um filme onde a bailarina esteja dançando sobre a mesa. Algumas técnicas para combinação de vídeos, como chroma key, são clássicas.

Chroma key é utilizada para substituir objetos em uma cena. Esta técnica consiste na filmagem do vídeo principal cobrindo-se os objetos que serão substituídos com uma cor que contraste com a dos demais objetos da cena, seguida pela substituição dos objetos cobertos. Figura 1.1 mostra uma cena do filme Forrest Gump, onde o ator Tom Hanks "contracena" com John Lennon, editada com Chroma Key.

Nos últimos anos, houve um grande avanço na produção de vídeo graças ao advento do vídeo digital. A principal razão para estes avanços é a possibilidade de edição utilizando-se ferramentas computacionais. Muitos pesquisadores interessam-se pela tecnologia de vídeo digital, desenvolvendo pesquisa nas áreas de edição de vídeo, teledifusão digital, imageamento de processos e 

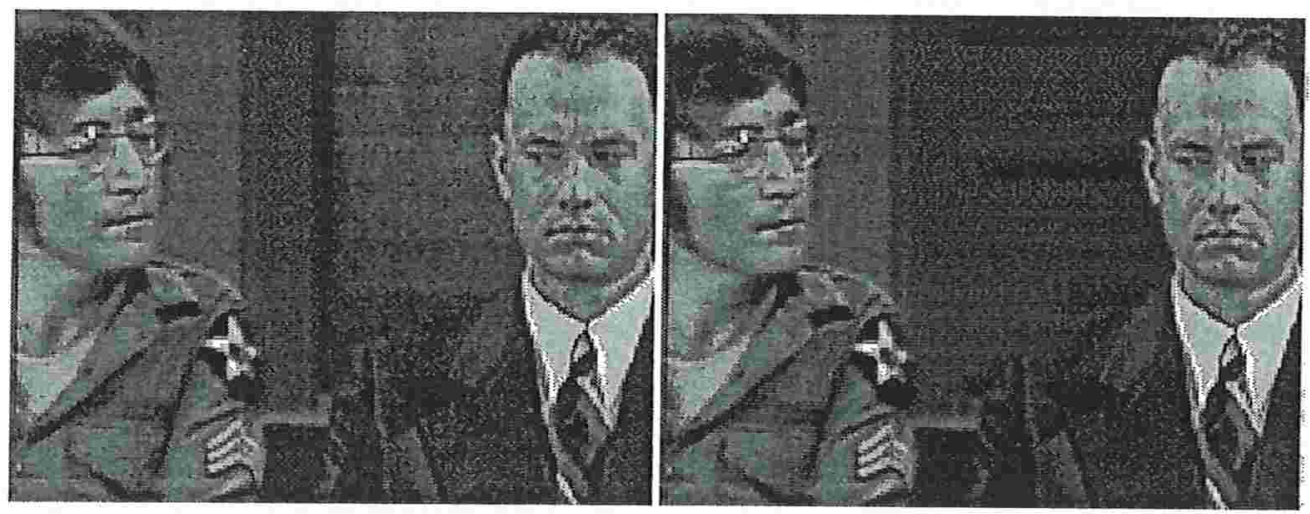

Figura 1.1: Aplicação de Chroma Key em Forrest Gump

automação de sistemas.

Relacionadas às áreas de vídeo digital, podemos encontrar pesquisas em codificação de vídeo, editoração eletrônica, separação de objetos em um vídeo, perseguição de alvos, estimação de movimento, reconstrução de fundo, entre outras.

O objetivo deste trabalho é propor uma ferramenta computacional que torne a edição de vídeo digital menos trabalhosa. Esta ferramenta seria uma técnica utilizada para encontrar e separar objetos em uma seqüência de vídeo $[2,3,4]$. Separar objetos em uma seqüência de vídeo pode ser uma tarefa trabalhosa, dependendo do tamanho da seqüência e da complexidade das formas dos objetos manipulados. O papel da ferramenta proposta é automatizar este processo de separação. Em Processamento Digital de Imagens, chamamos de segmentação o processo de separação de objetos em uma imagem

A ferramenta proposta nos próximos capítulos consiste na aplicação do Paradigma de BeucherMeyer $[5,6,7]$, uma técnica de segmentação, em cada quadro da seqüência de vídeo. Este paradigma reduz o problema de segmentação ao problema de detecção de marcadores, que são "apontadores" para os objetos a serem segmentados. Estes marcadores serão detectados por um operador aperture $[8,9,10]$, que promove a deteç̧ão do objeto de interesse em cada quadro da seqüência através da imposição de um marcador sobre o mesmo.

O Paradigma de Beucher-Meyer consiste na detecção exata das bordas dos objetos de interesse (Figura 1.2 (e)) via aplicação de um operador watershed em uma imagem cujos objetos possuem as bordas realçadas (Figura 1.2 (b)). Esta imagem de bordas realçadas deve ainda ter sido filtrada (Figura 1.2 (d)), de modo a eliminar todos os ruídos que levariam a uma segmentação incorreta. Porém, apesar do Paradigma de Beucher-Meyer reduzir o problema de segmentação ao problema de encontrar marcadores para os objetos a serem segmentados, não existe uma método sistemático para encontrar tais marcadores (Figura 1.2 (c)).

$\mathrm{Na}$ metodologia que será proposta, estes marcadores serão encontrados via aplicação de operadores aperture. Tais operadores são projetados através da observação de pares de imagens. Exemplos destes pares são apresentados na Figura 1.3. As imagens da esquerda representam as entradas para o problema que deve ser resolvido via aplicação do operador aperture, e as imagens da direita representam os respectivos resultados desejados da aplicação do operador aperture. 


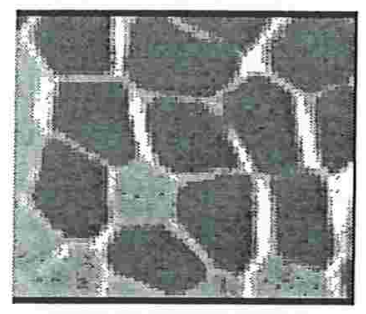

(a)

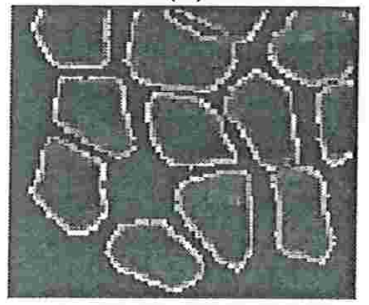

(d)

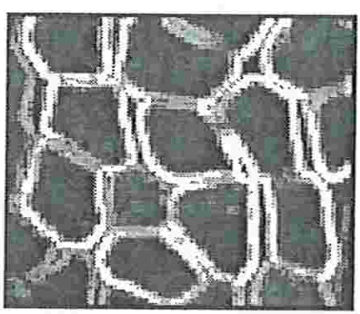

(b)

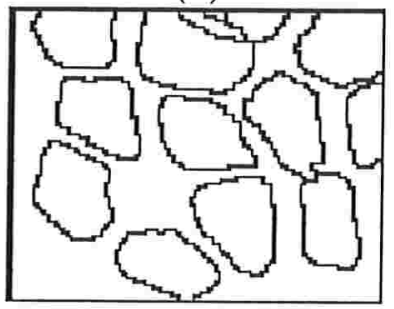

(e)

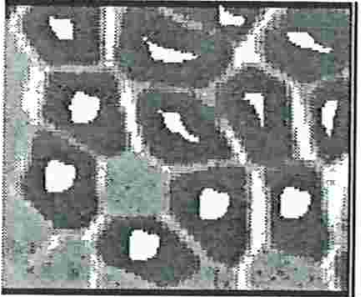

(c)

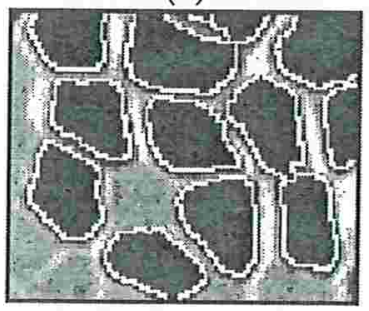

(f)

Figura 1.2: Etapas do Paradigma de Beucher-Meyer. (a) Imagem Original. (b) Imagem com Bordas Realçadas. (c) Marcadores. (d) Imagem Filtrada. (e) Bordas Detectadas. (f) Composição das Bordas Detectadas com a Imagem Original.

A primeira imagem citada que compõe um destes pares é chamada de imagem de observação. A outra imagem que compõe o par (a que contém o resultado esperado) é chamada de imagem ideal.

Um requisito que deve ser cumprido no projeto de operadores aperture é a similaridade estatística entre as imagens de observação utilizadas. Em outras palavras, todas as imagens de observação devem representar o mesmo problema a ser solucionado pelo operador aperture. Estas imagens de observação são selecionadas em vários instantes da seqüência de vídeo, de modo a cobrir todas as situações pelas quais os objetos desejados passam na sequiência. Uma outra opção é o projeto de um outro operador aperture caso ocorram mudanças drásticas na cena, tais como mudança na iluminação ou posicionamento de câmera.

A metodologia proposta pode ser aplicada em seqüências de imagens em níveis de cinza e coloridas, onde a metodologia aplicada em seqüências coloridas é uma extensão da aplicada em níveis de cinza. No caso colorido, fazem-se necessárias:

- a utilização de um modelo de representação de operadores aperture aplicados em imagens coloridas. A informação em imagens coloridas é composta por vários atributos, e para cada um deles é associada uma janela. A união destas janelas resulta na janela utilizada no projeto do operador aperture;

- a escolha de métricas para o realce de bordas em imagens coloridas. Ao contrário de imagens em níveis de cinza, o cálculo do gradiente em imagens coloridas não é natural pois não existe uma relação de ordem entre os pixels. Os gradientes coloridos estudados são imagens em níveis de cinza e podem ser utilizados no Paradigma de Beucher-Meyer. 

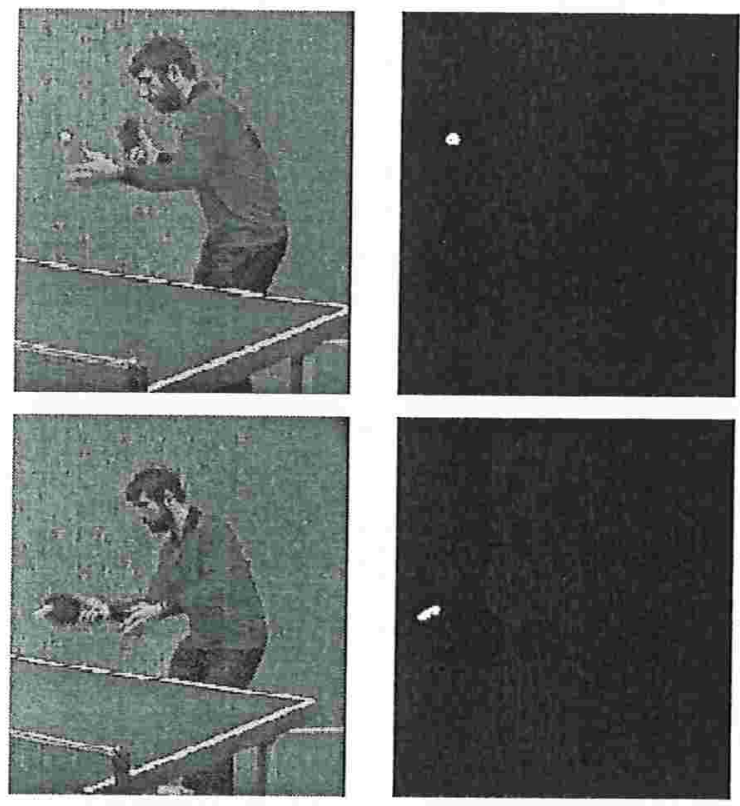

Figura 1.3: Projeto Automático de Operadores Aperture. Imagens de Observação e respectivas Imagens Ideais.

O Capítulo 2 apresenta os fundamentos da Morfologia Matemática bem como algumas definições importantes que foram usadas neste trabalho. O Capítulo 3 descreve todas as etapas que compõem o Paradigma de Beucher-Meyer e introduz os filtros conexos. O Capítulo 4 apresenta os operadores aperture. O Capítulo 5 mostra como os operadores aperture podem ser estimados via otimização estatística no espaço destes operadores. O Capítulo 6 descreve a metodologia proposta para segmentação de objetos em seqüências de imagens. O Capítulo 7 descreve vários resultados experimentais. E, finalmente, este trabalho é concluído no Capítulo 8. O Apêndice A apresenta uma revisão bibliográfica sobre segmentação em seqüência de imagens. O Apêndice B contém a notação utilizada neste trabalho. E o Apêndice $\mathrm{C}$ lista os artigos publicados resultantes deste trabalho. 


\title{
Capítulo 2
}

\section{Fundamentos da Morfologia Matemática}

\author{
Nós somos medo e desejo \\ Somos feitos de silêncio e som \\ Tem certas coisas que eu não sei dizer \\ Lulu Santos "Certas Coisas"
}

Este Capítulo apresenta uma breve introdução à Morfologia Matemática, que é uma teoria algébrica que estuda a decomposição de operadores entre reticulados completos em termos de operadores e operações elementares (erosão, dilatação, ínfimo, supremo, negação e composição) $[11,12,13,14,15,16,17]$ e tem sido amplamente aplicada em diversas áreas de pesquisas em Processamento Digital de Imagens e Visão Computacional como, por exemplo, análise de imagens, filtragem e segmentação.

A Seção 2.1 apresenta algumas definições importantes que serão utilizadas por todo este trabalho. A Seção 2.2 introduz os operadores e operações elementares dos quais os operadores morfológicos são compostos. Exemplos de operadores morfológicos, descritos em termos dos operadores descritos na Seção anterior, são apresentados na Seção 2.3. Finalmente, a Seção 2.4 apresenta os operadores morfológicos no contexto das imagens multibanda.

\subsection{Definições Preliminares}

Serão apresentadas nesta Seção algumas definições que serão utilizadas por todo o texto.

Uma relação de ordem parcial é uma relação com as propriedades reflexiva, transitiva e antisimétrica [18]. Um conjunto cujos elementos possuam uma relação de order parcial é chamado 
de conjunto parcialmente ordenado.

Dado um conjunto ordenado $\mathcal{L}$ com uma relação de ordem $\leq . \mathcal{L}$ é dito totalmente ordenado se, $\forall x, y \in \mathcal{L}, x \leq y$ ou $y \leq x$. A relação de ordem $\leq$ é dita total.

Um conjunto parcialmente ordenado $\mathcal{L}$ é um reticulado completo se, $\forall \mathcal{X} \subset \mathcal{L}, \mathcal{X}$ possui um ínfimo e um supremo [18].

Seja $E \subset \mathbb{Z} \times \mathbb{Z}$, um subconjunto retangular finito de pontos. Seja $|E|$ a cardinalidade de $E$. Seja $K=[0, k]$ um intervalo fechado de $\mathbb{Z}$. Denotemos por $F u n[E, K]$ o conjunto de todas as funções $f: E \rightarrow K$. Denotemos os elementos de $F u n[E, K]$ por letras minúsculas $f, g, \ldots$. Uma imagem (seja binária ou em níveis de cinza) é dada por uma função $f \in F u n[E, K]$.

Uma imagem binária pode ainda ser definida por subconjuntos $X \subset E$. Dado $x \subset E$, uma imagem $f \in F u n[E,\{0,1\}]$ é dada por, $\forall x \in E$,

$$
f(x)=\left\{\begin{array}{l}
1, \text { se } x \in X \\
0, \text { caso contrário. }
\end{array} .\right.
$$

O conjunto Fun $[E, K]$ é um reticulado completo, cuja relação de ordem é " $\leq$ " (menor ou igual a); dados $f, g \in F u n[E, K], f \leq g \Leftrightarrow f(x) \leq g(x), \forall x \in E$.

Sejam $X \subset E, y \in E$, a translação de $X$ por $y$ é dada por $X_{y}=\{x \in E: x-y \in X\}$. A translação de uma função $f \in F u n[E, K]$ por $y, y \in E$, é dada por $f_{y}(x)=f(x-y), \forall x \in E$.

Um operador é um mapeamento entre reticulados completos. Por exemplo, um operador entre imagens é dado por $\Psi: F u n[E, K] \rightarrow F u n[E, K]$. Um operador $\Psi$ pode possuir algumas das seguintes propriedades:

- Um operador $\Psi$ é extensivo se $f \leq \Psi(f)$.

- Um operador $\Psi$ é anti-extensivo se $f \geq \Psi(f)$.

- Um operador $\Psi$ é crescente se $f \leq g \Rightarrow \Psi(f) \leq \Psi(g)$.

- Um operador $\Psi$ é idempotente se $\Psi(f)=\Psi(\Psi(f))$.

Os operadores crescentes e idempotentes são chamados de filtros morfológicos [11].

\subsection{Operadores Elementares da Morfologia Matemática}

A Morfologia Matemática tem por objetivo o estudo de operadores decomponíveis em termos de operadores e operações elementares. Esta decomposição pode ser expressa através da linguagem morfológica [14], que é uma linguagem formal onde o vocabulário é composto pelos operadores de erosão e dilatação e pelas operações de supremo, ínfimo, negação e composição. Um operador morfológico é representado por uma frase da linguagem morfológica.

Sejam $f, g \in F u n[E, K]$, as operações de supremo, infimo e negação são, respectivamente, dadas por, $\forall x \in E$,

$$
(f \vee g)(x)=\max \{f(x), g(x)\}
$$




$$
\begin{gathered}
(f \wedge g)(x)=\min \{f(x), g(x)\} \\
\nu(f(x))=k-f(x),
\end{gathered}
$$

onde $k$ é o maior elemento de $K$.

Sejam $f, g \in F u n[E, K]$, as operações de adição e subtração são, respectivamente, dadas por,

$$
\begin{gathered}
(f+g)(x)=\min \{(f(x)+g(x)), k\} \\
(f-g)(x)=\left\{\begin{array}{l}
f(x)-g(x), \text { se } g(x)<f(x) \\
0, \text { caso contrário, }
\end{array}\right.
\end{gathered}
$$

$\forall x \in E . k$ é o maior elemento de $K$.

Sejam $\psi_{1}: F u n[E, K] \rightarrow F u n[E, K]$ e $\psi_{2}: F u n[E, K] \rightarrow F u n[E, K]$ dois operadores. A composição entre dois operadores $\psi_{1}$ e $\psi_{2}$ é dada por

$$
\psi_{2} \psi_{1}(f)=\psi_{2}\left(\psi_{1}(f)\right)
$$

Seja $\psi_{n} \psi_{n-1} \cdots \psi_{1}$ uma composição de $n$ operadores. A ordem de aplicação dos operadores é da direita pra esquerda.

Sejam $f \in F u n[E, K]$ e $B \subset E$, a dilatação de $f$ por $B$ é dada por, $\forall x \in E$,

$$
\delta_{B}(f)(x)=\bigvee_{y \in B_{x}} f(x-y)
$$

onde $B$ é o elemento estruturante.

A Figura 2.1 (a) apresenta uma função $f$ e a Figura 2.1 (b) mostra a dilatação de $f$ por um elemento estruturante de comprimento 7. A Figura 2.2 (b) mostra a dilatação da Figura 2.2 (a) por um elemento estruturante em formato de disco com diâmetro $d=15$. Note que a imagem resultante apresenta regiões mais claras que a imagem original e que vários objetos mais escuros, menores que o elemento estruturante, desapareceram.

Sejam $f \in F u n[E, K]$ e $B \subset E$, a erosão de $f$ por $B$ é dada por, $\forall x \in E$,

$$
\varepsilon_{B}(f)(x)=\bigwedge_{y \in B_{x}} f(x+y)
$$

onde $B$ é o elemento estruturante.

Observe na Figura 2.1 (c) o efeito da aplicação da erosão sobre a Figura 2.1 (a). Note que, ao contrário da Figura 2.1 (b), o resultado da erosão, também por um elemento estruturante em forma de disco com diâmetro $d=15$, apresenta regiões mais escuras que a Figura 2.1 (a), assim como os objetos mais claros menores que o elemento estruturante desapareceram.

Com relação à forma e ao tamanho do elemento estruturante, a escolha deste conjunto depende do problema que se quer resolver. Erosões que utilizam como parâmetro, por exemplo, um elemento estruturante em forma de disco com diâmetro $d=15$ eliminam mais objetos claros que elementos estruturante em forma de disco com diâmetros menores. 


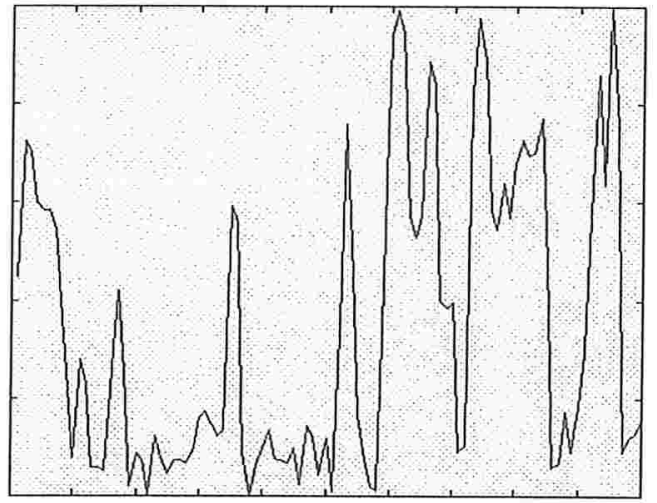

(a)

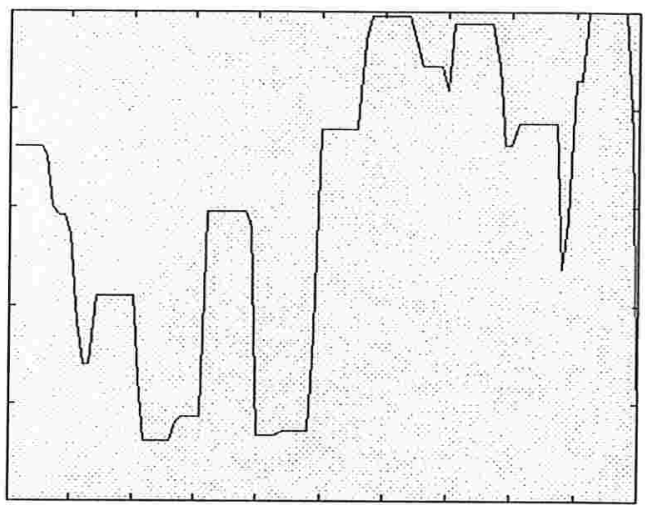

(b)

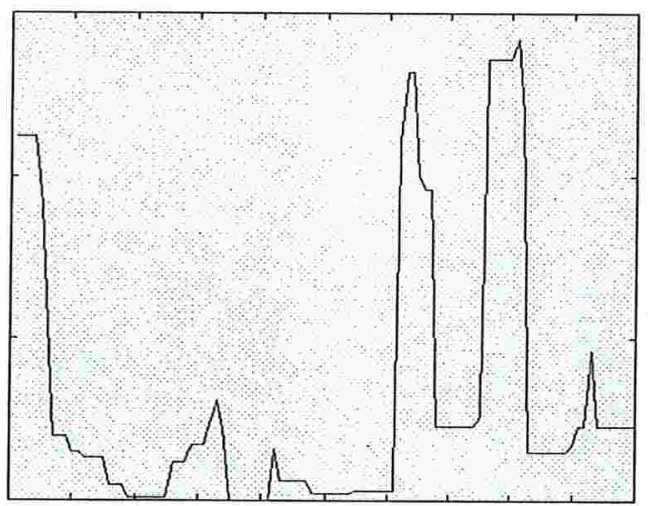

(c)

Figura 2.1: (a) Imagem Original. (b) Dilatação. (c) Erosão. 


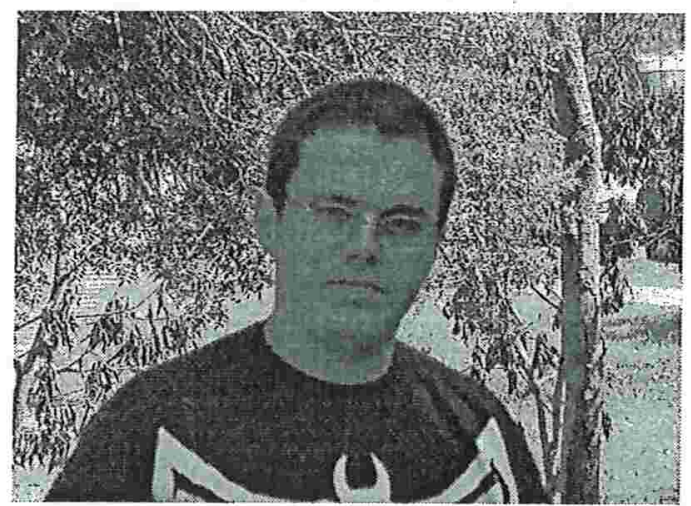

(a)

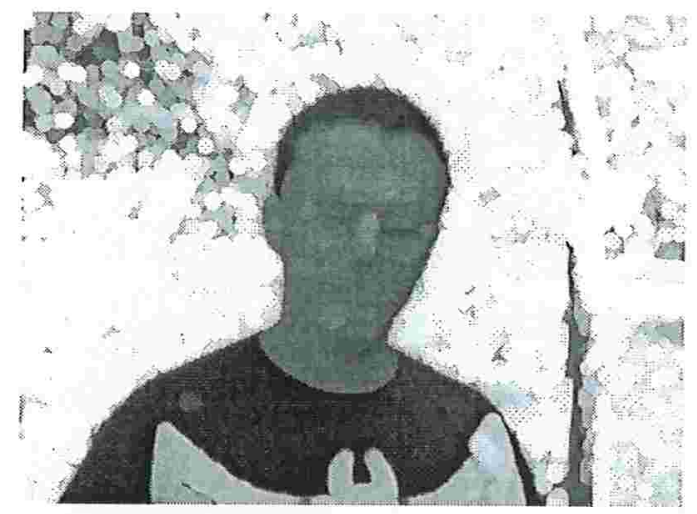

(b)

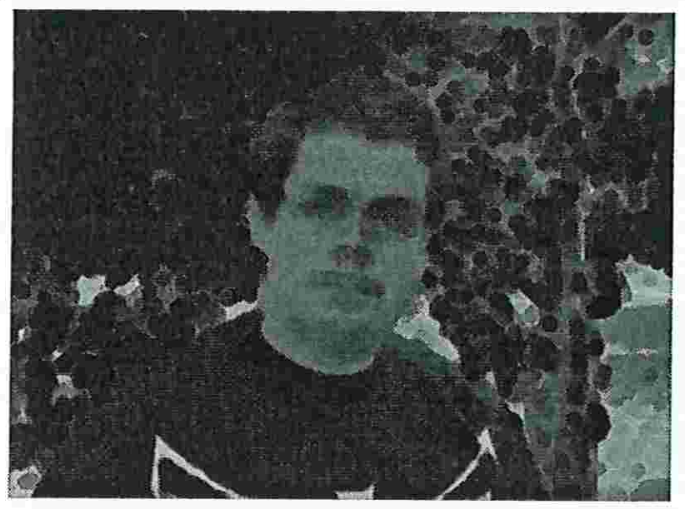

(c)

Figura 2.2: (a) Imagem Original. (b) Dilatação. (c) Erosão. 


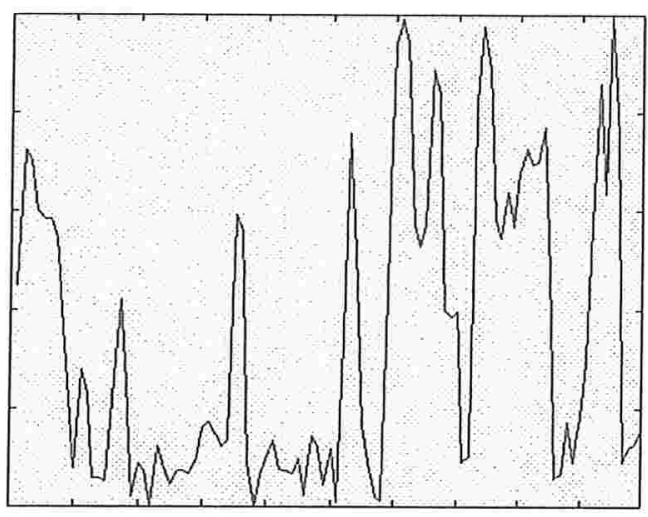

(a)

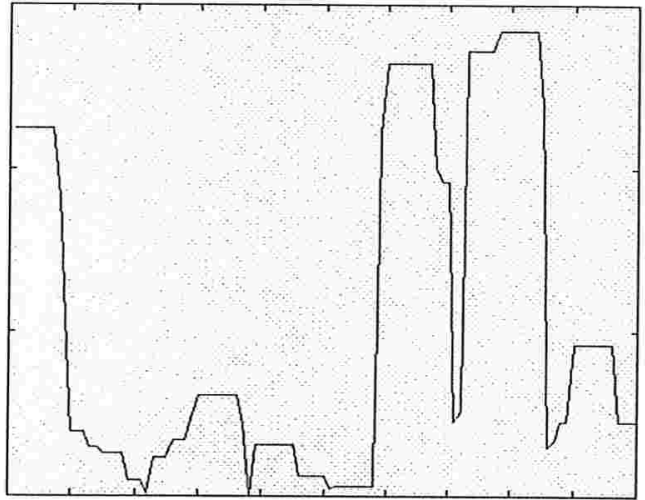

(b)

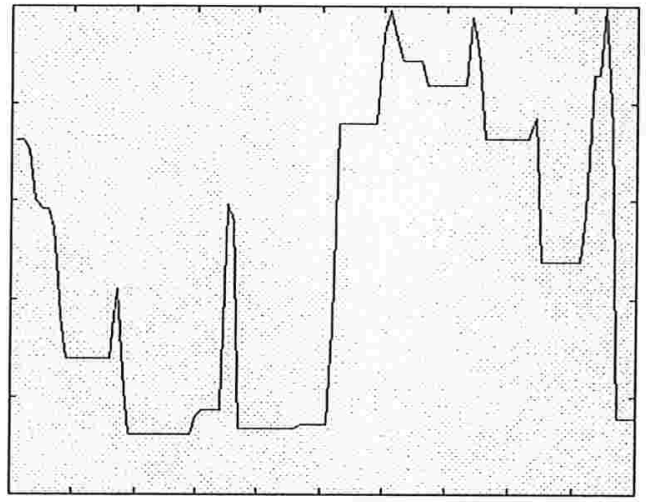

(c)

Figura 2.3: (a) Imagem Original. (b) Abertura. (c) Fechamento.

\subsection{Operadores Morfológicos}

Seguem abaixo as definições de alguns operadores morfológicos representados pelos operadores e operações apresentados na Seção anterior.

Seja $f \in F u n[E, K]$, a abertura e o fechamento de $f$ são definidos por

$$
\begin{gathered}
\gamma_{B}=\delta_{B} \varepsilon_{B} \\
\phi_{B}=\varepsilon_{B} \delta_{B},
\end{gathered}
$$

onde $B \subset E$ é o elemento estruturante.

A abertura e o fechamento são filtros morfológicos que eliminam elementos da imagem menores que o elemento estruturante, sem distorções drásticas dos elementos que não são eliminados. A abertura elimina, por exemplo, máximos regionais mais estreitos que o elemento estruturante. No caso do fechamento, o mesmo ocorre com os mínimos regionais. As Figuras 2.3 (b-c) mostram, respectivamente, a abertura e o fechamento de uma função $f$ (Figura 2.3 (a)). As Figuras 2.4 (b-c) mostram, respectivamente, os resultados da aplicação da abertura e do fechamento na Figura 2.4 (a). 


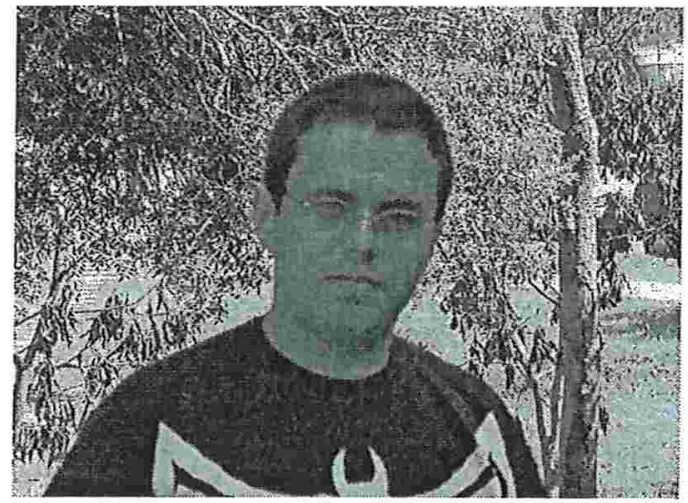

(a)

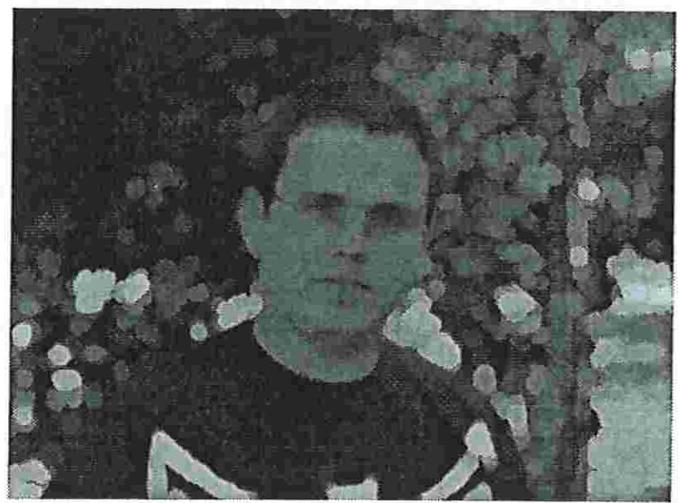

(b)

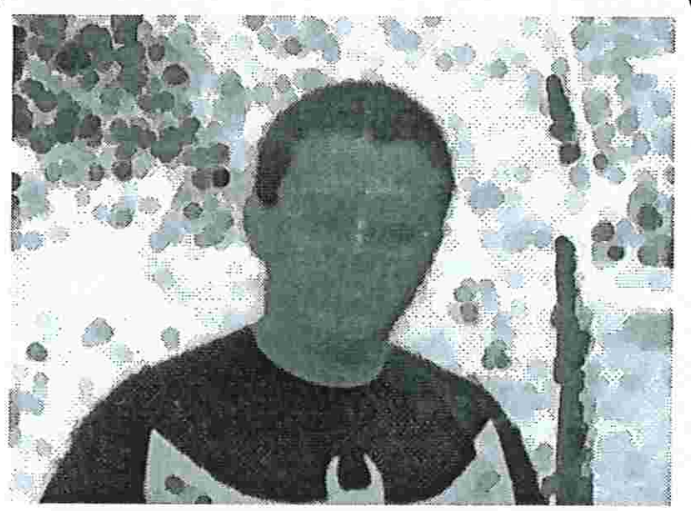

(c)

Figura 2.4: (a) Imagem Original. (b) Abertura. (c) Fechamento. 
Seja $f \in F u n[E, K]$, a $n$-dilatação e a $n$-erosão são dadas por

$$
\begin{aligned}
\delta_{B}^{n} & =\delta_{B} \delta_{B} \cdots \delta_{B}(n \text { vezes }), \\
\varepsilon_{B}^{n} & =\varepsilon_{B} \varepsilon_{B} \cdots \varepsilon_{B}(n \text { vezes }),
\end{aligned}
$$

onde $B \subset E$ é o elemento estruturante e $n$ é um inteiro não negativo.

Sejam $f, g \in F u n[E, K]$, a dilatação condicional e a erosão condicional são definidos por

$$
\begin{gathered}
\delta_{B, g}=\delta_{B} \wedge g \\
\varepsilon_{B, g}=\varepsilon_{B} \vee g,
\end{gathered}
$$

onde $B \subset E$ é o elemento estruturante.

Sejam $f, g \in F u n[E, K]$, a $n$-dilatação condicional e a $n$-erosão condicional são dadas por

$$
\begin{aligned}
\delta_{B, g}^{n} & \left.=\delta_{B, g} \delta_{B, g} \cdots \delta_{B, g} \text { ( } n \text { vezes }\right), \\
\varepsilon_{B, g}^{n} & =\varepsilon_{B, g} \varepsilon_{B, g} \cdots \varepsilon_{B, g}(n \text { vezes }),
\end{aligned}
$$

onde $B \subset E$ é o elemento estruturante e $n$ é um inteiro não negativo.

Sejam $f, g \in F u n[E, K]$, os operadores definidos por

$$
\begin{aligned}
& \rho_{B, g}=\delta_{B, g}^{\infty} \\
& \rho_{B, g}^{*}=\varepsilon_{B, g}^{\infty}
\end{aligned}
$$

são chamados, respectivamente, inf-reconstrução e sup-reconstrução. Estes operadores têm estes nomes porque, dada uma função $g$ cuja informação represente regiões de interesse na função $f$, "reconstroem" a função $f$ com somente os objetos "apontados" pela função. Chamaremos, doravante, as funções $g$ cuja informação "aponta" para objetos de interesse em uma função $f$ de marcadores. Estes marcadores são regiões conexas localizadas nos objetos que se quer preservar.

Seja $f \in F u n[E, K]$, a n-abertura e o $n$-fechamento de $f$ são definidos por

$$
\begin{gathered}
\gamma_{n, B}=\delta_{B}^{n} \varepsilon_{B}^{n} \\
\phi_{n, B}=\varepsilon_{B}^{n} \delta_{B}^{n},
\end{gathered}
$$

onde $B \subset E$ é o elemento estruturante.

Seja $f \in F u n[E, K]$. Sejam $\psi_{n, B}^{i}$ os seguintes operadores

$$
\begin{gathered}
\psi_{n, B}^{1}=\phi_{n, B} \gamma_{n, B} \\
\psi_{n, B}^{2}=\gamma_{n, B} \phi_{n, B} \\
\psi_{n, B}^{3}=\gamma_{n, B} \phi_{n, B} \gamma_{n, B} \\
\psi_{n, B}^{4}=\phi_{n, B} \gamma_{n, B} \phi_{n, B},
\end{gathered}
$$


onde $B \subset E$ é o elemento estruturante. O operador

$$
\psi_{n, B}^{i}=\psi_{n, B}^{i} \psi_{n-1, B}^{i} \cdots \psi_{1, B}^{i}
$$

é chamado filtro alternado sequencial.

A seguir, apresentamos alguns operadores morfológicos definidos pelo resíduo da aplicação de outros operadores. Seja $f \in F u n[E, K]$, os operadores top-hat são definidos por

$$
\begin{gathered}
\tau_{B}^{a b e}(f)=f-\gamma_{B}(f) \\
\tau_{B}^{f e c}(f)=\phi_{B}(f)-f
\end{gathered}
$$

onde $B \subset E$ é o elemento estruturante. Os operadores acima são chamados, respectivamente, de top-hat por abertura e top-hat por fechamento.

Seja $f \in F u n[E, K]$, o gradiente morfológico é definido por

$$
\nabla_{B}=\delta_{B}-\varepsilon_{B}
$$

onde $B \subset E$ é o elemento estruturante. Este operador é utilizado para realçar bordas de objetos. $\mathrm{O}$ gradiente definido acima realça as bordas internas e externas dos objetos. O realce de bordas internas e externas, é definido, respectivamente por

$$
\begin{gathered}
\nabla_{B}^{i}(f)=f-\varepsilon_{B}(f) \\
\nabla_{B}^{e}(f)=\delta_{B}(f)-f,
\end{gathered}
$$

onde $B \subset E$ é o elemento estruturante.

\subsection{Morfologia Matemática para Imagens Multibanda}

Sejam $L_{1}, L_{2}, \ldots, L_{m}$ conjuntos totalmente ordenados. Seja $L^{m}$ o produto cartesiano destes conjuntos $L_{i}, i=\{1, \ldots, m\}$; os elementos de $L^{m}$ são $m$-uplas $l=\left(l_{1}, l_{2}, \ldots, l_{m}\right), l_{i} \in L_{i}, i=$ $\{1, \ldots, m\}$.

Seja $\bar{f}: E \rightarrow L^{m}$. A função $\bar{f}$ é dada por uma $m$-upla de funções $f_{i}: E \rightarrow L_{i} . \forall z \in E$,

$$
\bar{f}(z)=\left(f_{1}(z), f_{2}(z), \ldots, f_{m}(z)\right) .
$$

Chamemos a função $\bar{f}$ de imagem multibanda ou multivalorada. Cada um dos mapeamentos $f_{i}$ representam uma banda da imagem $[19,20]$. Denotemos por $F u n\left[E, L^{m}\right]$ o conjunto de todas as funções $\bar{f}: E \rightarrow L^{m}$.

Seja $l \in L^{m}$. O transposto de $l$ é dado por,

$$
-(l)=\left(-l_{1},-l_{2}, \cdots,-l_{m}\right) .
$$

Seja $\bar{f}: E \rightarrow L^{m}$, a translação de $\bar{f}$ por $x \in E$ é dada por, $\forall z \in E$,

$$
\bar{f}_{x}(z)=\left(f_{1}(z-x), f_{2}(z-x), \cdots, f_{m}(z-x)\right) .
$$


Seja $\leq$ a relação de ordem parcial "menor ou igual" entre $\bar{f}$ e $\bar{g}, \bar{f}, \bar{g} \in F u n\left[E, L^{m}\right]$, definida por, $\forall z \in W$,

$$
\bar{f} \leq \bar{g} \Leftrightarrow\left(f_{1} \leq g_{1}, \cdots, f_{m} \leq g_{m}\right) \Leftrightarrow\left(f_{1}(z) \leq g_{1}(z), \cdots, f_{m}(z) \leq g_{m}(z)\right) .
$$

O conjunto Fun $\left[E, L^{m}\right]$ com a relação de ordem parcial $\leq$ define um reticulado completo. As operações de supremo e ínfimo entre $\bar{f}$ e $\bar{g}, \bar{f}, \bar{g} \in F u n\left[E, L^{m}\right]$, são definidas, respectivamente, por,

$$
\bigvee\{\bar{f}, \bar{g}\}=\left(f_{1} \vee g_{1}, f_{2} \vee g_{2}, \cdots, f_{m} \vee g_{m}\right)
$$

$\mathrm{e}$

$$
\bigwedge\{\bar{f}, \bar{g}\}=\left(f_{1} \wedge g_{1}, f_{2} \wedge g_{2}, \cdots, f_{m} \wedge g_{m}\right)
$$

Um operador entre imagens multibanda é um mapeamento $\bar{\Psi}: F u n\left[E, L^{m}\right] \rightarrow F u n\left[E, L^{m}\right]$.

Seja $\bar{f} \in F u n\left[E, L^{m}\right]$. A dilatação e a erosão de uma imagem multibanda são definidas, respectivamente, por

$$
\delta_{B}(\bar{f})=\left(\delta_{B}\left(f_{1}\right), \delta_{B}\left(f_{2}\right), \cdots, \delta_{B}\left(f_{m}\right)\right)
$$

$\mathrm{e}$

$$
\varepsilon_{B}(\bar{f})=\left(\varepsilon_{B}\left(f_{1}\right), \varepsilon_{B}\left(f_{2}\right), \cdots, \varepsilon_{B}\left(f_{m}\right)\right)
$$

onde $B \subset E$ é o elemento estruturante.

\subsubsection{Gradiente Colorido}

Existem vários métodos, "lineares" e não-lineares, para o cálculo do gradiente para imagens em níveis de cinza [21, 13, 20], tais como os Filtros de Sobel e Prewitt e o Gradiente Morfológico. Em cada um destes métodos, o valor do gradiente em um ponto é dado pelas diferenças de intensidade entre este ponto e seus vizinhos. Para imagens em níveis de cinza, as diferenças são facilmente calculadas, pois os valores das intensidades dos pixels neste tipo de imagem pertencem a um conjunto totalmente ordenado.

Para imagens, coloridas, porém, este cálculo não é tão simples, já que um espaço de cores não possui uma relação de ordem total. E se um relação de ordem for imposta, esta não refletirá o processo de detecção de bordas pelo olho humano, visto que este não decide qual é o supremo entre duas cores, por exemplo, azul e laranja.

Uma alternativa a ser seguida é a escolha de métricas e espaços de cores [21] adequados à definição de gradientes coloridos. Foram exploradas várias alternativas que serão apresentadas e discutidas a seguir.

\section{Gradiente $I$}

Seja $M$ um conjunto totalmente ordenado. Os gradientes apresentados nestas Sub-Seções serão definidos como mapeamentos $\Psi: F u n\left[E, L^{m}\right] \rightarrow F u n[E, M]$. Vários modelos de representação de cores [20] foram utilizados na aplicação de tais operadores. Dentre estes sistemas, estão o $R G B$, o $I H S$ e o $Y I Q$. 
Dada $\bar{f} \in F u n\left[E, L^{m}\right]$, o Gradiente $I$ de $\bar{f}, \nabla_{B}^{I}(\bar{f})$, é definido por

$$
\nabla_{B}^{I}(\bar{f})=\bigvee\left\{\nabla_{B}\left(f_{1}\right), \nabla_{B}\left(f_{2}\right), \nabla_{B}\left(f_{3}\right)\right\}
$$

onde $\nabla_{B}(f)$ é o gradiente morfológico definido na Seção anterior. O resultado deste gradiente é uma imagem em níveis de cinza contendo o supremo das diferenças máximas em cada banda da imagem $\bar{f}$.

\section{Gradiente II}

Dada $\bar{f} \in F u n\left[E, L^{m}\right]$, o Gradiente $I I$ de $\bar{f}, \nabla_{B}^{I I}(\bar{f})$, é definido por

$$
\nabla_{B}^{I I}(\bar{f})=\bigvee\left\{\nabla_{B}^{i}\left(f_{1}\right), \nabla_{B}^{i}\left(f_{2}\right), \nabla_{B}^{i}\left(f_{3}\right)\right\}
$$

$O$ resultado deste gradiente é similar ao do Gradiente $I$, porém, são realçadas somente as bordas internas dos objetos.

\section{Gradiente $I I I$}

Seja $d_{I I I}$ a norma de uma cor $l \in L^{m}$, definida por

$$
d_{I I I}(l)=\left\lfloor\left(l_{1}^{2}+l_{2}^{2}+l_{3}^{2}\right)^{\frac{1}{2}}\right\rfloor,
$$

onde $\lfloor p\rfloor$ é o valor de $p$ arredondado para baixo [22].

Dada $\bar{f} \in F u n\left[E, L^{m}\right]$, o Gradiente $I I I$ de $f, \nabla_{B}^{I I I}(\bar{f})$, é definido por

$$
\nabla_{B}^{I I I}(\bar{f})(x)=d_{I I I}\left(u_{f, x, B}\right)
$$

onde $u_{f, x, B}=\left(f_{1}\left(a_{x, B}\right)-f_{1}\left(b_{x, B}\right), f_{2}\left(a_{x, B}\right)-f_{2}\left(b_{x, B}\right), f_{3}\left(a_{x, B}\right)-f_{3}\left(b_{x, B}\right)\right)$, e $a_{x, B}, b_{x, B} \in E$ são dois pontos tais que $d_{I I I}\left(\bar{f}\left(a_{x, B}\right)\right)=\bigvee_{y \in B_{x}} d_{I I I}(\bar{f}(y))$ e $d_{I I I}\left(\bar{f}\left(b_{x, B}\right)\right)=\bigwedge_{y \in B_{x}} d_{I I I}(\bar{f}(y))$.

\section{Gradiente $I V$}

Seja $d_{I V}$ a distância de cor entre $l$ e $l^{\prime}, l, l^{\prime} \in L^{m}$, dada por

$$
d_{I V}\left(l, l^{\prime}\right)=\bigvee\left\{\left|l_{1}-l_{1}^{\prime}\right|,\left|l_{2}-l_{2}^{\prime}\right|,\left|l_{3}-l_{3}^{\prime}\right|\right\} .
$$

Dada $\bar{f} \in F u n\left[E, L^{m}\right]$, o Gradiente $I V$ de $\bar{f}, \nabla_{B}^{I V}(\bar{f})$, é definido por

$$
\nabla_{B}^{I V}(\bar{f})(x)=\bigvee_{y \in B_{x}} d_{I V}(\bar{f}(x), \bar{f}(y))
$$

Os quatro primeiros gradientes são computados sob o modelo de cores RGB. O próximo gradiente é computado sob o modelo de cores IHS. 


\section{Gradiente $V$}

No sistema IHS [20], o gradiente da intensidade e da saturação podem ser computados por $\nabla_{B}(\bullet)$, visto estas duas informações são representadas por funções $g \in F u n[E, K]$. No entanto, a informação de cor no modelo IHS é representada por funções $h \in F u n[E, \Theta]$, onde $\Theta=[0,359]$ não possui uma relação de ordem total por ser um conjunto de graus. Faz-se necessária a definição de uma métrica para o cálculo do gradiente para a informação de cor.

Seja $\theta_{1}, \theta_{2} \in \Theta$. A distância de cor entre $\theta_{1}$ e $\theta_{2}$ é dada por

$$
d_{h}\left(\theta_{1}, \theta_{2}\right)=\left\lfloor\bigwedge\left\{\left|\theta_{1}-\theta_{2}\right|, 360-\left|\theta_{1}-\theta_{2}\right|\right\}\right\rfloor .
$$

A distância de cor acima definida é uma função $d_{h}: \Theta \times \Theta \rightarrow[0,180]$. Faz-se necessária a normalização desta distância em $K$ para o cálculo do gradiente. Seja $m_{K}:[0,180] \rightarrow[0, k-1]$ a função de normalização.

Dada $h \in F u n[E, \Theta]$, o gradiente angular $\nabla_{\Theta}(h), \nabla_{\Theta}: F u n[E, \Theta] \rightarrow F u n[E, K]$, é dado por, $\forall x \in E$,

$$
\nabla \Theta(h)(x)=m_{K}\left(\bigvee_{y \in\left\{B_{x}-\{x\}\right\}} d_{h}(h(x), h(y))-\bigwedge_{y \in\left\{B_{x}-\{x\}\right\}} d_{h}(h(x), h(y))\right)
$$

onde $B$ é o elemento estruturante.

Sejam $a, b$ e $c$ três inteiros. O Gradiente $V$ é definido como uma combinação linear dos gradientes morfológicos para I e S e do gradiente angular para H. Os coeficientes da combinação linear são usados para realçar ou obscurecer os picos dos gradientes.

Seja $\bar{f} \in F u n\left[E, L^{m}\right]$ uma função representada no modelo IHS (aqui, $L^{m}=K \times \Theta \times K$ ). O Gradiente $V, \nabla_{B}^{V}: F u n\left[E, L^{m}\right] \rightarrow F u n[E, \mathbb{Z}]$, é definido por

$$
\nabla_{B}^{V}(f)=a \nabla_{B}\left(f_{1}\right)+b \nabla_{\Theta}\left(f_{2}\right)+c \nabla_{B}\left(f_{3}\right)
$$

onde $f_{1}, f_{2}$ e $f_{3}$ representam, respectivamente, as informações de intensidade, cor e saturação.

O Gradiente $V$ é chamado de soma dos gradientes ponderados pois cada gradiente é multiplicado por um escalar para que seu peso aumente ou diminua na soma. Isto nos permite regular quais informações são relevantes e quais não são no cálculo do gradiente. Por exemplo, em imagens onde a informação de cor é a mais importante, o gradiente de cor poderia ser utilizado. Porém, em alguns casos, tal informação não é suficiente para realçar a informação entre objetos com cores similares; faz-se então necessária a utilização de mais informação para que as bordas entre tais objetos sejam realçadas, e isto é feito, por exemplo, aumentando o peso da informação do gradiente de saturação.

Note que a abordagem acima também pode ser realizada sob outros modelos de cores.

O última gradiente colorido a ser definido é computado sob o modelo YIQ. 


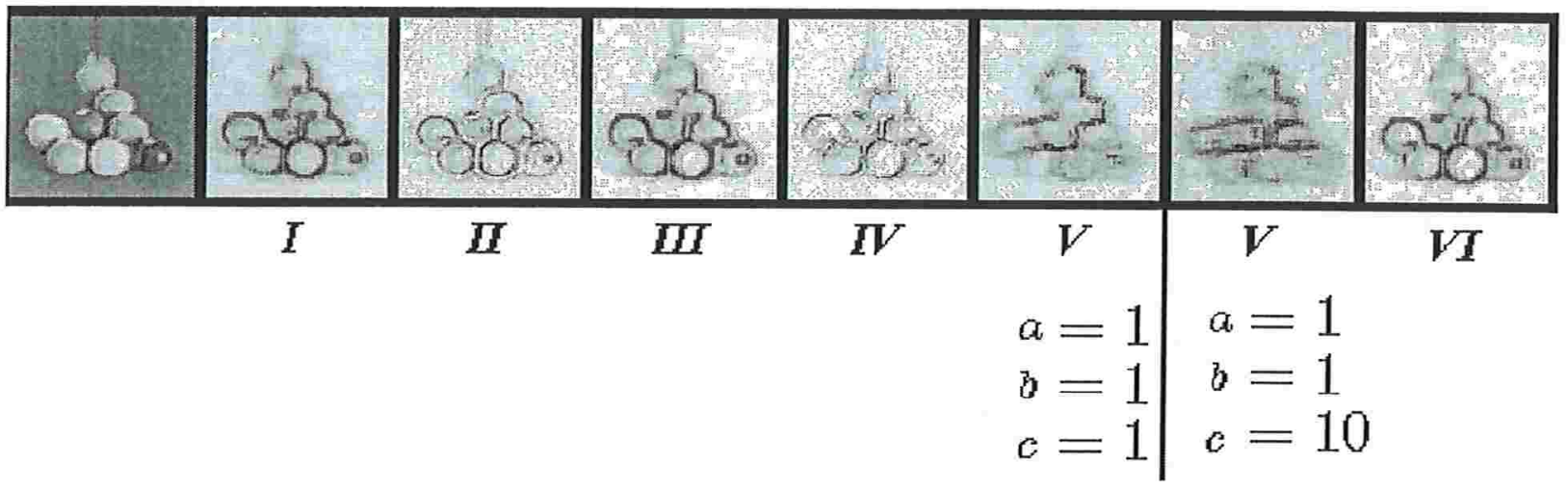

Figura 2.5: Resultados da Aplicação dos Gradientes Coloridos Apresentados.

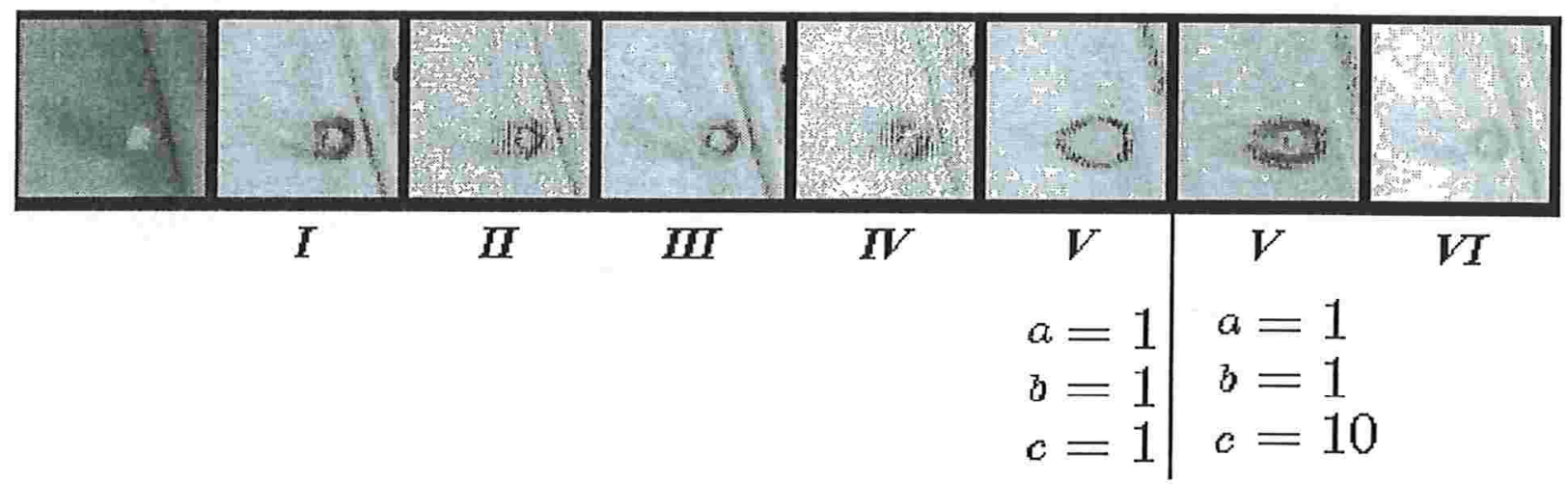

Figura 2.6: Resultados da Aplicação dos Gradientes Coloridos Apresentados.

\section{Gradiente $V I$}

Dada $f \in F u n\left[E, L^{m}\right]$, onde $f$ é representada no modelo YIQ, o Gradiente $V I$ de $f, \nabla_{B}^{V I}$ : $F u n\left[E, L^{m}\right] \rightarrow F u n[E, K]$, é definido por

$$
\nabla_{B}^{V I}(f)=\nabla_{B}\left(f_{1}\right),
$$

onde $f_{1}$ representa a informação de luminosidade $\mathrm{Y}$.

As Figuras 2.5 e 2.6 apresentam os resultados da aplicação dos gradientes definidos acima para algumas imagens coloridas. 


\title{
Capítulo 3
}

\section{Filtros Conexos e Segmentação Morfológica}

\author{
Me fiz em mil pedaços \\ Pra você juntar \\ E queria sempre achar \\ Explicação pro que eu sentia. \\ Legião Urbana "Quase Sem Querer"
}

Um dos ramos de pesquisa em Processamento Digital de Imagens mais desafiadores é a Segmentação de imagens. Um dos principais motivos é a ausência de um método sistemático a ser utilizado em quaisquer casos onde seja necessária a segmentação de um objeto na imagem; para cada problema é desenvolvida uma solução específica.

Segmentação de Imagens [20] é o particionamento de uma imagem em objetos de interesse. Este particionamento é feito seguindo-se algum critério e, geralmente, objetiva-se separar os objetos de uma imagem entre si ou simplesmente destacar um objeto-alvo entre vários outros.

Existem vários critérios utilizados neste particionamento, mas podemos classificá-los, basicamente, em duas categorias: borda e região. Os critérios que pertencem à primeira categoria são utilizados para definir os objetos unicamente pelas suas bordas, que costumam ser descontinuidades na imagem e podem facilmente serem detectadas por filtros passa-alta. Já os critérios que pertencem à segunda categoria particionam uma região inteira que caracterize o objeto. Estas regiões tendem a ser conjuntos de pixels similares e podem ser computadas, por exemplo, por algoritmos de crescimento de regiões.

Existem vários métodos clássicos de segmentação de imagens; alguns deles são apresentados em $[20,7]$. Uma delas, bastante poderosa e considerada clássica no contexto da Morfologia 
Matemática, além de prover a detecção exata das bordas dos objetos a serem segmentados, ainda simplifica substancialmente o problema de segmentação. Esta técnica, chamada de Paradigma de Beucher-Meyer [5, 6, 7], será estudada neste capítulo.

Introduziremos também neste capítulo uma família de filtros morfológicos, os filtros conexos. Estes filtros têm por característica reduzir o número de zonas planas [23, 24] (regiões conexas de pixels que possuem nível de cinza constante) sem a introdução de bordas. Note que estes filtros podem suprimir algumas bordas, mas ainda respeitam a condição de não introduzir outras bordas.

Filtros Conexos são utilizados para simplificar imagens, para eliminar objetos com determinadas áreas, e para aprimorar os resultados do Paradigma de Beucher-Meyer, entre outras aplicações.

\subsection{Definições Preliminares}

Uma grade de conectividade é um grafo não orientado $G=(E, V)$, onde $E \subset \mathbb{Z} \times \mathbb{Z}$ é o subconjunto retangular finito de pontos, onde os pontos representam os vértices do grafo e $V$, o conjunto de arestas de $G$ que definem uma relação entre os pontos de $E[11,7]$.

Estas arestas, que são pares de pontos $\{x, y\}, x, y \in E$, definem uma relação de vizinhança entre $x$ e $y$. Dois pontos $x$ e $y$ são vizinhos se $\{x, y\} \in V$.

Seja $N_{G}(x)=\{y \in E:\{x, y\} \in V\}$ o conjunto que denota a vizinhança de $x, x \in E$. Denotemos por $(a, b)$ as coordenadas de um ponto $x \in E$.

Dizemos que $E$ é 4-conectado se $\forall(a, b) \in E, N_{G}((a, b))=\{(a-1, b),(a+1, b),(a, b-1)$, $(a, b+1)$. Dizemos que $E$ é 8 -conectado se $\forall(a, b) \in E, N_{G}((a, b))=\{(a-1, b),(a+1, b),(a, b-1)$ $,(a, b+1),(a-1, b-1),(a-1, b+1),(a+1, b-1),(a+1, b+1)$.

Sejam $B_{4}, B_{8} \subset E$ dois elementos estruturantes. $B_{4}$ tem a forma de cruz e representa a 4-conectividade. $B_{8}$ tem a forma de um quadrado com dimensões $3 \times 3$ e representa a 8 conectividade.

Definimos caminho de $x$ a $y, x, y \in E$ como uma seqüência $C=\left\{p_{0}, p_{1}, \ldots, p_{n}\right\}$ de pontos de $E$ [7], onde $p_{0}=x, p_{n}=y$ e $\forall i \in[0, n-1], p_{i} \in N_{G}\left(p_{i+1}\right)$. O comprimento do caminho $C$ é dado por $|C|=n-1$.

Um subconjunto conexo de $E$ é um subconjunto $X \subset E$ tal que $\forall x, y \in X$, existe um caminho $C$ inteiramente contido em $X$.

Seja $f \in F u n[E, K]$. Uma zona plana de $f$ é um subconjunto conexo $X \subset E$, tal que $f(x)=f(y), \forall x, y \in X$.

Seja $f \in F u n[E, K]$. Sejam $X$ e $Y$ duas zonas planas de $f . X$ e $Y$ são adjacentes se $\exists x \in X, y \in Y$ tal que $x \in N_{G}(y)$.

Seja $f \in F u n[E,\{0,1\}]$ uma imagem binária. Seja $T$ uma árvore que tenha as seguintes caracteríticas: 
- $T$ tem um nó raiz $r$.

- Cada nó de $T$ representa uma zona plana de $f$.

- Um nó está no nível $t_{i}$ de $T$ se estiver a uma altura $i$ na árvore.

- O nó $r$ está em $t_{0}$ e representa o fundo da imagem.

- A zona plana representada por um nó $x$ que está em $t_{i}, i>0$, é adjacente à zona plana representada pelo nó pai de $x$.

A árvore descrita acima é chamada de árvore homotópica [11]. Duas imagens binárias são homotópicas se podem ser representadas pela mesma árvore.

Uma transformação $\psi$ é homotópica [11] se duas imagens binárias $X$ e $\psi(X)$ possuírem a mesma árvore homotópica. Um exemplo de transformação homotópica é a translação: uma imagem após transladada continua representada pela mesma árvore homotópica.

Seja $f \in F u n[E, K]$. Seja $\xi_{h}(f)=\{x \in E: f(x)=h\}, h \in K$ uma imagem binária. Duas funções $f, g \in F u n[E, K]$ são homotópicas se $\xi_{h}(f)$ e $\xi_{h}(g)$ são homotópicas, $\forall h \in K$ [17].

Seja $f \in F u n[E, K]$. Um mínimo regional (respectivamente, máximo regional) é uma zona plana $Z$ tal que $f(z)<f(n)$ (respectivamente, $f(z)>f(n)), z \in Z, n \in N \in \mathcal{F}_{Z}$, onde $\mathcal{F}_{Z}$ é a coleção de todas as zonas planas adjacentes a $Z$.

Seja $f \in F u n[E, K]$. Um vale é um subconjunto conexo $V$ que contém um único mínimo regional $R$, é adjacente a um conjunto $\mathcal{P}$ de zonas planas de $f, \mathcal{P}=\{F: F$ é um máximo regional de $f\}$, tal que para todo caminho $C\left(x=p_{0}, p_{1}, p_{2}, \cdots, p_{m}=y\right), x \in R, \forall y \in F \subset \mathcal{P}$, inteiramente contido em $V-\{y\}, f\left(p_{i}\right) \leq f\left(p_{i+1}\right)$.

Seja $f \in F u n[E, K]$. Um pico é um subconjunto conexo $V$ que contém um único máximo regional $R$, é adjacente a um conjunto $\mathcal{P}$ de zonas planas de $f, \mathcal{P}=\{F: F$ é um mínimo regional de $f\}$, tal que para todo caminho $C\left(x=p_{0}, p_{1}, p_{2}, \cdots, p_{m}=y\right), x \in R, \forall y \in F \subset \mathcal{P}$, inteiramente contido em $V-\{y\}, f\left(p_{i}\right) \geq f\left(p_{i+1}\right)$.

Seja $f \in F u n[E, K]$. Uma transformação $\zeta: F u n[E, K] \rightarrow F u n[E, K]$ é homotópica se $\zeta(f)$ preserva os mínimos e máximos regionais de $f[6]$.

\subsection{Filtros Conexos}

Os filtros conexos têm uma grande aplicabilidade em segmentação e simplificação de imagens. A propriedade destes filtros é a redução do número de zonas planas na imagem. Uma outra propriedade importante é a não introdução de novas bordas na imagem [23, 7]. No entanto, a aplicação destes filtros pode eliminar bordas. Em outras palavras, os filtros conexos reduzem o número de zonas planas através da união de zonas planas adjacentes; duas ou mais zonas planas podem passam a ser uma só após a aplicação destes filtros.

Um operador conexo é um mapeamento $\psi: f \rightarrow \psi(f)=g, f, g \in F u n[E, K]$, onde $\forall p, q \in$ $E:(p, q)$ são vizinhos, $f(p)=f(q) \Rightarrow g(p)=g(q)$. Um planing é o resultado $g$ da aplicação 


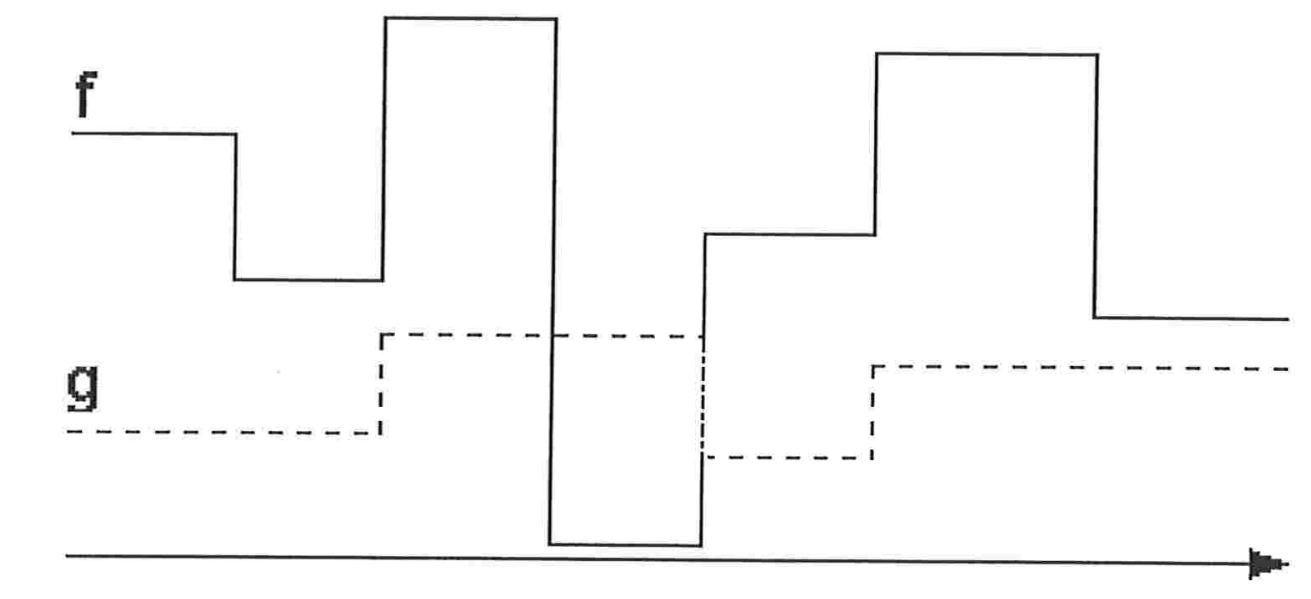

Figura 3.1: Planing.

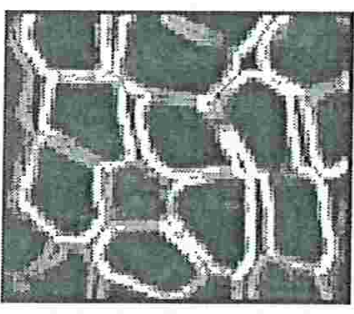

(a)

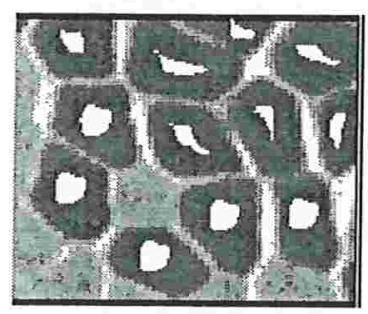

(b)

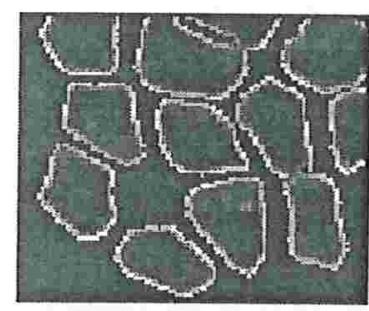

(c)

Figura 3.2: Filtragem Homotópica. (a) Gradiente. (b) Marcadores. (c) Gradiente Filtrado.

de um filtro conexo sobre $f$ [24]. A Figura 3.1 mostra um exemplo de planing; observe que não existem pares $(p, q)$ de pixels vizinhos em $f$ que não o sejam em $g$.

As próximas Sub-seções apresentarão algumas categorias de filtros conexos, bem como a aplicação destes filtros.

\subsubsection{Filtragem Homotópica}

Como será visto na Seção 3.3, o operador gradiente morfológico, usado para realçar as bordas dos objetos, é muito sensível a ruídos. Quando este operador é aplicado ele realça não só as bordas dos objetos mas também as "bordas" dos ruídos. Quando o operador watershed é aplicado sobre o gradiente de uma imagem ruidosa, ocorre o fenômeno de supersegmentação (Figura 3.12). Isto ocorre devido ao excessivo número de vales resultantes da aplicação do operador gradiente.

A idéia é "tapar" os vales indesejados através da aplicação de um filtro morfológico conexo que, a partir de regiões conexas que apontam os objetos de interesse, devolve uma imagem que possua vales somente para estes objetos. Observe que o filtro descrito muda a homotopia da imagem original cortando alguns ramos de sua árvore homotópica.

Seja $f \in F u n[E, K]$ a imagem que possui os objetos a serem segmentados. Seja $g \in$ 


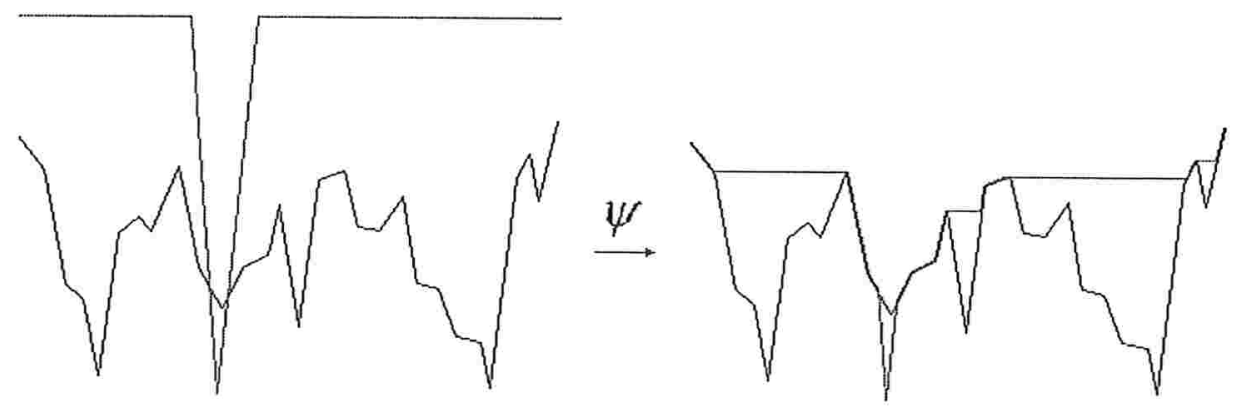

Figura 3.3: Filtragem Homotópica: Somente os Mínimos Regionais são Alterados.

Fun $[E, K]$ o gradiente morfológico de $f$. Seja $M$ o conjunto de todas as regiões conexas de $E$ que apontem os objetos a serem segmentados. Chamemos $M$ de conjunto de marcadores (Figura $3.2(\mathrm{~b}))$. Seja $m \in F u n[E, K]$ a função que representa estes marcadores, definida por

$$
m(x)=\left\{\begin{array}{c}
k, \text { se } x \in M \\
0, \text { caso contrário }
\end{array} .\right.
$$

O operador de mudança de homotopia $\theta$, definido por

$$
\theta(g)=\rho_{B,(g \wedge \nu(m))}^{*}(\nu(m))
$$

faz uma filtragem homotópica do gradiente $g$ através de uma reconstrução dual de $m$. O resultado deste operador é uma mudança de homotopia porque alguns mínimos regionais do gradiente são eliminados (Figura 3.2 (c)). Em outras palavras, o operador tapa todos os vales da imagem de gradiente [7] (exceto os vales que possuiam marcadores) (Figura 3.3). Além disto, o operador não inclui novos picos na imagem, e as bordas que definem os objetos a serem segmentados são preservadas.

\subsubsection{Levelings}

Uma outra categoria de filtros conexos morfológicos proposta por Meyer [24] tem por característica a simplificação de uma imagem através de aberturas e fechamentos por reconstrução adaptativos, isto é, as reconstruções são feitas somente em determinadas áreas da imagem. As funções $g$ que apresentem, com relação a uma imagem original $f$, estas duas características: redução de zonas planas e não criação de mínimos e máximos regionais são chamadas de levelings, e serão estudadas nesta Seção. Antes, dois tipos especiais de planings são definidos.

Um planing $g$ é um flattening de uma função $f, f, g \in F u n[E, K]$, se e somente se, $\forall p, q \in$ $E:(p, q)$ vizinhos,

$$
g(p)>g(q) \Rightarrow\left[\begin{array}{c}
f(p) \geq g(p) \text { e } g(q) \geq f(q) \\
\text { ou } \\
f(q) \geq g(p) \text { e } g(q) \geq f(p)
\end{array}\right] .
$$




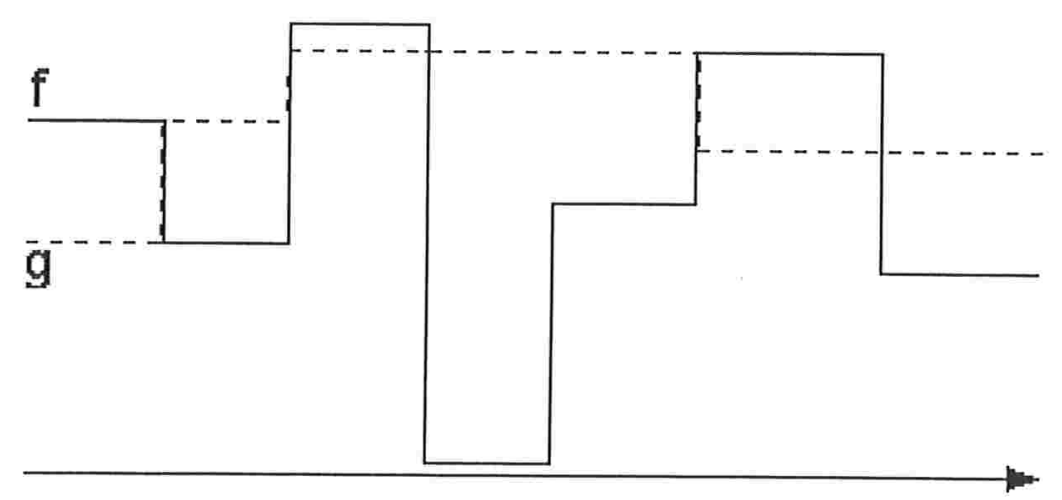

Figura 3.4: Flattening.

Em outras palavras, $g$ é um flattening de $f$ se toda transição em $g$ é delimitada por uma transição em $f$ (Figura 3.4). Apesar de $g$ possuir variações mais suaves que as de $f, g$ pode possuir novos mínimos e máximos regionais. Um exemplo é o operador que executa a operação de negação. As transições em $g$ estão delimitadas pelas transições em $f$ mas os mínimos regionais de $f$ passaram a ser máximos regionais de $g$, e vice-versa.

Observe na Figura 3.4, que a função $g$ tem três transições, e todas estão delimitadas pelas transições em $f$, satisfazendo a implicação acima.

Uma função $g$ é um monotone planing de $f, f, g \in F u n[E, K]$, tal que $\forall p, q \in E:(p, q)$ vizinhos,

$$
g(p)>g(q) \Rightarrow f(p)>f(q) .
$$

Uma característica de um operador monotone planing é de jamais criar um mínimo/máximo regional.

Uma função $g$ que seja, ao mesmo tempo, um flattening e um monotone planing de $f$, $f, g \in F u n[E, K]$, tal que,

$$
g(p)>g(q) \Rightarrow f(p) \geq g(p) \text { e } g(q) \geq f(q),
$$

é um leveling (Figura 3.5). Se $g$ satisfaz a condição apresentada, as suas transições são mais suaves que as respectivas transições em $f$ sem que hajam acréscimos de mínimos e máximos regionais.

Observe na Figura 3.5 que $g$ é um flattening de $f$ porque, além de todas as transições em $g$ estarem delimitadas por uma transição em $f$ ( $g$ é um flattening de $f$ ), $g$ preservou a relação de ordem de $f$ ( $g$ é um monotone planing de $f$ ).

Dada uma função $f$, pode se construir um leveling a partir de filtros morfológicos por reconstrução através da escolha das áreas em $f$ onde serão aplicados estes filtros. Dados dois subconjuntos $X, Y \subset E: X \cap Y=\emptyset$, o operador conexo $\Phi_{Y}^{X}(f)$, que será um leveling de $f$, é projetado da seguinte forma:

- $\gamma_{0}(f)(x)=\left\{\begin{array}{l}0, x \in X \\ f(x), x \in X^{c}\end{array}\right.$ 


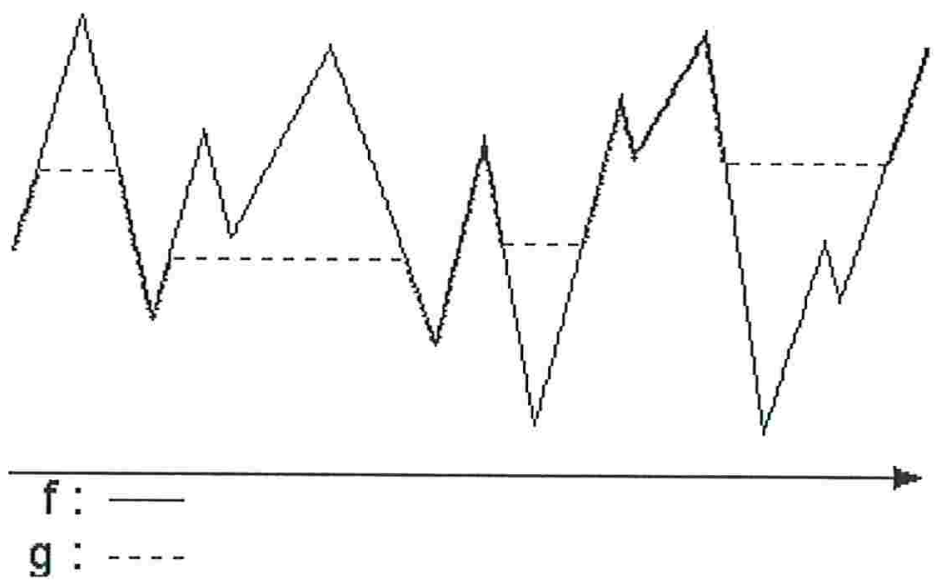

Figura 3.5: Leveling.

- $\gamma(f)=\rho_{B, f}\left(\gamma_{0}(f)\right)$;

- $\varphi_{0}(f)(x)=\left\{\begin{array}{c}k, x \in Y \\ f(x), x \in Y^{c}\end{array}\right.$;

- $\varphi(f)=\rho_{B, f}^{*}\left(\varphi_{0}(f)\right)$;

- $\Phi_{Y}^{X}(f)(x)=\left\{\begin{array}{l}\gamma(f)(x), x \in X \\ \varphi(f)(x), x \in Y \\ f(x), x \in \overline{X \cup Y}\end{array}\right.$.

Seja $\succ$ uma relação de ordem parcial. $\Psi_{1}$ é mais ativo que $\Psi_{2}[12]$, ou seja, $\Psi_{1} \succ \Psi_{2}$ se a seguinte equivalência é verdadeira:

$$
\Psi_{1} \succ \Psi_{2} \Leftrightarrow \begin{aligned}
& f \vee \Psi_{1}(f) \geq f \vee \Psi_{2}(f) \\
& f \wedge \Psi_{1}(f) \leq f \wedge \Psi_{2}(f)
\end{aligned} .
$$

Em outras palavras, $\Psi_{1}$ é mais ativo que $\Psi_{2}$ se, dado um conjunto $X \subset E, \Psi_{1}$ remove mais pontos de $X$, colocando-os em $\bar{X}$ do que $\Psi_{2}$.

A relação de atividade entre operadores conexos que calculam levelings é dada pelo tamanho dos conjunto $X$ e $Y$ utilizados no projeto do operador: $\begin{aligned} & X_{1} \subset X_{2} \\ & Y_{1} \subset Y_{2}\end{aligned} \Rightarrow \Phi_{Y_{2}}^{X_{2}}(f) \succ \Phi_{Y_{1}}^{X_{1}}(f)$.

Na prática, um leveling para $f$ é encontrada utilizando-se uma função marcadora $g$ para a definição dos conjuntos $X$ e $Y$ (Figura 3.6). Sejam os seguintes conjuntos,

$$
\begin{aligned}
& X_{f}^{g}=\{x \in E: f(x)<g(x)\} \\
& X_{g}^{f}=\{x \in E: f(x)>g(x)\}
\end{aligned},
$$

chamados, respectivamente, de conjuntos extensivo e anti-extensivo. O leveling de $f$ com relação a $g$ é calculado através do filtro $\Phi_{X_{f}^{g}}^{X_{g}^{f}}(f)$ (Figura $3.7(\mathrm{c})$ ). Normalmente a função marcadora 


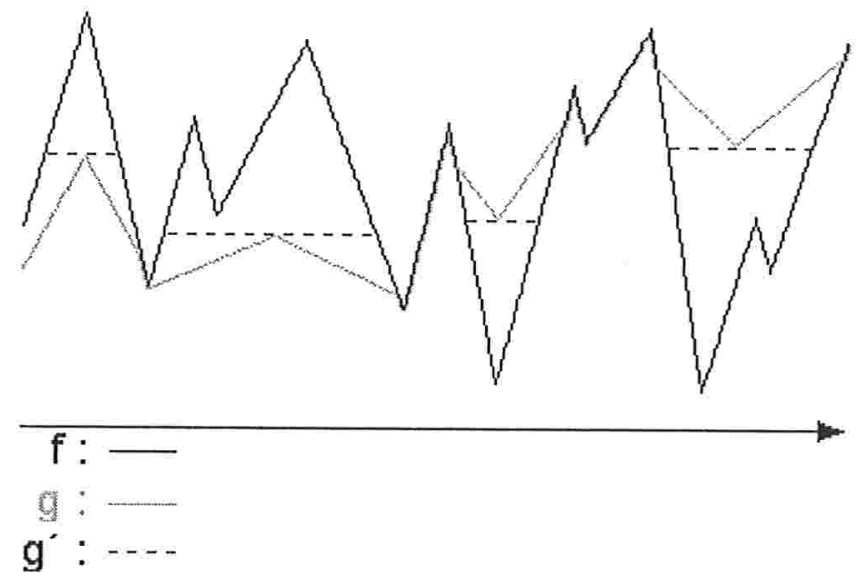

Figura 3.6: Construção de um Leveling para uma função $f$ utilizando-se uma Função Marcadora $g \cdot g^{\prime}$ é um Leveling de $f$.

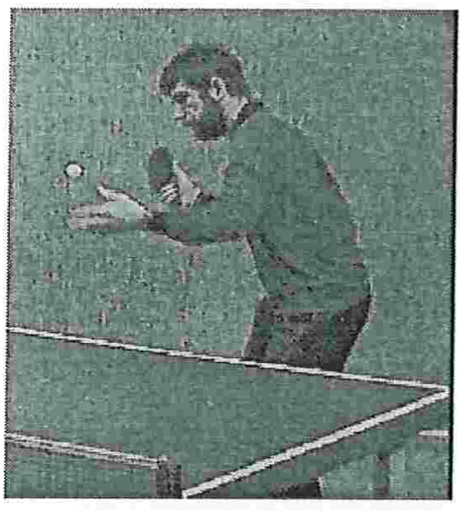

(a)

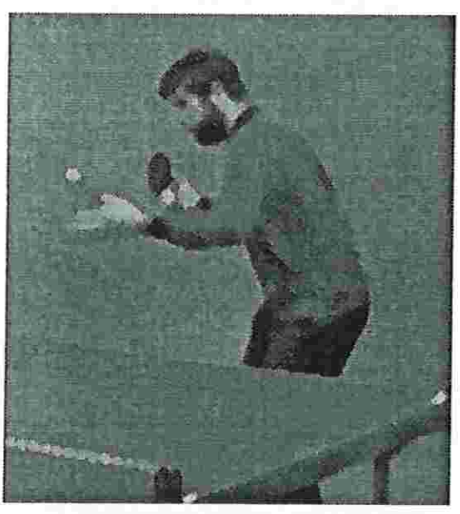

(b)

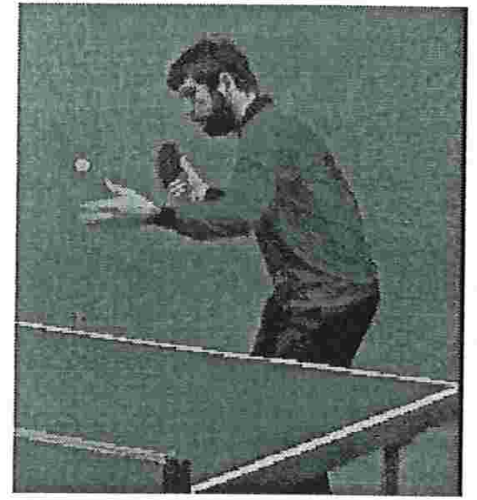

(c)

Figura 3.7: Função Marcadora obtida por um Filtro Alternado Seqüencial. (a) Imagem Original. (b) Função Marcadora. (c) Leveling.

$g$ utilizada no cálculo do leveling de uma função $f$ é obtida através da aplicação de um filtro alternado seqüencial (Figura 3.7 (b)). Os tamanhos dos conjuntos extensivo e anti-extensivo de $f$ irão depender de quão ativo seja o filtro alternado seqüencial utilizado no cálculo de $g$.

\subsubsection{Area Opening}

A area opening é uma filtragem conexa aplicada em imagens binárias, objetivando eliminar zonas planas que possuem valor $1 \mathrm{com}$ áreas menores que um limiar de área $a$. Como nos filtros apresentados anteriormente, nenhuma borda é criada com a aplicação deste filtro, mas algumas bordas são removidas.

Seja $\mathcal{F}$ o conjunto de todas as zonas planas de uma imagem binária $f$ que tenham valor 1 . Seja $a \in \mathbb{Z}^{+}$um limiar de área. Seja $\mathcal{F}_{a} \subset \mathcal{F}$ o conjunto de todas as zonas planas $F \in \mathcal{F}$ cuja 


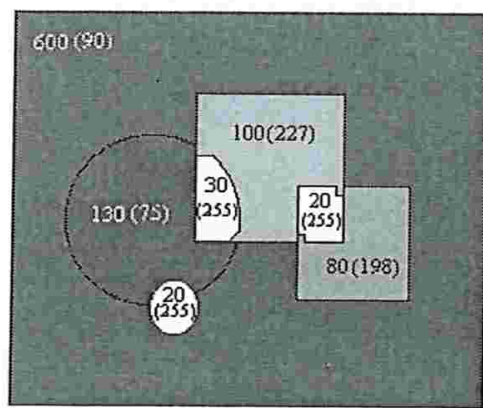

(a)

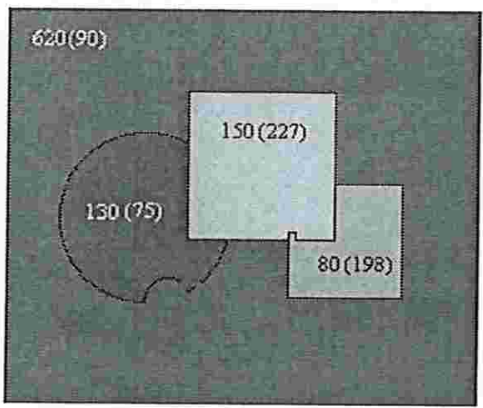

(b)

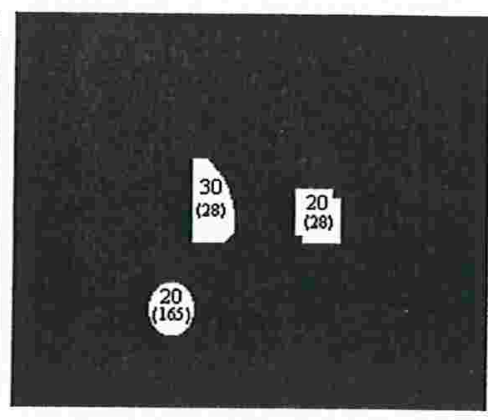

(c)

Figura 3.8: Area Opening. (a) Imagem Original. (b) Resultado da Filtragem.

(c) Resíduo da Filtragem.

área é maior que $a$. O filtro area opening é definido por

$$
\gamma_{a}{ }^{\text {área }}(f)=\bigvee_{F \in \mathcal{F}_{a}} \gamma_{F}(f),
$$

onde $\gamma_{B}$ é a abertura morfológica. Heijmans [23] também define o este filtro simplesmente como a união dos elementos de $\mathcal{F}_{a}$.

Seja $f \in F u n[E, K]$. Seja a imagem binária, $\forall x \in E$,

$$
f^{i}(x)=\left\{\begin{array}{c}
1, \text { se } f(x)=i \\
0, \text { caso contrário }
\end{array} .\right.
$$

O filtro area opening aplicado em uma imagem $f \in F u n[E, K]$ é definido por

$$
\Gamma_{a}^{\text {área }}(f)=\sum_{i=0}^{k} \gamma_{a}^{\text {área }}\left(f^{i}\right)
$$

A Figura 3.8 exemplifica a aplicação do area opening em imagem em níveis de cinza. As zonas planas contidas na Figura 3.8 (a) apresentam os valores de suas áreas (sem parênteses) e dos seus níveis de cinza (com parênteses). A Figura 3.8 (b) mostra o resultado da aplicação deste filtro na Figura 3.8 (a) com limiar de área $a=50$. A Figura 3.8 (c) mostra o resíduo da filtragem para o exemplo dado na Figura 3.8.

O filtro dual do area opening é o filtro area closing. Enquanto o area opening elimina picos com áreas menores que um limiar $a$, o area closing elimina os vales menores que um limiar $a$. O filtro area closing é definido por

$$
\Phi_{a}^{\text {área }}(f)=\nu\left(\Gamma_{a}^{\text {área }}(\nu(f))\right)
$$

\subsubsection{Area Merging}

A filtragem por area merging é semelhante à filtragem por area opening, com relação à eliminação de zonas planas cuja área se encontra abaixo de um limiar. A diferença entre estes filtros é que 
o filtro area merging é aplicado diretamente na imagem em níveis de cinza atribuindo-se, para cada região eliminada, o nível de cinza da zona plana adjacente de área maior.

Seja $\mathcal{F}$ o conjunto de todas as zonas planas de uma imagem $f$. Seja $a \in \mathbb{Z}$ um limiar de área. Seja $\mathcal{F}_{a} \subset \mathcal{F}$ o conjunto de todas as zonas planas $F \in \mathcal{F}$ com área menor que $a$.

Seja $\mathcal{N}(F)=\{G \in \mathcal{F}: G$ é adjacente a $F\}, F \in \mathcal{F}$. Seja $\operatorname{Max}(F) \in \mathcal{N}(F)$ a zona plana adjacente a $F$ que possuir a maior área. Seja $l(F), F \in \mathcal{F}$, a função que devolve o nível de cinza associado à zona plana $F$.

Dada uma imagem $f$, o conjunto $\mathcal{F}$ de todas as suas zonas planas e um limiar de área $a$, o filtro area merging $\mu_{a}: F u n[E, K] \rightarrow F u n[E, K]$ é definido por, $\forall x \in E$,

$$
\mu_{a}(f)(x)=\left\{\begin{array}{c}
l(\operatorname{Max}(F)), x \in F, \text { se } F \in \mathcal{O}_{a} \\
f(x), \text { caso contrário }
\end{array} .\right.
$$

A filtragem por area merging pode ser implementada facilmente em computador. Sejam as seguintes funções:

- $r \in F u n[E, \mathbb{Z}]$ Rotulador $(f \in F u n[E, K]$, elemento estruturante $B)$;

Esta função recebe como parâmetros uma função $f \in F u n[E, K]$ e um elemento estruturante que representa uma conectividade $\left(B_{4}\right.$ ou $\left.B_{8}\right)$, e devolve uma imagem $r \in F u n[E, \mathbb{Z}]$ onde cada zona plana de $f$ recebe um rótulo $l \in \mathbb{Z}$. Esta rotulação é feita de acordo com a conectividade dada por $B$.

- vetor $H$ Histograma $(r \in F u n[E, \mathbb{Z}])$;

Esta função recebe uma imagem $r \in F u n[E, \mathbb{Z}]$, computa seu histograma e o devolve em um vetor.

- vetor MaioresAdjacentes $(f, r, H, B)$;

Esta função recebe as imagens $f \in F u n[E, K]$ e $r \in F u n[E, \mathbb{Z}]$, o vetor que contém o histograma de $r$ e um elemento estruturante que representa uma conectividade. Devolve um vetor $A$ que contém uma tabela que associa a cada zona plana, a zona plana adjacente que tenha a maior área. O algoritmo para a função MaioresAdjacentes é dado a seguir. 
Função Maiores Adjacentes

- Entrada: Imagem $f \in F u n[E, K]$

Imagem $r \in$ Fun $[E, \mathbb{Z}] ; / *$ Imagem Rotulada */

vetor $H ; /$ / Histograma contendo as áreas das zonas planas *

elemento estruturante $B ; / *$ define a conectividade do filtro */

- Saída : vetor $A$;

vetor $A u x / *$ vetor auxiliar que guarda as maiores áreas */

$1 \quad A \leftarrow 0 ; / *$ inicializa o vetor */

$2 \quad$ Aux $\leftarrow 0 ; / *$ inicializa o vetor */

$3 \quad$ para $x \leftarrow 0 \cdots|E|$ faça

se $\left(\exists y \in B_{x}: f(x) \neq f(y)\right)$

então $\forall y \in B_{x}: f(x) \neq f(y)$;

se $H[r(y)]>A u x[r(x)]$

então $A u x[r(x)] \leftarrow H[r(y)]$

fim para

$A[r(x)] \leftarrow f(y)$

O algoritmo area merging segue abaixo. 


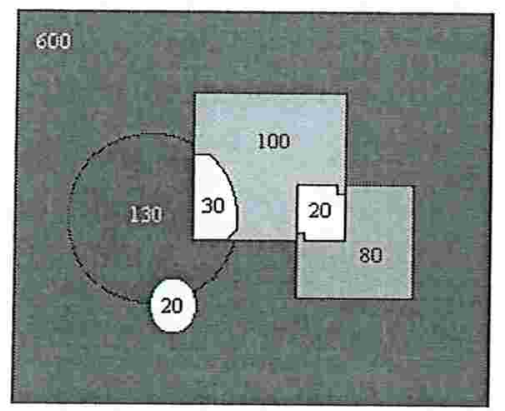

(a)

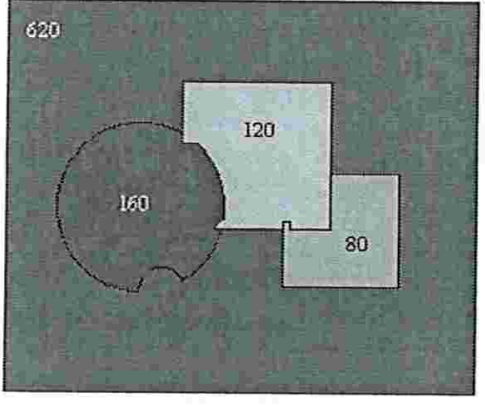

(b)

Figura 3.9: Area Merging. (a) Imagem Original. (b) Resultado da Filtragem.

Algoritmo Area Merging

- Entrada: Imagem $f \in F u n[E, K]$

inteiro $a ; / *$ limiar de área */

elemento estruturante $B ; / *$ define a conectividade do filtro */

- Saída : Imagem $\mu_{a}(f) \in F u n[E, K]$

vetor $H ; /^{*}$ vetor para armazenar o histograma da imagem rotulada.

O índice $i$ deste vetor é dado pelo rótulo de uma zona plana

e o valor de $H[i]$ armazena a área da zona plana com rótulo $i * /$

Imagem $r \in F u n[E, \mathbb{Z}] ; / *$ imagem que receberá as zonas planas de $f$ rotuladas */

vetor $A ; /^{*}$ vetor para armazenar os níveis de cinza das maiores zonas planas adjacentes. O índice $i$ deste vetor é dado pelo rótulo de uma zona plana e o valor de $A[i]$ armazena o nível de cinza da maior zona plana adjacente a zona plana com rótulo $i$.

$1 \quad r \leftarrow$ Rotulador $(f, B)$;

$2 \quad H \leftarrow \operatorname{Histograma}(r)$;

$3 \quad A \leftarrow$ MaioresAdjacentes $(f, r, H, B)$;

$4 \quad$ para $x \leftarrow 0 \cdots F$ faça $(F$ : tamanho da imagem $f)$

se $(H[r[x]]<a)$

então $\mu_{a}(f)(x)=A[r[x]]$;

senão $\mu_{a}(f)(x)=f(x)$;

fim para

Após a aplicação do filtro area merging, algumas poucas zonas planas que possuem área abaixo do limiar $a$ ainda permanecem na imagem. Fazem-se necessárias aplicações sucessivas do filtro até a estabilidade, ou seja, quando a imagem não tiver mais nenhuma zona plana com área abaixo do limiar. No Algoritmo Area Merging, basta iterar o algoritmo, usando como condição 
de parada um flag que indique que nenhuma zona plana foi eliminada.

Esta filtragem é útil para eliminação simultânea de zonas planas claras em fundo escuro e vice-versa. Sua outra função é eliminar ruído de borda dos objetos, que não é facilmente eliminado por uma abertura ou uma erosão. A Figura 3.9 mostra o resultado da filtragem por area merging.

\subsection{Linha de Partição de Águas (Watershed)}

Seja $A$ um subconjunto de $E$. Seja $d$ uma métrica sobre $E$. Seja $C$ um caminho inteiramente contido em $A$ entre dois pontos $x$ e $y$. A distância geodésica entre dois pontos $x \in A$ e $y \in A[7]$ é definida por

$$
d_{A}(x, y)=\min \{|C|:(C \text { é um caminho } x \rightarrow y) \text { e }(C \subset A)\} .
$$

A distância geodésica entre um ponto $x \in A$ e um subconjunto $S \subset A: x \notin S$ é dada por

$$
d_{A}(x, S)=\min \left\{d_{A}(x, y): y \in S\right\} .
$$

Seja $B$ um conjunto composto por $k$ subconjuntos de $A, B_{1}, B_{2}, \ldots, B_{k}$. A zona de influência geodésica de um subconjunto $B_{i}$ é dada por

$$
\theta_{A}\left(B_{i}\right)=\left\{x \in A, \forall j \in[1, k], i \neq j, d_{A}\left(x, B_{i}\right)<d_{A}\left(x, B_{j}\right)\right\},
$$

e a união das zonas de influência geodésica de todas as componentes de $B$ é denotada por $\Theta_{A}(B)=\bigcup_{i \in[1, k]} \theta_{A}\left(B_{i}\right), B_{i} \in B[7]$.

Dada $f \in F u n[E, K]$, um mínimo regional de $f$ de altitude $h$ é um subconjunto conexo $R_{h}(f)=\{x \in E: f(x)=h\}$. O conjunto de todos os mínimos regionais de $f$ de altitude $h$ é denotado por $\Sigma_{h}(f)$.

Seja $f \in F u n[E, K]$. A seção inferior de $f$ a um nível $h$ é dada por $f^{h}=\{x \in E: f(x) \leq h\}$.

Seja o conjunto $X_{0}=f^{0}$ e seja a recorrência

$$
X_{h+1}=\Sigma_{h+1}(f) \cup \Theta_{f^{h+1}}\left(X_{h}\right),
$$

o conjunto das bacias de captação de $f$ são representadas pelo conjunto $X_{k} \in E$, obtido através do cálculo da recorrência, $\forall h \in[0, k]$.

Seja $f \in F u n[E, K]$. Seja $\xi(f) \in E, \xi(f)=X_{k}$, o conjunto de todas as bacias de captação de $f$. O conjunto

$$
\Xi(f)=E-\xi(f)
$$

define as linhas de partição de águas de $f$. Chamemos o operador que encontra estas linhas de operador watershed.

Uma analogia pode ser feita para uma melhor compreensão desta teoria. Considere uma imagem como uma superfície semelhante a um relevo composto por picos e vales de diversas 


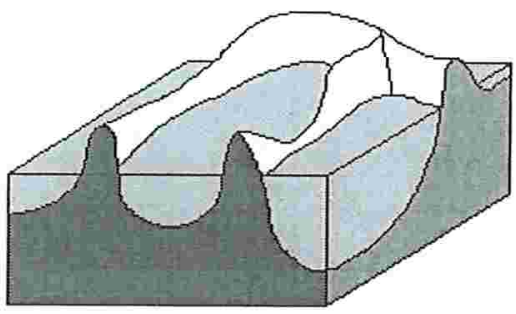

(a)

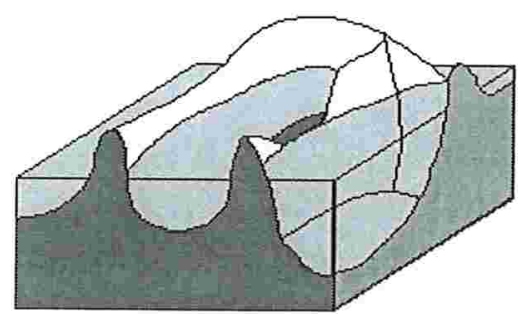

(b)

Figura 3.10: Bacias de Captação. (a) Inundação das Bacias a partir dos Mínimos Regionais. (b) Construção do Muro (Linha de Partição de Águas) que impede que duas Bacias se unam.

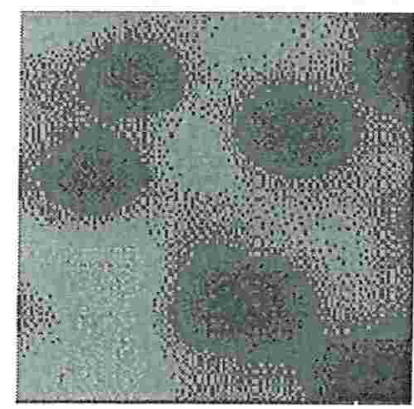

(a)

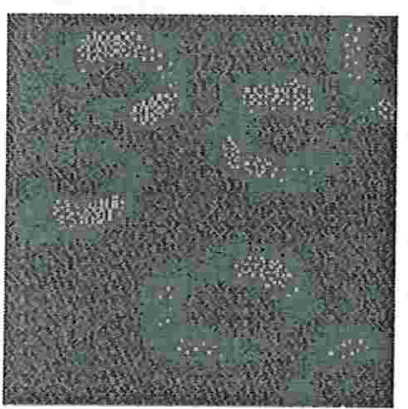

(b)

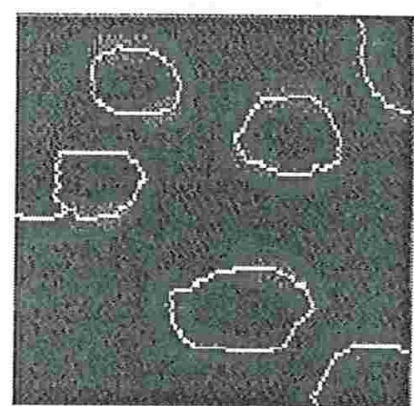

(c)

Figura 3.11: Watershed. (a) Imagem Original. (b) Gradiente. (c) Watershed do Gradiente.

altitudes, e que em cada um destes vales haja um pequeno furo. Imagine que esta superfície possa ser lentamente submersa em uma piscina, paralelamente à água. À medida que a superfície é submersa, a água entra pelos furos, enchendo os vales de água (Figura 3.10 (a)). Inicialmente, as bacias de altitude mínima começam a encher, mas a cada vez que a água atinge a altitude de um mínimo regional, uma nova bacia começa a encher. Cada um destes vales representa uma bacia de captação e o processo de enchimento de cada umas destas bacias prossegue até que toda a superfície esteja submersa.

Agora, pense no instante em que, durante a submersão, a água de duas bacias de captação se juntam. Neste instante, um muro deve ser construído para impedir que as águas se misturem e, a medida que o nível da água sobe, este muro deve ser aumentado para ainda impedir que as águas não se misturem (Figura 3.10 (b)). Tais muros são as linhas de partição de águas.

O watershed é uma ferramenta poderosa para a detecção de contornos de objetos. A idéia é considerar o objeto a ser segmentado como uma bacia de captação; as linhas de partição de água resultantes darão o contorno exato do objeto.

$\mathrm{O}$ operador watershed geralmente não é aplicado sobre a imagem original mas sobre o gradiente morfológico da mesma (Figura 3.11), visto que o operador gradiente realça as bordas dos objetos. Um grande problema, no entanto, é que o operador gradiente é muito sensível a ruídos. Ao se aplicar o operador watershed sobre o gradiente morfológico de uma imagem rui- 


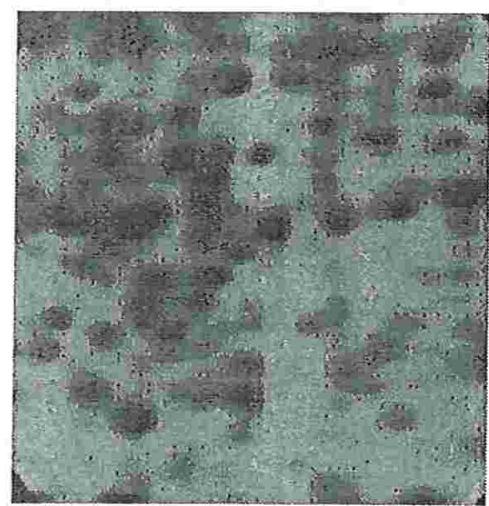

(a)

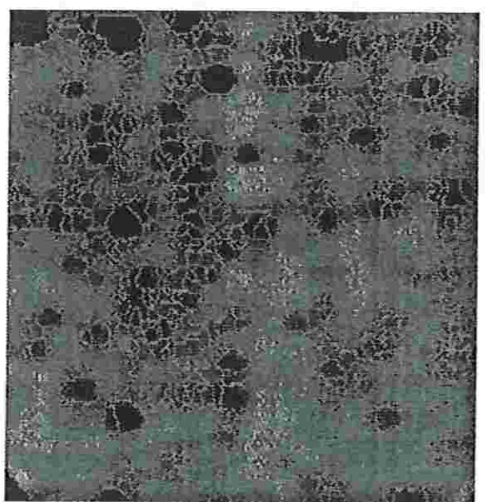

(b)

Figura 3.12: Supersegmentação. (a) Imagem Original. (b) Supersegmentação.

dosa, obtém-se um número excessivo de linhas de partição de águas: esse fenômeno é chamado de supersegmentação (Figura 3.12).

Uma das soluções para o problema de supersegmentação é a filtragem homotópica da imagem. Após a imposição de marcadores aos objetos a serem segmentados e a filtragem da imagem, restam somente os mínimos regionais associados a estes objetos, e o operador watershed detectará somente as bordas desejadas.

\subsection{Paradigma de Beucher-Meyer}

O Paradigma de Beucher-Meyer [5, 6, 7] consiste na aplicação seqüencial de alguns operadores morfológicos objetivando segmentar objetos através da detecção exata das bordas dos mesmos. Os operadores utilizados neste método foram descritos nas Seções anteriores, consistindo basicamente na aplicação dos operadores gradiente morfológico, operador de mudança de homotopia e o operador watershed.

Seja $f \in F u n[E, K]$ a imagem a ser segmentada (Figura 3.13 (a)). Inicialmente, aplica-se sobre $f$ o operador gradiente morfológico e obtém-se a imagem $g$ com as bordas dos objetos realçadas (Figura 3.13 (b)). Lembre-se que não somente as bordas dos objetos mas também o ruído é realçado, e é devido a isso que $g$ possui bacias de captação em excesso, o que gera supersegmentação.

O passo seguinte consiste na construção de uma imagem $m$ que contenha os marcadores para os objetos a serem segmentados. $m$ é uma imagem cujos pixels que pertençam aos marcadores possuem o valor de nível de cinza máximo enquanto que os demais pixels possuem o valor de nível de cinza mínimo. A Figura 3.13 (c) mostra a composição dos marcadores com a imagem original.

De posse da imagem de marcadores $m$ faz-se a filtragem de $g$ através do operador de mudança de homotopia, que irá tapar todas as bacias de captação de $g$, exceto as bacias que foram 


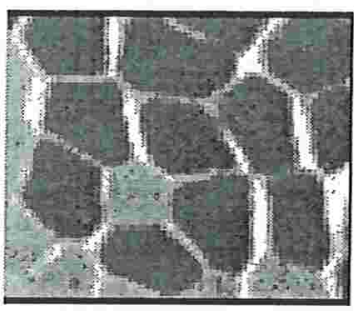

(a)

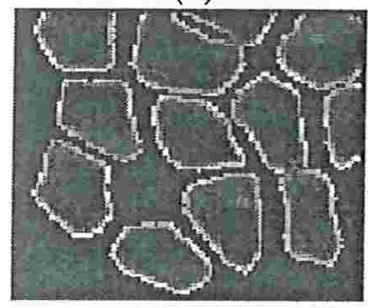

(d)

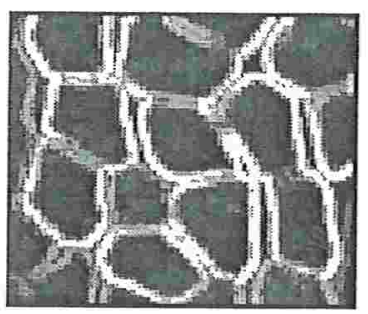

(b)

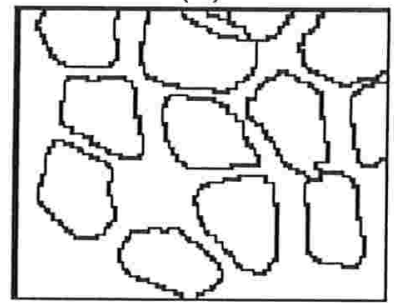

(e)

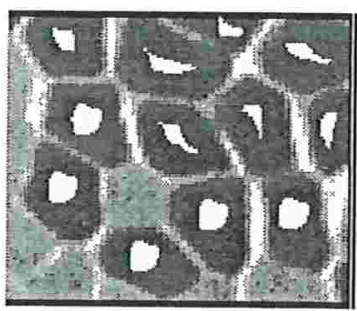

(c)

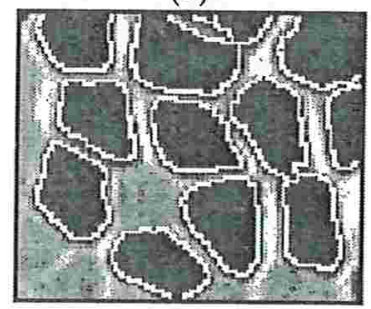

(f)

Figura 3.13: Etapas do Paradigma de Beucher-Meyer. (a) Imagem Original. (b) Gradiente. (c) Marcadores. (d) Filtragem Homótopica. (e) Watershed. (f) Composição do Watershed com a Imagem Original.

marcadas (Figura 3.13 (d)). Somente os vales na imagem são mudados. Não foi criado nenhum pico: os picos pertencentes à imagem resultante $r$ também pertencem à $g$. Porém, os únicos vales que restaram foram as bacias de captação marcadas.

Finalmente, aplica-se o operador watershed sobre a imagem simplificada $r$ e obtém-se as linhas de partição de águas somente dos objetos segmentados (Figura 3.13 (e)).

O Paradigma de Beucher-Meyer mostra-se como um método eficaz para segmentação por bordas, pois além de detectá-las, ainda reduz o problema de segmentação ao problema de encontrar marcadores para os objetos.

Porém, o problema de encontrar marcadores para os objetos a serem segmentados também é um problema complicado, pois não existe um método sistemático para encontrar tais marcadores. Atualmente, os marcadores são fornecidos manualmente ou encontrados por operadores ad hoc.

Nos próximos Capítulos apresentaremos uma outra maneira de encontrar marcadores, que é através da aplicação de operadores aperture projetados por aprendizado computacional.

\subsection{Filtros Conexos Multibanda e Segmentação Colorida}

A aplicação dos filtros conexos apresentados nas Seções anteriores também foram extendidas para imagens multibanda. Esta Seção apresenta tal extensão, bem como a adaptação do Paradigma de Beucher-Meyer aplicado em imagens coloridas. 


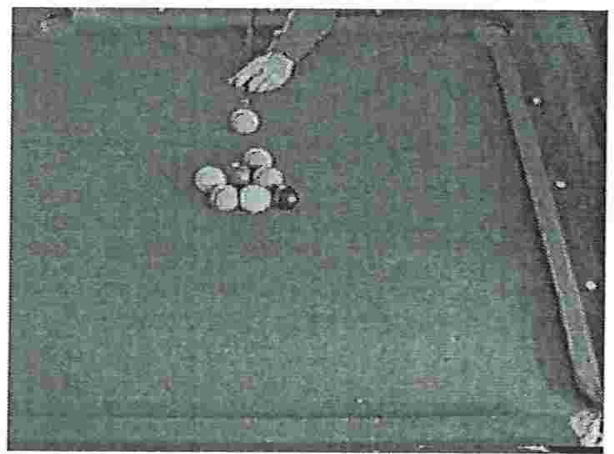

(a)

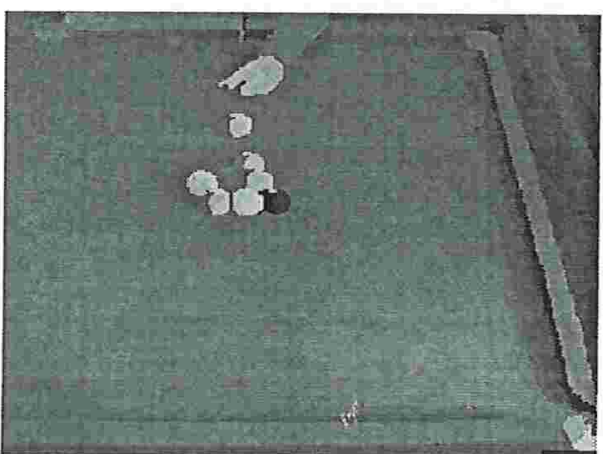

(b)

Figura 3.14: Area Merging. (a) Imagem Original. (b) Resultado da Filtragem.

\subsubsection{Area Opening}

O filtro area opening aplicado em imagens multibanda é definido por, $\forall \bar{f} \in F u n\left[E, L^{m}\right], a \in \mathbb{Z}^{+}$,

$$
\Gamma_{a}^{\text {área }}(\bar{f})=\left(\Gamma_{a}^{\text {área }}\left(f_{1}\right), \Gamma_{a}^{\text {área }}\left(f_{2}\right), \cdots, \Gamma_{a}^{\text {área }}\left(f_{m}\right)\right) .
$$

\subsubsection{Area Merging}

Seja $\bar{f} \in F u n\left[E, L^{m}\right]$. Uma zona plana multivalorada de $\bar{f}$ é um subconjunto conexo $X \subset E$, tal que $\bar{f}(x)=\bar{f}(y), \forall x, y \in X$.

O projeto de filtros area merging estendido para imagens multivaloradas é similar ao projeto deste filtro para imagens em níveis de cinza. Os detalhes que diferem são:

- O filtro area merging multivalorado é um operador $\mu_{a}: F u n\left[E, L^{m}\right] \rightarrow F u n\left[E, L^{m}\right]$.

- Seja $\overline{\mathcal{F}}$ o conjunto de todas as zonas planas multibanda em uma função multivalorada $\bar{f} \in F u n\left[E, L^{m}\right]$. A função $l(\bar{F}), \bar{F} \in \overline{\mathcal{F}}$, devolve o valor de $\bar{f}(x), x \in \bar{F}$.

- Foi implementada uma função de rotulação para imagens coloridas $(r \in F u n[E, \mathbb{Z}]$ Rotulador $\left(f \in F u n\left[E, L^{m}\right]\right.$, elemento estruturante $\left.\left.B\right)\right)$.

- Seja $\mathcal{N}(\bar{F})=\{\bar{G} \in \overline{\mathcal{F}}: \bar{G}$ é adjacente a $\bar{F}\}, \bar{F} \in \overline{\mathcal{F}}$. Seja $\operatorname{Max}(\bar{F}) \in \mathcal{N}(\bar{F})$ a zona plana multibanda adjacente a $\bar{F}$ que possuir a maior área. Cada zona plana multibanda $\bar{F} \in \overline{\mathcal{F}}$ compõe uma linha da tabela de zonas planas multibanda adjacentes de maior área. As informações de cada linha da tabela compõem um índice para a zona plana multibanda $\bar{F}$ e para os valores de $l(\operatorname{Max}(\bar{F}))$.

A Figura 3.14 apresenta o resultado da aplicação do area merging colorido. Foi utilizado um elemento estruturante cruz (conectividade 4) e limiar de área $a=40$. 


\subsubsection{Paradigma de Beucher-Meyer}

O Paradigma de Beucher-Meyer também pode ser utilizado para segmentação de imagens coloridas. Porém, nenhuma mudança no Paradigma é feita para a aplicação em imagens coloridas, mas sim nestas imagens. O gradiente colorido é um operador $\bar{\Psi}: F u n\left[E, L^{m}\right] \rightarrow F u n[E, K]$, e uma vez que é aplicado em imagens multibanda, o resultado do gradiente é uma imagem em níveis de cinza e o Paradigma supracitado é aplicado como descrito nas Seções anteriores. No entanto, o problema do cálculo do gradiente colorido não é tão simples quanto o cálculo do gradiente morfológico (veja a Seção 2.4). 


\title{
Capítulo 4
}

\section{Operadores Aperture}

\author{
Vejo seu rosto nos aeroportos, \\ Nas ruas, nos cinemas, nos jornais. \\ Vejo seus olhos nos faróis do meu carro, \\ À noite eles sempre brilham mais. \\ Camisa de Vênus "Rostos e Aeroportos"
}

Os operadores aperture (ou $W K$-operadores) são operadores $\Psi: F u n[E, K] \rightarrow F u n[E, K]$ invariantes por translação e localmente definidos espacialmente e nos níveis de cinza $[8,9,10]$. Eles têm a propriedade de serem caracterizados por funções características, que são mapeamentos $\psi$ que associam a uma função um valor inteiro.

A partir deste Capítulo denotaremos os operadores por letras gregas maiúsculas $(\Psi, \Xi, \cdots)$ e as funções características por letras gregas minúsculas $(\psi, \xi, \cdots)$.

Estes operadores, inicialmente definidos para imagens em níveis de cinza, também foram generalizados para imagens multibanda. A Seção 4.1 apresenta os operadores aperture para imagens em níveis de cinza, bem como as funções que os caracterizam. A Seção 4.2 apresenta a extensão dos operadores aperture para imagens multibanda.

\subsection{Níveis de Cinza}

Sejam $L, M$ dois conjuntos totalmente ordenados (chains). Seja $f \in F u n[E, L]$. Seja $\Psi$ : $F u n[E, L] \rightarrow F u n[E, M]$ um operador. Seja um conjunto finito $W \subset E$. Uma janela em uma imagem é uma função definida de $W$ até $L$. Denotemos o conjunto de todas estas funções por Fun $[W, L]$. 


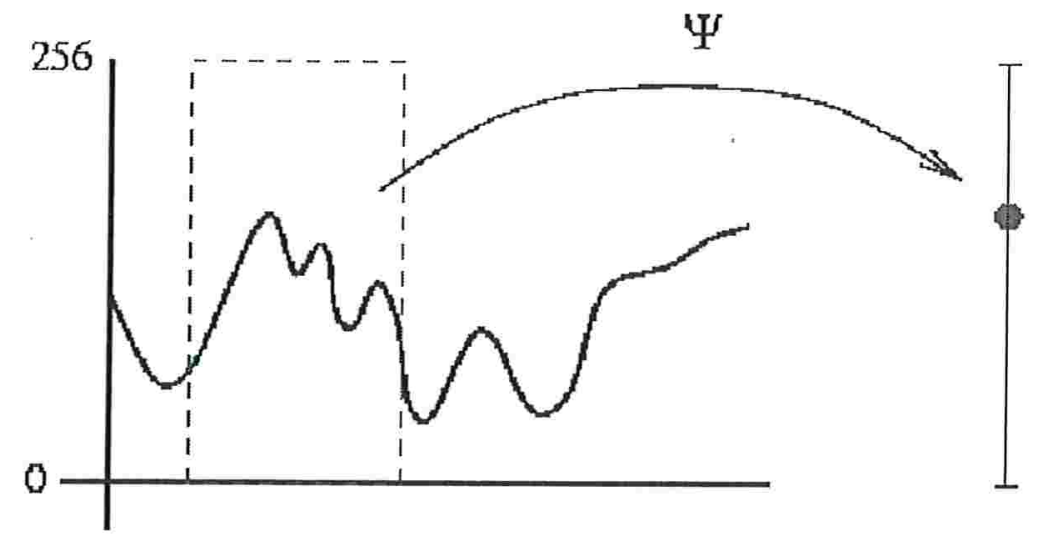

Figura 4.1: Operador Localmente Definido.

Seja $f$ uma função em $F u n[E, L]$. A restrição de $f$ em uma janela $W$ é uma janela $f / W \in$ Fun $[W, L]$, onde, $\forall z \in W,(f / W)(z)=f(z)$. A família de imagens que compõem a classe de restrição $W$ em $f$ é dada por

$$
\mathcal{F}_{f / W}=\{g \in F u n[E, L]: f / W=g / W\} .
$$

Um operador $\Psi$ é localmente definido espacialmente em uma janela $W$ (Figura 4.1) se e somente se, $\forall f \in F u n[E, L], \forall x \in E$,

$$
\Psi(f)(x)=\Psi(g)(x), \forall g \in \mathcal{F}_{f_{-x} / W} .
$$

Um operador $\Psi$ é invariante por translação espacialmente (Figura 4.2) se e somente se, $\forall z \in E$,

$$
\Psi\left(f_{z}\right)=\Psi(f)_{z} .
$$

Um operador que seja ao mesmo tempo espacialmente localmente definido e espacialmente invariante por translação é um $W$-operador.

A função característica [8], é uma função $\psi: F u n[W, L] \rightarrow M$ que caracteriza unicamente um W-operador. Um W-operador $\Psi$ é caracterizado por uma função característica $\psi$ onde, $\forall f \in L^{E}, \forall x \in E$,

$$
\Psi(f)(x)=\psi\left(f_{-x} / W\right) .
$$

Quando $L$ e $M$ são conjuntos finitos as funções características são também chamadas de funções computacionais. Dada uma janela $W$, o número de famílias de $\mathrm{W}$-operadores que podem ser caracterizadas por funções computacionais é $l^{m^{|W|}}$, onde $l$ e $m$ são a cardinalidade de $L$ e $M$, respectivamente.

No caso dos operadores binários, $l=m=2$ e o número de famílias de W-operadores caracterizáveis por funções computacionais é $2^{2^{|W|}}$, e, dependendo de $|W|$, este número é enorme. $\mathrm{Na}$ maioria das aplicações em processamento de imagens, $l=m=256$, ou seja o número 


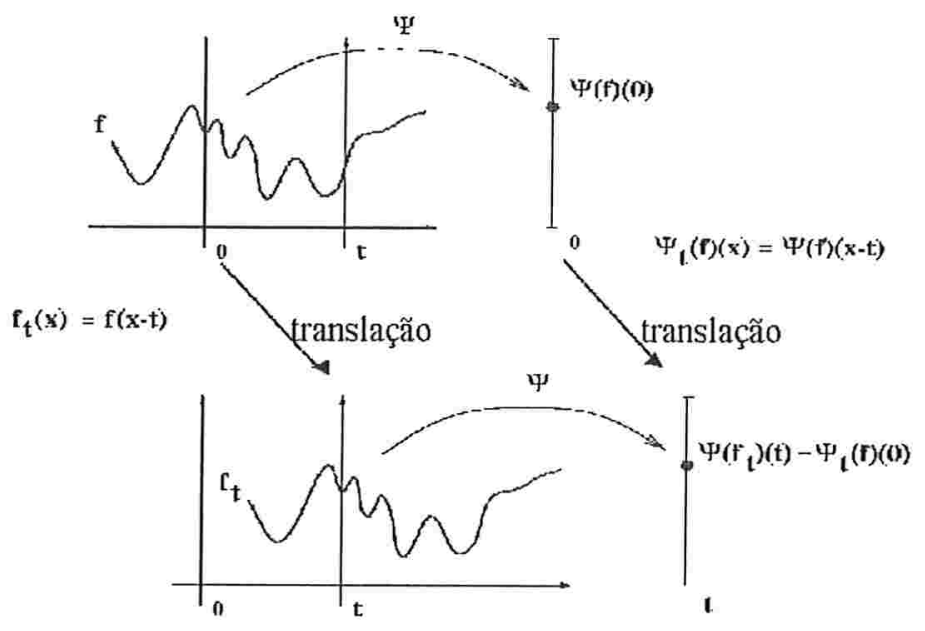

Figura 4.2: Operador Invariante por Translação.
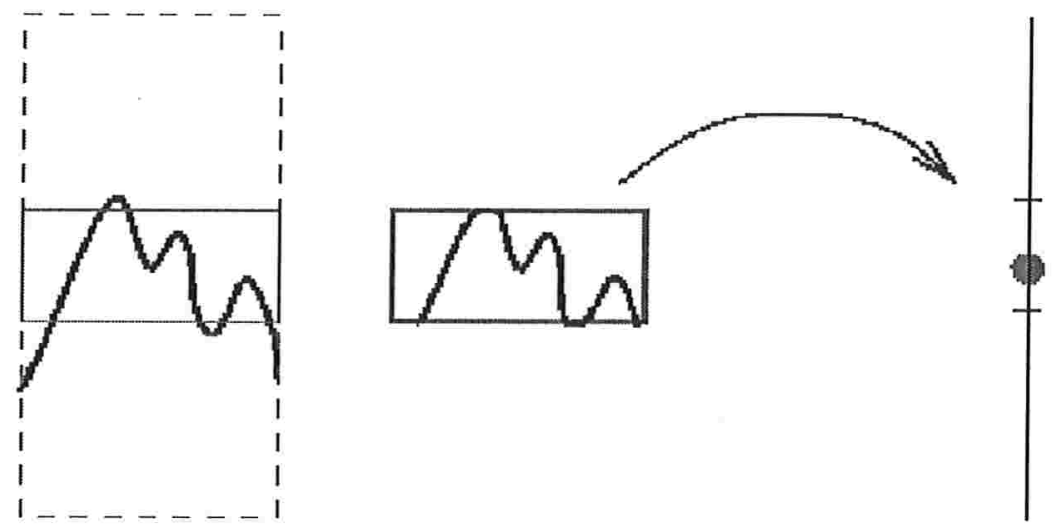

Figura 4.3: Enjanelamento nos Níveis de Cinza.

de famílias de $\mathrm{W}$-operadores que processam imagens em níveis de cinza é normalmente muito grande.

O fato do número de famílias de W-operadores aumentar exponencialmente a medida que se aumenta o tamanho da janela traz sérios problemas quando se quer projetar um $\mathrm{W}$-operador por aprendizado computacional (veja Capítulo 5), já que este deve ser aprendido entre muitas famílias de W-operadores.

Uma solução é a restrição de um operador não somente no domínio espacial mas também no domínio dos níveis de cinza [8], através de uma janela nos níveis de cinza. Esta janela restringe o número de níveis de cinza considerados a um intervalo. Se $K$ for uma janela nos níveis de cinza e $k$ a sua cardinalidade, o número de famílias de W-operadores a serem caracterizados será $k^{k^{|W|}}$. As funções computacionais que caracterizam as famílias de operadores restritas no domínio espacial e nos níveis de cinza são chamadas operadores aperture. 
Para simplificar, vamos nos referenciar ao domínio dos níveis de cinza simplesmente como níveis de cinza e vamos considerar que $L=M=\mathbb{Z}$. A translação nos níveis de cinza de uma função $u \in F u n[W, \mathbb{Z}]$ por $y \in \mathbb{Z}$ é dada por, $\forall z \in W$,

$$
(u+y)(z)=u(z)+y \text {. }
$$

Uma janela nos níveis de cinza é um subconjunto finito $K$ de $\mathbb{Z}$, definido por

$$
K=\left\{-\frac{k-1}{2}, \ldots,-1,0,1, \ldots, \frac{k-1}{2}\right\}
$$

onde $k$ é um inteiro ímpar positivo e 0 é a origem da janela. O enjanelamento de $u$ em $y$ por uma janela em níveis de cinza $K$ (Figura 4.3) é a função $u / K_{y}: W \rightarrow K$ definida por, $\forall z \in W$,

$$
\left(u / K_{y}\right)(z)=\bigwedge\left\{\bigvee\left\{-\frac{k-1}{2}, u(z)-y\right\}, \frac{k-1}{2}\right\}
$$

Uma função computacional $\psi$ é invariante por translação nos níveis de cinza se e somente se

$$
\psi(u+y)=\psi(u)+y
$$

e localmente definida nos níveis de cinza em $K$ se e somente se

$$
\psi(u)=u(o)+\beta_{u(o)}\left(u / K_{u(o)}\right)
$$

$\forall y \in \mathbb{Z}, \forall u \in F u n[W, \mathbb{Z}]$. o é a origem da janela $K$ e $\beta_{y}: F u n[W, K] \rightarrow K, y \in \mathbb{Z}$, é uma função computacional.

Uma função computacional invariante por translação e localmente definida nos níveis de cinza é chamada de função $K$-computacional e é definida por

$$
\psi(u)=u(o)+\beta_{\psi}\left(u / K_{u(o)}\right) .
$$

Os operadores aperture (também chamados $W K$-operadores), são operadores invariantes por translação e localmente definidos, tanto espacialmente quanto nos níveis de cinza e são caracterizados por uma função K-computacional.

A Figura 4.4 apresenta um exemplo de aplicação de um operador aperture cujas janelas são $W=\{0,1\}$ e $K=\{-2,-1,0,1,2\}$. No lado esquerdo da Figura está uma tabela com os valores de $\beta_{\psi}(u), u \in F u n[W, L]$. Os índices das linhas são os valores de $u(0)$ e os índices das colunas são os valores de $u(1)$. Este operador foi aplicado na função de entrada mostrada à direita da Figura (mostrada com barras escuras). O resultado está apresentado em barras mais claras. Note a saturação na janela $K$ em todos os pontos.

Seja $p$ o primeiro ponto da esquerda para a direita do domínio da função de entrada (em barras escuras, na Figura 4.4). Quando a janela $W$ é transladada até $p$, os valores de $f(0)=5$ e $f(1)=20,\{0,1\} \in W$. Após o enjanelamento de $f$ por $W$ e por $K$ temos $f / K_{f(0)}(0)=0$ e $f / K_{f(0)}(1)=2$, e $\beta_{\psi}\left(f / K_{f(0)}\right)=2$. Finalmente, $\Psi(f)(p)=5+2=7$. 

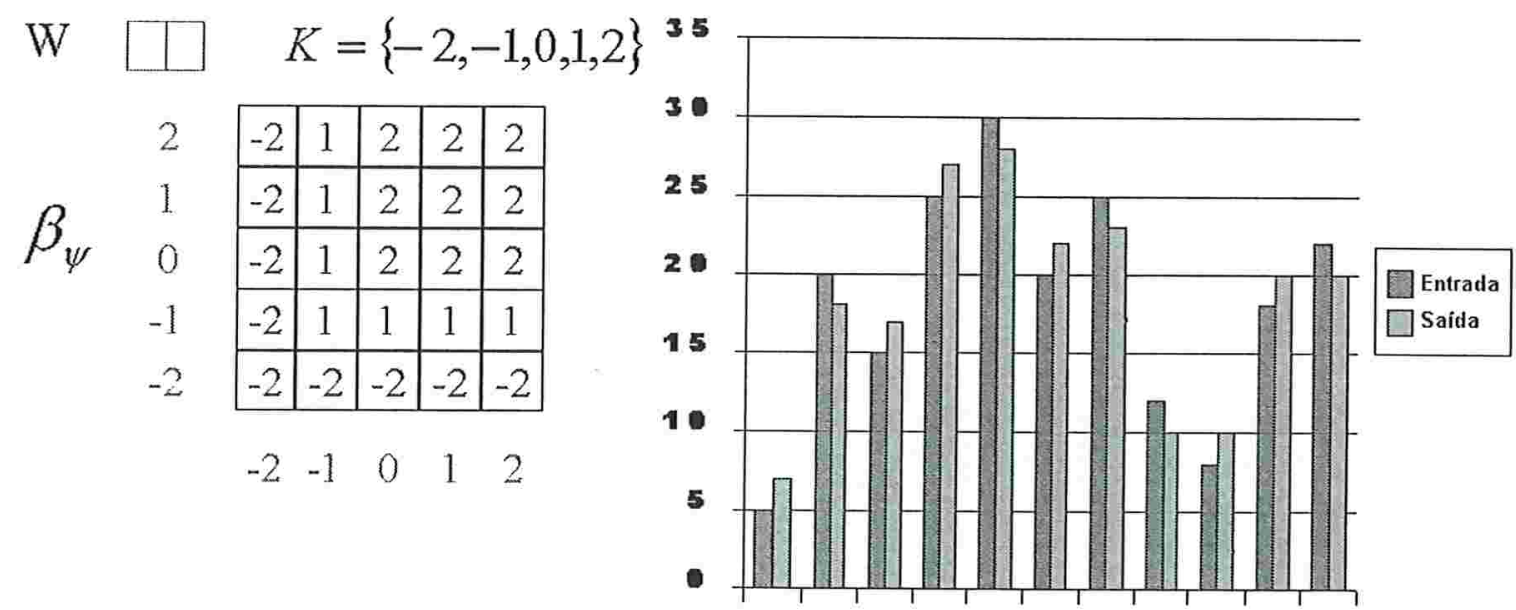

Figura 4.4: Exemplo de Aplicação do Aperture.

\subsection{Imagens Multibanda}

Seja $\bar{W}$ um conjunto de janelas $\left\{W_{i}: i=1,2, \ldots, m\right\}$, onde $W_{i} \subset E$; chamemos $\bar{W}$, por simplicidade, de janela. Seja $\bar{f} / \bar{W}$ a restriçâao de uma função $\bar{f}: E \rightarrow L^{m}$ por uma janela $\bar{W}$, $\forall z \in \bar{W}$

$$
\bar{f} / \bar{W}(z)=\left(f_{1} / W_{1}(z), f_{2} / W_{2}(z), \ldots, f_{m} / W_{m}(z)\right)=\left(f_{1}(z), f_{2}(z), \ldots, f_{m}(z)\right),
$$

onde $f_{i} / W_{i}$ é a restrição de uma função $f_{i}: E \rightarrow L_{i}$ por uma janela $W_{i}$. A classe de restrição $\bar{W}$ em $\bar{f}$ é dada por

$$
\mathcal{F}_{\bar{f} / \bar{W}}=\left\{\bar{g} \in F u n\left[E, L^{m}\right]: \bar{f} / \bar{W}=\bar{g} / \bar{W}\right\} .
$$

Chamemos de Fun $\left[W, L^{m}\right]$ o conjunto de todas as funções $\bar{f}: \bar{W} \rightarrow L^{m}$.

Um operador $\bar{\Psi}$ é localmente definido espacialmente em uma janela $\bar{W}$ se e somente se, $\forall \bar{f} \in F u n\left[E, L^{m}\right], \forall x \in E$,

$$
\bar{\Psi}(\bar{f})(x)=\bar{\Psi}(\bar{g})(x), \forall \bar{g} \in \mathcal{F}_{\bar{f}_{-x} / \bar{W}} .
$$

Um operador $\bar{\Psi}$ é invariante por translação espacialmente se e somente se, $\forall z \in E$,

$$
\bar{\Psi}\left(\bar{f}_{z}\right)=\bar{\Psi}(\bar{f})_{z} .
$$

Um operador $\bar{\Psi}: F u n\left[E, L^{m}\right] \rightarrow F u n\left[E, L^{m}\right]$ é um $W$-operador se for espacialmente localmente definido por uma janela $\bar{W}$ e espacialmente invariante por translação. Um W-operador pode ser caracterizado unicamente por uma função computacional $\bar{\psi}: F u n\left[W, L^{m}\right] \rightarrow L^{m}$. Tal caracterização é dada por,

$$
\bar{\Psi}(\bar{f})(x)=\bar{\psi}\left(\bar{f}_{-x} / \bar{W}\right),
$$

$\forall f \in L^{E}, \forall x \in E$. 
Vamos definir agora a restrição de um operador no domínio $L^{m}$. Esta restrição nos permitirá definir o operador aperture para imagens multibanda. Sejam $L=\mathbb{Z}$.

Seja $k \in L^{m}, k=\left(k_{1}, k_{2}, \cdots, k_{m}\right)$, onde $k_{i}$ é um inteiro positivo. Seja $\bar{K}=\left\{K_{i}: i \in[1, m]\right\}$ um conjunto de janelas em um conjunto totalmente ordenado, onde, $\forall i \in[1, m]$,

$$
K_{i}=\left\{-k_{i}, \ldots,-1,0,1, \ldots, k_{i}\right\} .
$$

onde 0 é a origem da janela $K_{i}$. Chamemos $\bar{K}$ de uma janela em $L^{m}$.

Seja $\bar{u} \in F u n\left[W, L^{m}\right]$. O enjanelamento de $\bar{u}$ em $y$ por uma janela $\bar{K}$ é uma função $\bar{u} / \bar{K}_{y}$ definida por,

$\forall z \in \bar{W}$.

$$
\left(\bar{u} / \bar{K}_{y}\right)(z)=\bigwedge\{\bigvee\{-k, \bar{u}(z)-y\}, k\} .
$$

Seja $\bar{\psi}$ uma função computacional. Seja $y \in \mathbb{Z}^{m}$. Seja $\bar{u} \in F u n\left[W, L^{m}\right]$. A função computacional $\bar{\psi}$ é invariante por translação em $L^{m}$ se e somente se

$$
\bar{\psi}(\bar{u}+y)=\bar{\psi}(\bar{u})+y,
$$

e localmente definida em $L^{m}$ em $\bar{K}$ se e somente se

$$
\psi(\bar{u})=\bar{u}(o)+\beta_{\bar{u}(o)}\left(\bar{u} / \bar{K}_{\bar{u}(o)}\right)
$$

onde $o$ é a origem da janela $\bar{K}$ e $\beta_{y}, y \in \mathbb{Z}^{m}$, é uma função computacional $F u n\left[W, L^{m}\right] \rightarrow L^{m}$.

Uma função K-computacional é uma função computacional invariante por translação e localmente definida em $L^{m}$. A função computacional $\bar{\psi}$ definida por, $\forall \bar{u} \in F u n\left[W, L^{m}\right]$,

$$
\bar{\psi}(\bar{u})=\bar{u}(o)+\beta_{\bar{\psi}}\left(\bar{u} / \bar{K}_{\bar{u}(o)}\right) .
$$

é chamada função K-computacional. Um operador aperture multibanda é unicamente caracterizado por uma função K-computacional.

Sejam $L^{m}$ e $M^{n}, m, n \in \mathbb{Z}^{+}$, dois produtos cartesianos entre conjuntos totalmente ordenados. O operador aperture para imagens multibanda é um operador $\bar{\Psi}: F u n\left[E, L^{m}\right] \rightarrow F u n\left[E, M^{n}\right]$ com as propriedades de invariância por translação e definição local espacialmente e em $L^{m}$.

Dentre os operadores aperture para imagens multibanda, encontram-se duas sub-famílias particulares:

- Sejam $L^{m}, M^{n}$, tais que $L=[0, l-1]$ e $M=[0, m-1](m=n=1)$. O operador aperture para imagens multibanda $\bar{\Psi}: F u n\left[E, L^{m}\right] \rightarrow F u n\left[E, M^{n}\right]$ é o mesmo que foi apresentado na Seção 4.1 e é um mapemento entre imagens em níveis de cinza.

- Sejam $L^{m}, M^{n}$, tais que $L=L_{1} \times L_{2} \times L_{3}$ e $M=[0, m-1](m=3, n=1)$. O operador aperture para imagens multibanda $\bar{\Psi}: F u n\left[E, L^{m}\right] \rightarrow F u n\left[E, M^{n}\right]$ é aplicado em imagens coloridas e o resultado é uma imagem em níveis de cinza. Operadores $\bar{\Psi}$ desta sub-família foram aplicados para classificar objetos em uma imagem colorida, associando um rótulo distinto para cada objeto classificado. Estes operadores foram utilizados para encontrar marcadores para segmentação de imagens coloridas, na metodologia proposta para segmentação de sequencias de imagens coloridas (veja o Capítulo 6). 


\title{
Capítulo 5
}

\section{Projeto de Operadores por Aprendizado Computacional}

\author{
Mantenho o passo, alguem me vê \\ Nada acontece, não sei porque \\ Se eu não perdi nenhum detalhe \\ Onde foi que eu errei? \\ Kid Abelha \& Os Abóboras Selvagens "A \\ Fórmula do Amor"
}

Neste capítulo estudaremos como projetar operadores aperture por aprendizado computacional. Este projeto consiste, dado um conjunto de dados de entrada, em uma otimização estatística no espaço destes operadores.

A Seção 5.1 apresenta o modelo computacional aplicado ao aprendizado de operadores aperture [9]. A Seção 5.2 mostra a extensão da teoria apresentada na Seção anterior aplicada ao projeto de operadores aperture multibanda.

\subsection{Projeto de Apertures}

Aprendizado Computacional [25, 26, 27] é o estudo de métodos computacionais para o aprendizado de um determinado conceito $c \in \mathcal{C}$, onde $\mathcal{C}$ é o conjunto universo cujos elementos são da mesma natureza que $c$. No caso do projeto de operadores aperture por aprendizado computacional, o conceito que estamos interessados em aprender é um operador $\Psi \in \Psi_{W K}$, onde $\Psi_{W K}$ é o espaço de todos os operadores aperture definidos por uma janela $W$ e uma janela $K$. 


\section{CAPÍTULO 5. PROJETO DE OPERADORES POR APRENDIZADO COMPUTACIONAL}

Sejam dois conjuntos aleatórios discretos $\mathrm{X}$ e $\mathrm{Y}$ que definem, respectivamente, a imagem observada e a imagem ideal [26, 28]. X é um processo aleatório que corresponde à imagem de entrada para um dado operador $\Psi$, e $\mathrm{Y}$ é um processo aleatório que representa $\Psi(\mathrm{S})$.

O objetivo do modelo de aprendizado de operadores é estimar, pela observação de $m$ pares de imagens $\left(X_{1}, Y_{1}\right),\left(X_{2}, Y_{2}\right), \cdots,\left(X_{m}, Y_{m}\right)$, chamados pares de treinamento, um operador $\Psi$ onde $\Psi(\mathrm{X})$ seja o mais próximo possível de $\mathrm{Y}$. Este critério de proximidade é dado por uma função de erro $\epsilon[\mathrm{Y}, \Psi(\mathrm{X})]$. Um operador $\Psi_{\text {opt }}$ é ótimo, se

$$
\epsilon\left[\mathrm{Y}, \Psi_{\text {opt }}(\mathrm{X})\right] \leq \epsilon[\mathrm{Y}, \Psi(\mathrm{X})], \Psi_{\text {opt }} \in \Psi_{W K}, \forall \Psi \in \Psi_{W K}
$$

Em outras palavras, o objetivo deste modelo é encontrar um operador ótimo $\Psi_{\text {opt }}$, onde $\epsilon\left[\mathbf{Y}, \Psi_{\text {opt }}(\mathrm{X})\right]$ seja mínimo.

Seja $l$ uma função definida de $K \times K \rightarrow[0, \infty)$. Uma função de perda $l(a, b)$ mede o custo da diferença entre $a$ e $b$, e uma função de erro $\epsilon[\mathbf{Y}, \Psi(\mathbf{X})]$ pode ser dada por uma função de perda. Dois exemplos de funções de perda são a função de perda do módulo da diferença e a função de perda do quadrado da diferença, dadas, respectivamente, por, $\forall z \in E$,

$$
\begin{gathered}
l_{M A E}(\mathrm{Y}(z), \Psi(\mathrm{X})(z))=|\mathrm{Y}(z)-\Psi(\mathrm{X})(z)| \\
l_{M S E}(\mathrm{Y}(z), \Psi(\mathrm{X})(z))=(\mathrm{Y}(z)-\Psi(\mathrm{X})(z))^{2},
\end{gathered}
$$

onde "MAE" e "MSE" são, respectivamente, as abreviações de mean absolute error e mean square error. Ambas as funções de perda definem, para cada $z$, um erro entre $\mathrm{Y}$ e $\Psi(\mathrm{X})$, porém a função de perda do quadrado da diferença apresenta de maneira mais realçada, o mesmo erro dado pela função de perda do módulo da diferença; quanto maior o erro dado pela uma função de perda do módulo da diferença, maior será o mesmo erro dado pela função de perda do quadrado da diferença.

Dado um conjunto de pares de treinamento e uma janela $W$, a função computacional $\psi$ que caracteriza o operador $\Psi$ é estimada através de um processo de treinamento, dividido em três etapas:

1. Sejam $W$ e $K$ duas janelas, uma janela espacial e outra nos níveis de cinza, respectivamente. Seja $\mathcal{M}$ um conjunto de realizações x que são funções $f: W \rightarrow K$. O conjunto $\mathcal{M}$ é criado na etapa de coleta de dados. Para cada realização $\mathrm{x} \in \mathcal{M}$ coletada em um ponto $z$ do domínio de $X_{i}$, é associado um valor $y \in K$ dado pelo mesmo ponto $z$ em $Y_{i}$. E, dada uma realização $\mathrm{x} \in \mathcal{M}$ e um valor $y \in K$ associado a $\mathrm{x}$, é armazenado o número de vezes em que $y$ foi associado a $\mathbf{x}$.

2. Na etapa de decisão, o valor de $\psi(\mathrm{x})$ é estimado, $\forall \mathrm{x} \in \mathcal{M}$.

3. Seja $\mathcal{X}$ o conjunto de todas as funções $F u n[W, K]$ ao qual pertencem todos os exemplos de treinamento possíveis e seja $|\mathcal{X}|$ a sua cardinalidade. Note que, usualmente, $|\mathcal{M}|<|\mathcal{X}|$. Ou seja, não foram decididos os valores de $\psi(u), \forall u \in(\mathcal{X}-\mathcal{M})$. Os valores $y \in K$ associados aos elementos de $(\mathcal{X}-\mathcal{M})$ são decididos na etapa de minimização. 


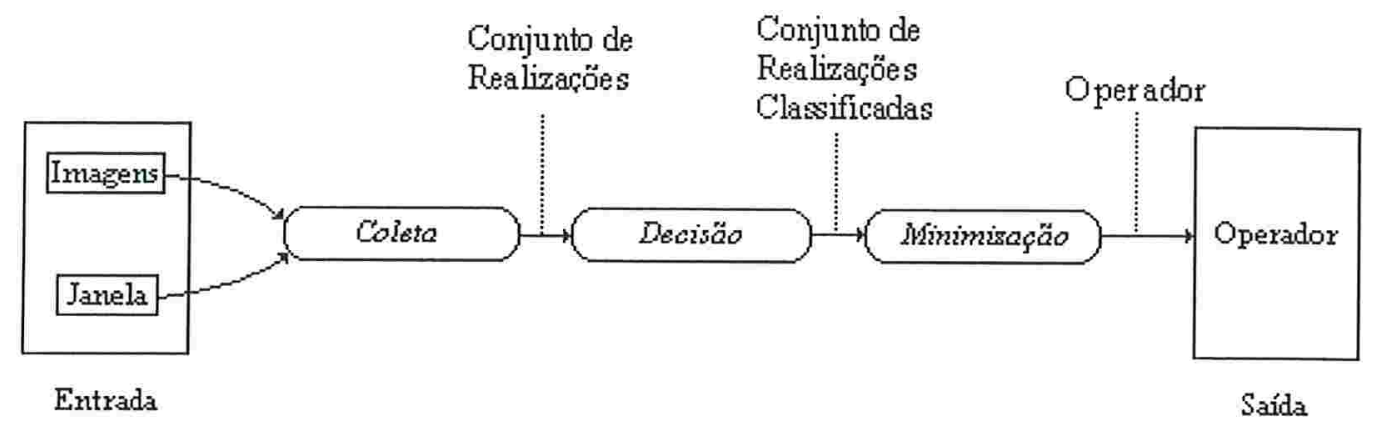

Figura 5.1: Etapas de Treinamento.

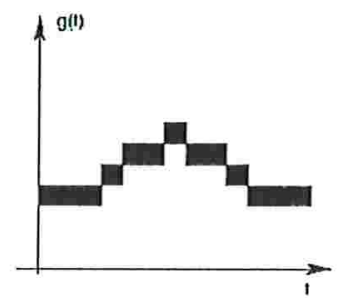

(a)

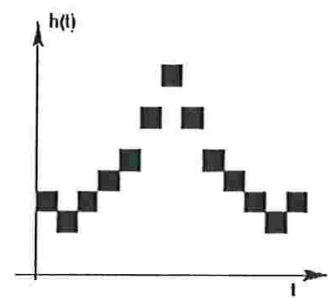

(b)

Figura 5.2: Par de Treinamento. (a) Imagem de Observação. (b) Imagem Ideal.

A Figura 5.1 apresenta as etapas do modelo de aprendizado descrito.

Seja $f \in F u n[E, L]$. Seja $W$ e $K$, respectivamente, as janelas no espaço e nos níveis de cinza. O objetivo do estimador de um operador aperture $\Psi$ é encontrar uma função computacional $\psi$ que caracterize este operador. $\psi$ é estimado através da associação de um rótulo $y$ para cada observação x em $f$ restrita por $W$ e por $K$.

Da mesma forma que um operador binário, um operador aperture é estimado por pares de treinamento $(\mathrm{x}, y)$ (Figura 5.2), onde $\mathrm{x}$ é um exemplo de treinamento e y é um rótulo associado a $\mathbf{x}$. Seja $m$ o número de vezes que um dado $\mathbf{x}$ é observado. $\mathbf{x}$ está associado com $m$ rótulos $y_{1}, y_{2}, \ldots, y_{m}$. O rótulo final associado a $\mathrm{x}$ é calculado através da média entre estes $m$ rótulos, por

$$
R f(\mathrm{x})=\frac{1}{m} \sum_{i=1}^{m} y_{i} \mid \mathbf{x},
$$

onde $y_{i} \mid \mathbf{x}$ é o valor de um dos $m$ rótulos de $\mathbf{x}$ [9].

A função computacional $\psi: F u n[W, K] \rightarrow K$ é estimada por $E[Y \mid \mathcal{X}]$, onde $E$ denota esperança e $Y$ é uma variável aleatória que representa os rótulos que um exemplo de treinamento pode receber. $\psi$ pode ser estimado por uma função $\psi_{N}$ composta por pares $(\mathbf{x}, y)$ onde $\mathbf{x}$ é um dos $N$ exemplos de treinamento e $y$ é seu respectivo rótulo final.

Denote $\mathcal{M} \subseteq \mathcal{X}$ como o conjunto de todos os exemplos observados durante o treinamento. Normalmente $\mathcal{M} \subset \mathcal{X}$, ou seja, existem elementos de $\mathcal{X}$ que não foram observados durante o treinamento e, consequentemente, não receberam um rótulo. Assim, o operador não está 
completamente caracterizado devido à ausência de rótulos para os elementos do conjunto $\mathcal{X}-\mathcal{M}$. Uma forma de solucionar este problema é encontrar uma maneira de representar o operador de forma a generalizar $\psi_{N}$ de $\mathcal{M}$ para $\mathcal{X}$. A etapa de generalização é importante no processo de estimação de um operador, já que é nesta etapa que os elementos de $\mathcal{X}-\mathcal{M}$ passam a receber um rótulo.

Uma das formas de se representar um operador é através de árvores de decisão [9]. A idéia é particionar $\mathcal{M}$ em conjuntos puros, utilizando-se uma árvore de decisão (um conjunto $\mathcal{M}^{u} \subseteq \mathcal{M}$ é puro quando todos os seus elementos possuem o mesmo rótulo). A árvore de decisão $T$ é construída atribuindo-se $\mathcal{M}$ à raíz $T_{0}$ e particionando $\mathcal{M}$ em $n$ subconjuntos $\mathcal{M}_{i}^{u}, i=1 . . n$, onde cada um destes conjuntos é mais puro com relação a $\mathcal{M}$. Em seguida atribui-se cada um dos subconjuntos $\mathcal{M}_{i}^{u}$ a cada filho $T_{i}, i=1 . . n$, de $T_{0}$. Este processo se propaga para os níveis seguintes da árvore até que se encontre um conjunto puro que não será particionado, mas que gerará um nó folha contendo o rótulo dos elementos deste conjunto puro. O resultado deste processo de particionamento de $\mathcal{M}$ em conjuntos puros é uma árvore de decisão, onde os nós internos representam um teste e os nós folhas armazenam um rótulo. $\mathrm{O}$ algoritmo básico para computar uma árvore de decisão a partir de $\mathcal{M}$ é descrito pelos seguintes passos:

1. Seja $u$ um nó qualquer da árvore e $\mathcal{M}^{u} \subset \mathcal{M}$ um subconjunto dos exemplos de treinamento considerados em $u$. Se $\mathcal{M}^{u} \neq \emptyset$ for um conjunto puro, então $u$ é um nó folha que representará o rótulo associado a todos os elementos de $\mathcal{M}^{u}$.

2. Se $\mathcal{M}^{u} \neq \emptyset$ não for um conjunto puro, então $\mathcal{M}^{u}$ deve ser particionado em $n$ partes. Este particionamento é feito considerando-se todas as partições possiveis de $\mathcal{M}^{u}$ e avaliando-se a pureza da partição. É escolhida então a partição mais pura, ou seja, a partição com o maior número de subconjuntos puros possíveis de $\mathcal{M}^{u}$. $u$ é um nó interno que representa um teste e seus filhos estarão associados com cada elemento da partição escolhida de $\mathcal{M}^{u}$ e com os resultados possíveis do teste.

Um critério de pureza para se avaliar um subconjunto $\mathcal{M}^{u} \subset \mathcal{M}$ associado a um nó $u$ da árvore de decisão é chamado de twoing [9] que é o cálculo de um valor $V_{r l}$ para todas as partições possíveis de $\mathcal{M}^{u}$ em 2 subconjuntos $S_{r}$ e $S_{l}$ e a escolha da partição que possui $V_{r l}$ máximo. Os valores $V_{r l}$ são dados por

$$
V_{r l}=P_{r} P_{l}\left[\sum_{j \in K}\left|p\left(j \mid S_{l}\right)-p\left(j \mid S_{r}\right)\right|\right]^{2},
$$

onde $P_{i}$ é a probabilidade de um exemplo pertencer a $S_{i}$ e $p\left(j \mid S_{i}\right)$ é a probabilidade do rótulo $j$ pertencer a $S_{i}$.

O operador caracterizado por $\psi$ pode ser generalizado de $\mathcal{M}$ para $\mathcal{X}$, pois $\forall \mathrm{x} \in \mathcal{X}$, existe um caminho, seguido pelos testes em cada nó interno, da raiz da árvore de decisão até um nó folha, que está associado a um rótulo y que será associado a $\mathrm{x}$.

A Figura 5.3 exemplifica o particionamento de $\mathcal{M}$ em conjuntos mais puros. O conjunto Fun $[W, K]$ com a relação de ordem $\leq$ formam um reticulado completo e os elementos de $\mathcal{M}$ 


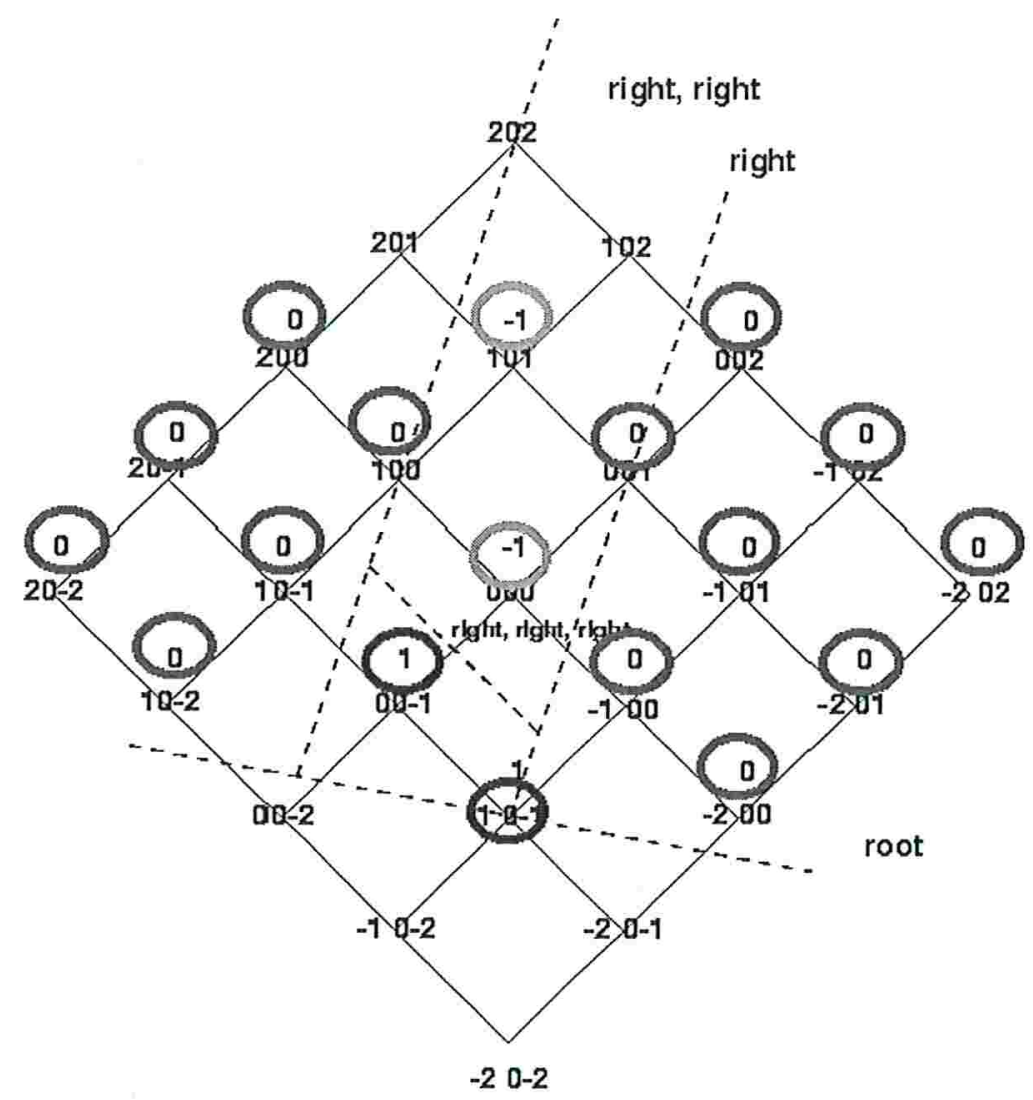

Figura 5.3: Particionamento de $\mathcal{M}$. 


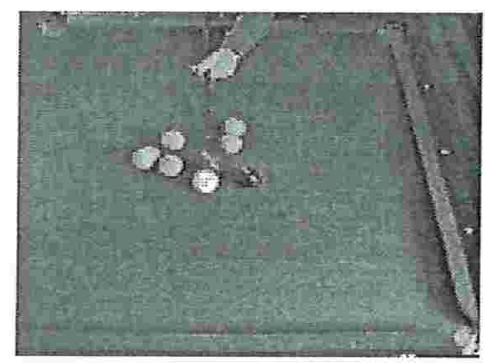

(a)

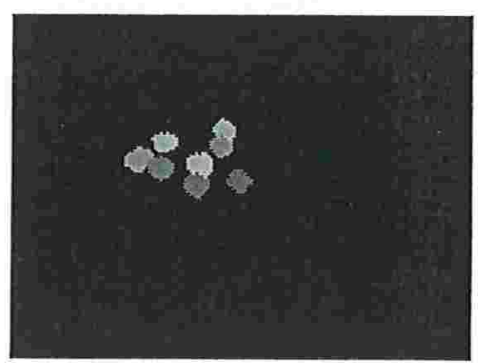

(b)

Figura 5.4: Par (S,I) de Imagens de Treinamento (a) Imagem de Observação S. (b) Imagem Ideal $I$.

estão espalhados por este reticulado. No exemplo da Figura 5.3, $W=\{-1,-0,1\}$ e $K=$ $\{-2,-1,0,-1,-2\}$. Para cada $\mathrm{x} \in \mathcal{M}$ foi associado um rótulo $y \in K$. Os elementos de $\mathcal{M}$ são identificados na Figura 5.3 pelos rótulos associados. Os conjuntos puros são separados por hiperplanos, cujas equações são armazenadas em nós internos da árvore de decisão e definem os testes de decisão nesses nós.

\subsection{Projeto de Apertures Multibanda}

Dada a extensão algébrica dos operadores aperture para imagens coloridas, o projeto automático destes operadores segue o modelo já definido na Seção anterior. Somente o procedimento de coleta que é realizado de um modo particular. São utilizados pares de imagens $\left(X_{1}, Y_{1}\right),\left(X_{2}, Y_{2}\right)$, $\cdots,\left(X_{m}, Y_{m}\right)$, no treinamento do operador. A Figura 5.4 exemplifica um destes pares. A imagem $X_{i}$, naturalmente, é uma imagem colorida (Figura 5.4 (a)); a imagem $Y_{i}$ contém rótulos associados a vários objetos na Figura 5.4 (a) (Figura 5.4 (b)).

Um exemplo de modelo de cores utilizado para representar as imagens de observação é o $R G B$ [20, 19]; as imagens de observação $\mathbf{X}$ são dadas por uma terna de conjuntos aleatórios $\mathrm{X}=\left(\mathrm{X}_{1}, \mathrm{X}_{2}, \mathrm{X}_{3}\right)$. $\mathrm{X}_{1}, \mathrm{X}_{2}$ e $\mathrm{X}_{3}$ estão associados, respectivamente, às informações de cor, vermelha, verde e azul. A janela $\bar{W}$ utilizada para o projeto do operador aperture multibanda é dada por $\bar{W}=\left\{W_{1}, W_{2}, W_{3}\right\}$, onde $W_{i}$ está associada a $\mathbf{X}_{i}$.

Antes da coleta ser realizada, a imagem colorida $f$ é decomposta em três imagens, $X_{1}, X_{2}$ e $X_{3}$, que contêm, respectivamente, as bandas vermelha, verde e azul (Figura 5.5 (a)). Em seguida, passeamos com a janela $\bar{W}$ sobre $X_{i}$. Para cada ponto $z=(x, y) \in E$, posiciona-se a janela $W_{1}$ sobre este mesmo ponto em $X_{1}$ e coleta-se um exemplo (Figura 5.5 (b)). Procede-se da mesma maneira com as demais bandas; posiciona-se $W_{2}$ no ponto $z$ em $X_{2}$ e $W_{3}$ no ponto $z$ em $X_{3}$, coletando-se os exemplos em cada janela. Para cada ponto $z=(x, y) \in E$, o exemplo observado em uma janela $\bar{W}$ é dado pelos exemplos observados em $W_{1}$ no ponto $z$ em $X_{1}$, em $W_{2}$ no ponto $z$ em $X_{2}$ e em $W_{3}$ no ponto $z$ em $X_{3}$ (Figura 5.5 (c-d)).

Os exemplos observados por $\bar{W}$ são armazenados em uma tabela que também armazena, para cada configuração de $\bar{W}$, o número de vezes que um dado rótulo foi associado a esta configuração. A partir da geração desta tabela o método de projeto automático do operador aperture segue 


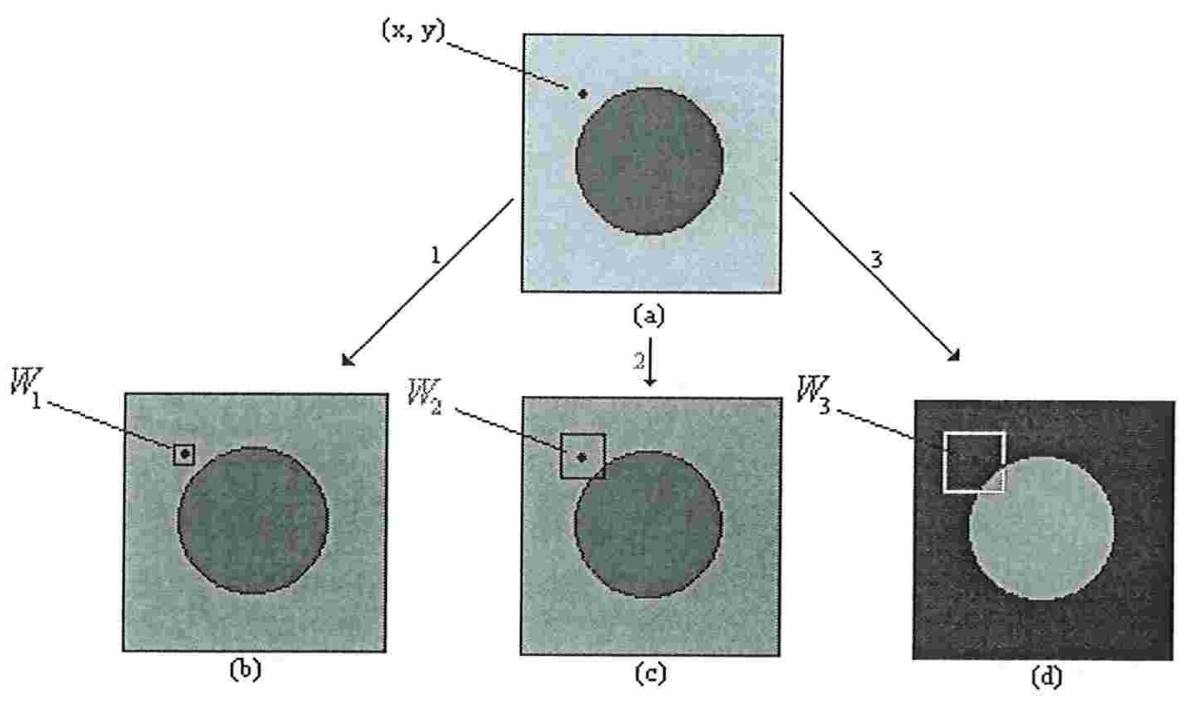

Figura 5.5: (a) Imagem Colorida. (b-d) Posicionamento das janelas $W_{1}, W_{2}$ e $W_{3}$ em suas respectivas bandas no ponto $(x, y)$

como definido na Seção anterior. A etapa de decisão recebe esta tabela e decide o valor de funçã característica para cada realização $\mathrm{x}$ observada e na etapa de minimização é aplicada a técnica de generalização para estimar os valores da função característica para os elementos do conjunto $\mathcal{X}-\mathcal{M}$. Todos estes passos foram descritos na Seção anterior.

Uma observação importante. Seja $|\bar{W}|=\left|W_{1}\right|+\left|W_{2}\right|+\ldots+\left|W_{m}\right|, W_{i} \in W$, a cardinalidade da janela $W$. No caso dos operadores aperture projetados para a resolução de problemas em imagens em níveis de cinza, o número de configurações de $|W|$ que comporão a tabela a ser preenchida na etapa de coleta de dados é $l^{m^{|W|}}$, onde $|W|$ é a cardinalidade da janela $W$ e $l$ e $m$ são, respectivamente, a cardinalidade dos conjuntos $L$ e $M$. Já no caso dos operadores aperture projetados para a resolução de problemas em imagens coloridas, o tamanho da referida tabela é $l^{m^{|\bar{W}|}}$. Para o caso onde $\bar{W}=\left\{W_{1}, W_{2}, W_{3}\right\}$, o tamanho desta tabela é $l^{m^{\left|W_{1}\right|+\left|W_{2}\right|+\left|W_{3}\right|}}$.

Se o problema de projeto de um operador aperture para imagens em níveis de cinza já era complexo, o projeto de um operador aperture para imagens multivaloradas pode ser ainda mais. Observe o que acontece quando $|W|=\left|W_{1}\right|=\left|W_{2}\right|=\left|W_{3}\right|$. Se a complexidade de treinamento de um operador aperture para níveis de cinza é da ordem de $l^{m^{|W|}}$, a complexidade de treinamento de um operador aperture para imagens multivaloradas é da ordem de $l^{m^{3|W|}}$. Apesar de imagens multivaloradas manterem uma maior quantidade de informação que imagens em níveis de cinza, o treinamento de um operador aperture para imagens multivaloradas poderia exigir uma quantidade ainda maior de dados para poder preencher a tabela com as configurações observadas. Assim, faz-se imprescindível a aplicação de alguma técnica que diminua a quantidade de dados requerida e/ou que aumente a confiabilidade nos dados observados. Para os nossos experimentos foram utilizados vários filtros com o intuito de reduzir o número de flat zones coloridas e, consequentemente, reduzir a quantidade de configurações distintas observadas.

O modelo de aprendizado de operadores aperture para níveis de cinza é aplicável para o 
aprendizado de operadores aperture multibanda, porque o reticulado completo $\left(F u n\left[E, L^{m}\right], \leq\right)$ (veja Seção 2.4) pode ser particionado por hiperplanos do mesmo modo que o reticulado completo $(F u n[E, K], \leq)$ (veja a Seção anterior para detalhes deste particionamento). 


\title{
Capítulo 6
}

\section{Segmentação Morfológica de Seqüências de Imagens}

Mas quem tem coragem de ouvir Amanheceu o pensamento

Que vai mudar o mundo

Com seus moinhos de vento

Barão Vermelho "O Poeta está Vivo"

\begin{abstract}
Neste capítulo apresentamos uma metodologia para segmentação de objetos em uma seqüência de imagens $[2,3,4]$, consistindo na perseguição dos objetos de interesse via detecção automática de marcadores para os mesmos através da aplicação de operadores aperture e do Paradigma de Beucher-Meyer para segmentar os objetos marcados. Na Seção 6.1 apresentamos com detalhes esta metodologia aplicada em seqüências de imagens em níveis de cinza. A Seção 6.2 apresenta um exemplo de aplicação da metodologia proposta em uma seqüência sintética e a Seção 6.3 apresenta um estudo comparativo da performance dos operadores aperture aplicado em detecção de marcadores comparada com a performance de dois outros multiclassificadores, definidos na mesma Seção.
\end{abstract}

\subsection{Metodologia Proposta}

A metodologia para segmentação de objetos via aplicação do Paradigma de Beucher-Meyer com deteç̧ão de marcadores por operadores aperture é dividida em duas fases. Na primeira delas é realizado o treinamento do operador aperture para detecção dos marcadores. Na segunda fase, o aperture treinado é utilizado para encontrar os marcadores para os objetos que serão 
segmentados através da aplicação do paradigma.

A fase de treinamento é dividida em duas etapas:

- Seja o conjunto de $n$ pares de treinamento $\left(X_{i}, Y_{i}\right), i=1, \ldots, n$. Antes de se treinar o operador com estes pares, pode-se, opcionalmente, treinar o operador com outros $n$ pares de treinamento $\left(\Gamma\left(X_{i}\right), Y_{i}\right), i=1, \ldots, n$, onde $\Gamma$ é um filtro, usualmente, conexo. Este filtro é aplicado para diminuir a complexidade estatística da imagem; diminuindo-se o conjunto de realizações observáveis, o operador é estimado com maior precisão. Chamamos esta etapa opcional de pré-processamento.

- A etapa de treinamento é realizada utilizando-se $n$ pares de imagens $\left(X_{i}, Y_{i}\right), i=1, \ldots, n$ (Figura 6.1), onde $X_{i}$ é uma imagem (um quadro) de observação retirada da seqüência, e $Y_{i}$ é uma imagem ideal, contendo os marcadores para os objetos a serem segmentados em $X_{i}$. Não é necessário que $X_{i}$ e $X_{i+1}$ sejam consecutivos na seqüência. No entanto, o conjunto de todas as imagens de observação devem representar todas as situações em que o objeto de interesse se encontra na seqüência. Por exemplo, se um objeto localiza-se inicialmente em uma região de pouca luminosidade e instantes depois se move para uma região de luminosidade mais intensa, então pelo menos um quadro de cada uma destas situações deve ser tomado como imagem de observação. Uma outra possibilidade é o treinamento de um outro operador para cada uma das situações em que o objeto de interesse se encontra (por exemplo, um operador $\Psi_{1}$ aplicado quando o objeto atravessa uma região clara na imagem e um outro operador $\Psi_{2}$ aplicado quando o mesmo objeto atravessa uma região mais escura). Outra característica do treinamento é que os exemplos de treinamento ( $\mathrm{x}, y)$ não são coletados da imagem inteira, mas somente de uma área que contenha os objetos de interesse e suas vizinhanças, definidas pela velocidade em que os objetos se movem. Esta área define uma máscara $R$ que será o domínio da imagem de observação, onde os exemplos de treinamento serão coletados.

A fase de tracking é dividida em três etapas, a etapa de tracking, propriamente dita, a etapa de filtragem dos marcadores e a etapa de segmentação.

- A etapa de tracking tem início com a aplicação do operador aperture treinado. Este operador é aplicado em todos os quadros, para a deteç̧ão do marcador para o objeto de interesse, exceto para o primeiro quadro, onde os objetos foram segmentados com marcadores impostos manualmente. Seja $f_{i}$ a imagem que contém os objetos de interesse segmentados no $i$-ésimo quadro. Estes objetos definem uma imagem $M_{i}$ que contém uma máscara de restrição $R$ para a aplicação do aperture no $(i+1)$-ésimo quadro. $R$ é calculada dilatando-se os objetos segmentados contidos em $f_{i}$ por um disco com diâmetro mínimo $\Delta s=V_{0} \Delta t$, onde $V_{0}$ é a velocidade do objeto de interesse que se move mais rápido na seqüência. O aperture então é aplicado somente na área definida por $R$. A Figura 6.2 exemplifica a aplicação do operador aperture restrita por uma máscara $R$. Observe na Figura 6.2 (a) que a máscara $R \in M_{i}$ é uma área em forma de coração, delimitada no exemplo por uma linha branca. Esta máscara $R$ é definida pelo objeto segmentado em $f_{i}$ (no exemplo, o objeto com textura similar a uma impressão digital). A máscara restringirá 

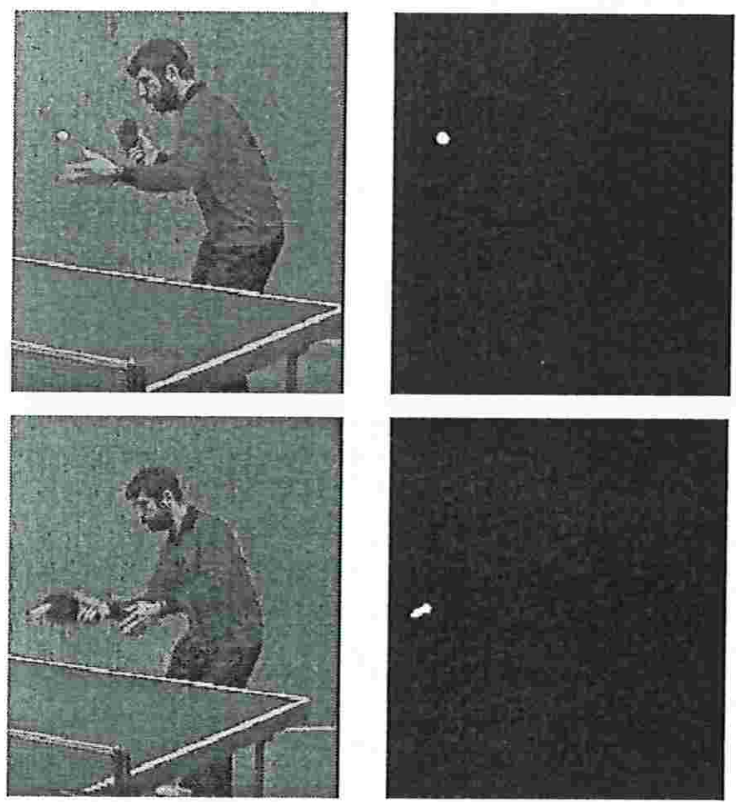

Figura 6.1: Pares de Treinamento. Coluna da Esquerda: Imagens de Observação. Coluna da Direita: Imagens Ideais.

a aplicação do aperture no quadro $i+1$. A Figura 6.2 (b) ilustra o resultado da aplicação do aperture restrita à máscara $R$ ilustrada na Figura 6.2 (a).

- O resultado do operador aperture contém, além dos marcadores para os objetos de interesse, o ruído causado pelos erros de classificação do aperture. Este erro ocorre devido à insuficiência de dados de treinamento no projeto do operador aperture. Como o ruído se apresenta como vários pontos isolados ou pequenas zonas planas, eventualmente o marcador não está bem definido sobre o objeto de interesse; como consequência, o objeto de interesse pode ser segmentado incorretamente. Faz-se necessária uma filtragem do resultado do aperture para que, além de eliminar o ruído, elimine os pixels dos marcadores que se estendem para fora do objeto (Figura 6.3). A filtragem é composta por erosões e filtragens areaopen e areamerge (veja as Seções 3.2.3 e 3.2.4 para maiores detalhes).

- O resultado da filtragem apresenta um marcador bem mais definido e inteiramente contido no objeto. Aplica-se, finalmente, o Paradigma de Beucher-Meyer, utilizando-se os marcadores filtrados.

A Figura 6.4 mostra o diagrama de blocos com os principais etapas da metodologia proposta. 


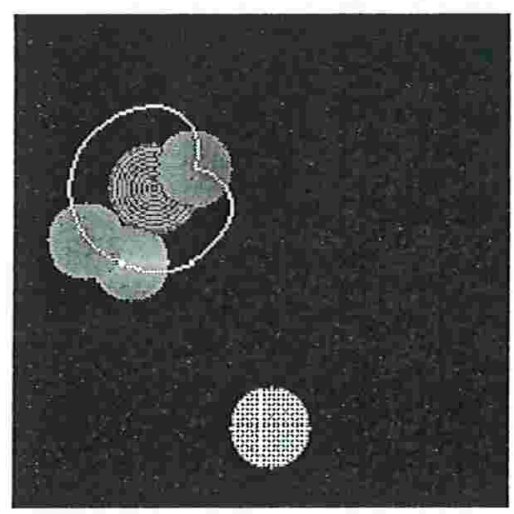

(a)

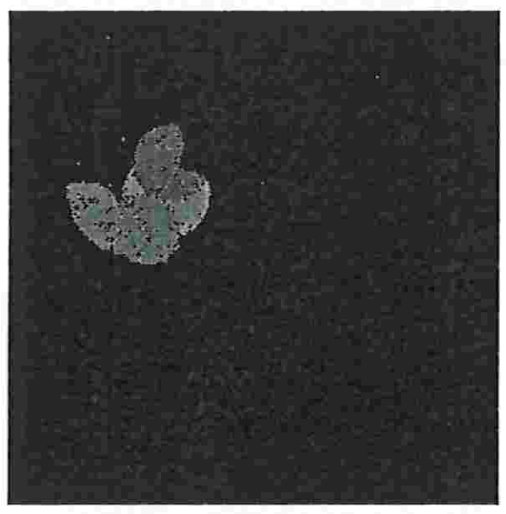

(b)

Figura 6.2: Aplicação do Operador Aperture. (a) $M_{i}$ calculada em função de $f_{i}$ (o objeto que lembra uma impressão digital), em composição com o quadro $i$. (b) Resultado do Operador Aperture restrito em $M_{i}$.

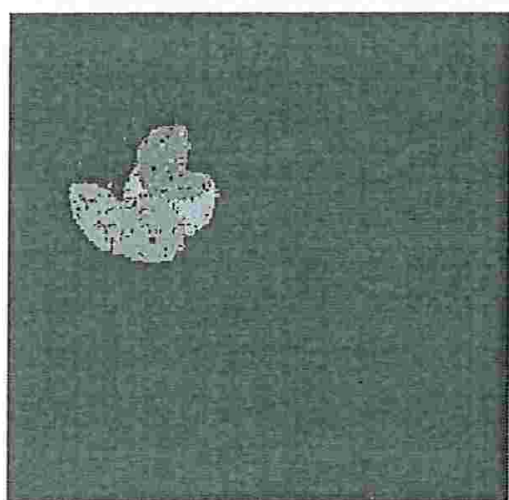

(a)

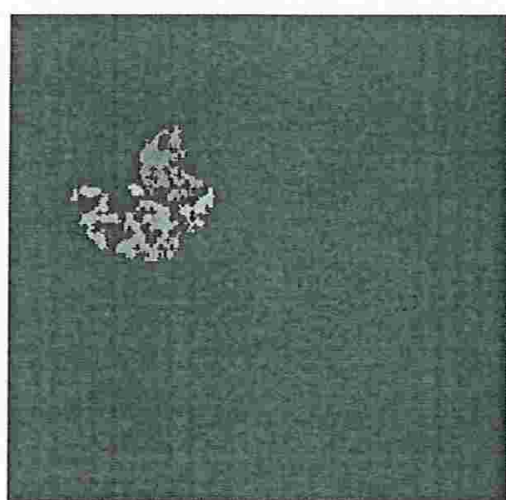

(b)

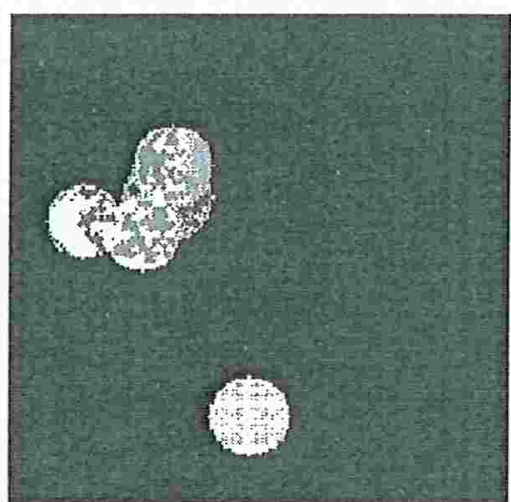

(c)

Figura 6.3: Filtragem do Marcador. (a) Resultado do Aperture. (b) Marcadores Filtrados. (c) Composição com quadro. 


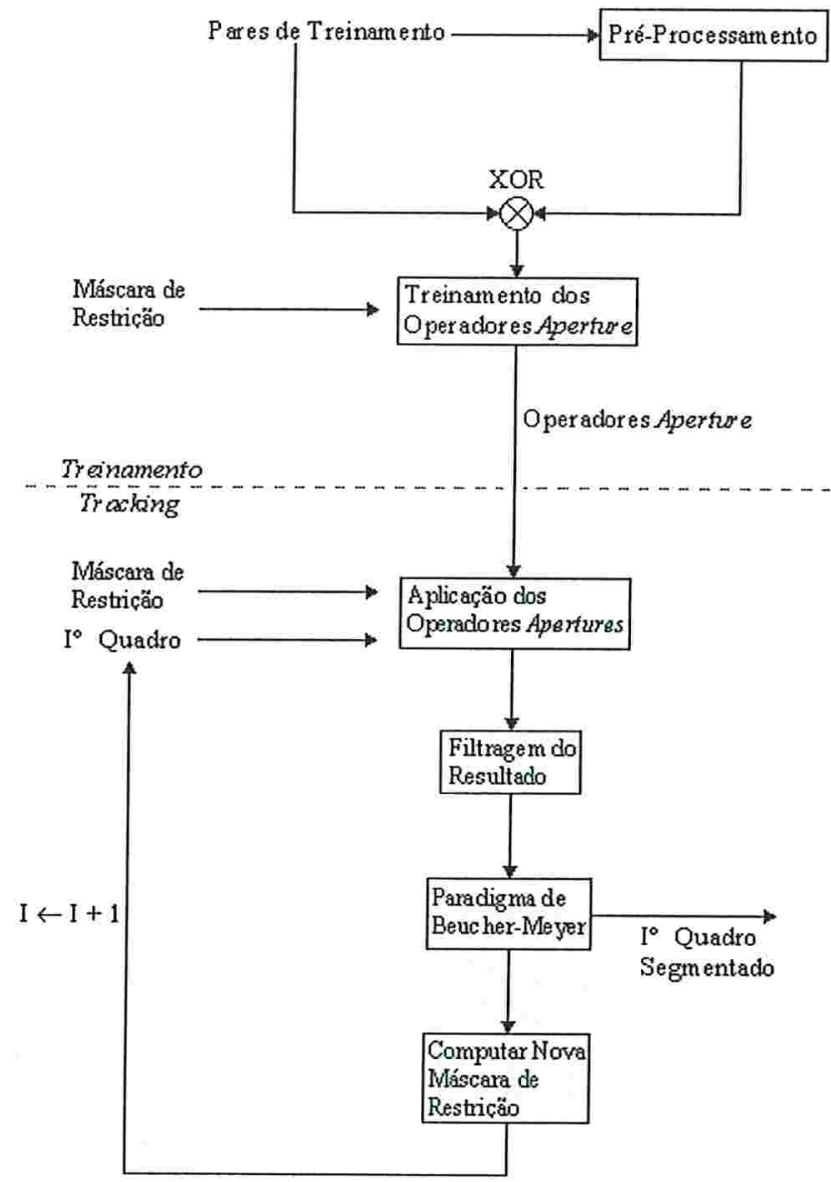

Figura 6.4: Diagrama de Blocos com as Principais Etapas da Metodologia Proposta. 


\subsection{Aplicação em uma Seqüência Sintética}

Apresentamos aqui um experimento onde a metodologia proposta foi aplicada para segmentar um objeto em uma seqüência sintética. Esta seqüência, chamada Simulação de Sistema de Partículas foi criada por um programa escrito em $\mathrm{C}$ com interface no sistema Khoros [29, 15]. O programa permite criar uma seqüência que possua algumas características escolhidas pelo usuário, como dimensões da seqüência (largura e comprimento dos quadros e número de quadros), a taxa de ruído gaussiano adicionado aos quadros, e o número de partículas, bem com qual delas será segmentada. Estas partículas são círculos (cujos diâmetros também são escolhidos pelo usuário) que possuem texturas distintas (waffer, inpressão digital, etc). Outra característica das partículas é que estas se movem em movimento retilíneo uniforme e só mudam de direção quando colidem com as bordas dos quadros. A velocidade inicial das partículas, bem como a direção seguida por elas é escolhida aleatoriamente. As partículas não colidem entre si, podendo haver oclusão quando duas partículas ocupam a mesma região no quadro.

A sequiência utilizada foi criada com 50 quadros em níveis de cinza com dimensões $200 \times 200$. A seqüência apresenta cinco partículas que possuem diâmetros aproximados. Foi escolhida para ser segmentada a partícula com textura parecida com uma impressão digital, pois esta ficou parcialmente oclusa durante alguns instantes da seqüência. Durante a criação desta seqüência foi adicionado ruído gaussiano com média zero e variância 10 sobre $20 \%$ dos pixels da mesma.

O treinamento do operador aperture foi realizado utilizando-se dez pares de imagens compostos por dez dos cinqüenta quadros da seqüência, cada um deles formando par com uma imagem ideal contendo os rótulos para cada partícula. O objetivo do aperture treinado é associar um rótulo distinto para cada uma das partículas.

Esta variação do operador aperture é fundamental para a resolução deste problema. Se o operador simplesmente posicionasse somente um marcador para o objeto de interesse, poderiam haver situações em que o objeto de interesse se encontrasse com outros objetos, formando assim uma bacia de captação que causaria a segmentação não só do objeto de interesse mas de todos os outros objetos que o toquem.

De posse do operador aperture treinado, a etapa de segmentação do objeto é iniciada. O objeto de interesse no primeiro quadro já está segmentado. Calcula-se, então, a área de aplicação do operador aperture no quadro $i+1$, utilizando-se o objeto segmentado no quadro $i$. O resultado do operador aperture é uma imagem com rótulos para as partículas que se encontram dentro da restrição em que o operador aperture foi aplicado.

Em seguida é feita uma filtragem para eliminar o ruído resultante do erro do operador aperture. Foi aplicada, para todos os quadros, uma erosão por uma cruz, seguida por um operador areaopen, que elimina todas as zonas planas com área menor que 10.

Aplica-se então o Paradigma de Beucher-Meyer, utilizando-se a imagem rotulada (resultado filtrado do operador aperture) como imagem de marcadores. Foi utilizada aqui uma outra versão do algoritmo de watershed, que "inunda" as bacias de captação com o nível de cinza dos marcadores utilizados para marcá-las. Como resultado, temos todos os objetos que "invadem" a área de restrição do aperture rotulados. Finalmente, aplica-se uma limiarização que devolva somente o objeto de interesse segmentado. Os resultados podem ser observados na Figura 6.5. 


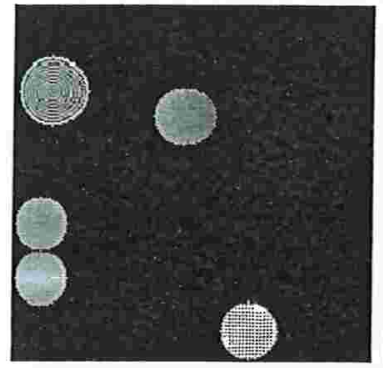

35

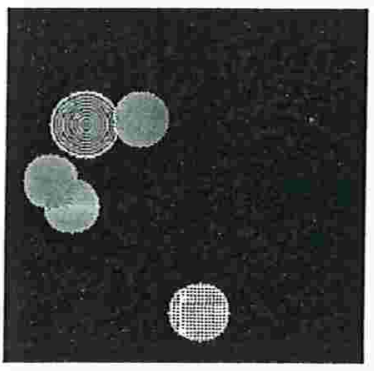

39

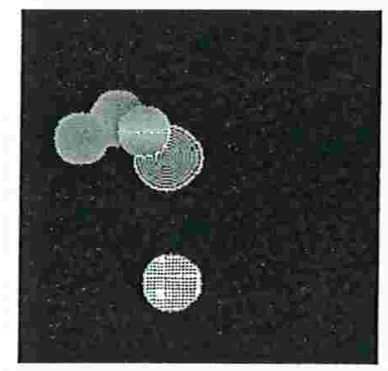

43

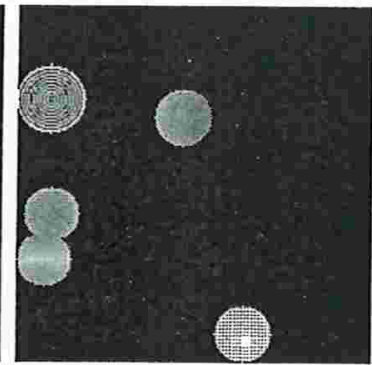

36

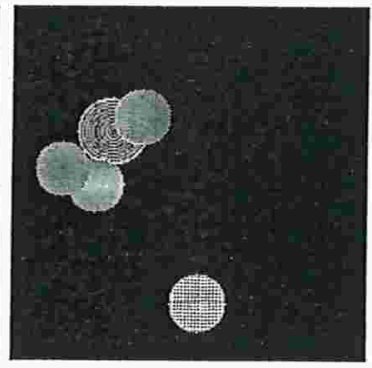

40

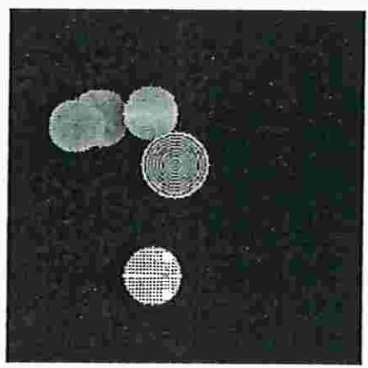

44

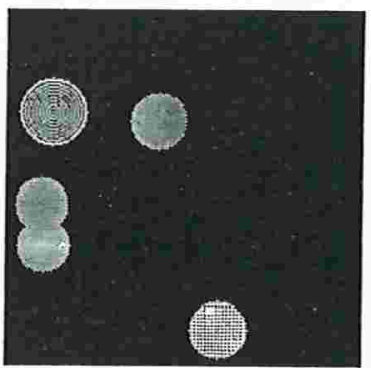

37

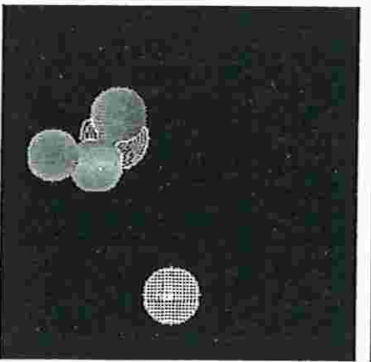

41

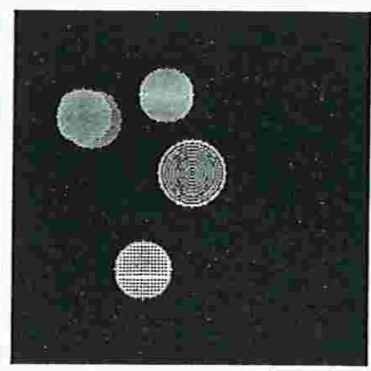

45

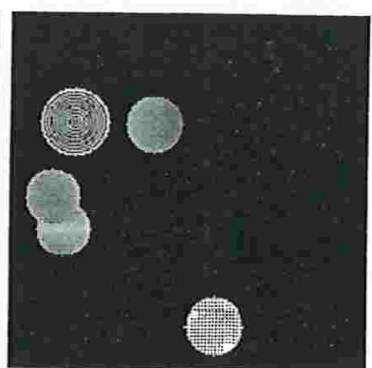

38

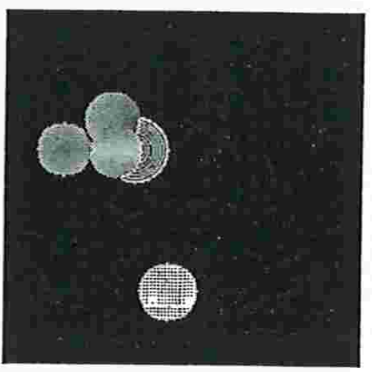

42

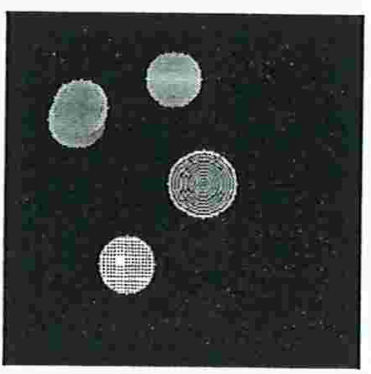

46

Figura 6.5: Segmentação de uma Partícula. quadros 35-46 da seqüência. 
A linha de partição de águas para o objeto segmentado (o que possui textura similar a uma impressão digital) foi sobreposta (em cor branca) sobre o mesmo para visualização.

\subsection{Comparação de Performance entre Multiclassificadores}

Na Seção 6.2 foi descrita uma aplicação dos operadores aperture em multiclassificação de texturas. Chamaremos neste Capítulo os operadores aperture de multiclassificadores aperture. Os parâmetros de entrada para o multiclassificador aperture são a imagem com os objetos a serem segmentados e uma área de restrição para a aplicação do multiclassificador. A saída do multiclassificador aperture é um conjunto de rótulos com valores distintos para cada um dos objetos a serem segmentados. Estes rótulos serão utilizados como marcadores na etapa de segmentação.

A performance do multiclassificador aperture foi comparada com a de dois outros multiclassificadores, projetados para esta comparação [4]. No primeiro deles, é aplicada uma variação da técnica clássica de correlação [20]. No outro, uma técnica para o cálculo de diferença entre duas funções. Ambos os multiclassificadores recebem como entrada a imagem com os objetos a serem segmentados, um conjunto de kernels, que são funções usadas tanto pela correlação quanto pela diferença entre funções, e uma área de restrição para a aplicação do multiclassificador, devolvendo um conjunto de rótulos distintos para cada objeto.

Os multiclassificadores comparados com o multiclassificador aperture foram projetados de maneira idêntica. Nas Sub-Seções seguintes, serão apresentadas a metodologia utilizada no projeto dos multiclassificadores estudados, as técnicas aplicadas e, finalmente, o estudo comparativo entre os multiclassificadores projetados e o multiclassificador aperture. Os resultados de cada um dos experimentos realizados nesta comparação podem ser conferidos no $c d$-rom que acompanha este texto, bem como no web site http://www.vision.ime.usp.br/demos.

\subsubsection{Multiclassificação}

Ambos os multiclassifidores propostos são aplicados da mesma maneira que o operador aperture. Vamos definir a máscara de restrição como um subconjunto $R \subset E$ denotando o domínio de aplicação dos multiclassificadores. Seja $\Psi$ um multiclassificador. A aplicação de $\Psi$ restrita a $R$ é dada por, $\forall f \in F u n[E, L], \forall x \in E$,

$$
\Psi_{R}(f)(x)=\left\{\begin{array}{l}
\Psi(f)(x), \text { if } x \in R \\
0, \text { otherwise }
\end{array} .\right.
$$

Dado o objeto desejado segmentado no quadro $i-1$ da seqüência, a máscara de aplicação é dada pela dilatação deste objeto por um elemento estruturante na forma de disco, com raio maior que $\Delta S=V_{0} \Delta T$, onde $V_{0}$ é a velocidade estimada do objeto e $\Delta T$ é é a diferença temporal. Isto é feito para garantir a presença do objeto na máscara de aplicação. Uma vez que esta é computada, o multiclassificador é aplicado no quadro $i$ restrito a $R$. O resultado é um conjunto de rótulos distintos, cada um deles associado a um único objeto dentro da máscara de restrição. Finalmente, estes rótulos são utilizados como marcadores no Paradigma de Beucher-Meyer. 


\subsubsection{Multiclassificação por Correlação}

A correlação é uma das ferramentas mais usadas em template matching [20]. Através do casamento entre funções (usualmente entre uma função não conhecida e um conjunto de funções conhecidas, chamadas kernels) os pontos de maior similaridade entre elas é computado. Esta similaridade é computada através da análise dos resultados da correlação. Quanto maior a correlação entre duas funções $f$ e $g$, maior a similaridade entre elas.

Sejam $f$ e $g$ duas funções contínuas, onde $g$ é chamada de kernel. A correlação entre $f$ e $g$ é definida por

$$
(f \circ g)(x)=\int_{-\infty}^{\infty} f(\alpha) g(x+\alpha) d \alpha .
$$

Sejam $f$ e $g$ duas funções discretas. Sejam $F$ e $G$, respectivamente, o domínio finito de $f$ e $g(f \in F u n[F, K], g \in F u n[G, K])$. A correlação discreta entre $f$ e $g$ é definida por

$$
(f \circ g)(x)=\sum_{m=0}^{|F|-1} f(m) g(x+m) .
$$

onde $|F|$ é a cardinalidade de $F$.

Normalmente, os pontos $x \in F$ onde $(f \circ g)(x)$ tem os valores máximos são os pontos de correlação máxima. Porém, nem sempre isto é verdade. Seja $C$ um conjunto de pontos $c \in F$ onde $(f \circ g)(c)$ é máxima. Seja $R$ um outro conjunto de pontos $r \in F$ onde $(f \circ g)(r)$ não é a correlação máxima mas tem altos picos em sua função resultante. Apesar de $f(c)$ e $g(c)$ serem mais correlacionados que $f(r)$ e $g(r), c \in C, r \in R$, isto não implica que $(f \circ g)(c)>(f \circ g)(r)$. Isto acontece devido aos altos valores de níveis de cinza em $f(r)$ ou $g(r)$, que resultam em altos valores de $(f \circ g)(r)$, mesmo não sendo altamente correlacionados.

Este problema é resolvido através de uma normalização. A correlação normalizada é definida por, $\forall x \in[0,|F|-1]$,

$$
(f \circ g)(x)=\frac{\sum_{m=0}^{|F|-1} f(m) g(x+m)}{\sqrt{\sum_{m=0}^{|F|-1} f^{2}(m) j(x+m)}},
$$

onde $j \in \operatorname{Fun}[G, K], j(x)=1, \forall x \in G$.

Vamos definir o multiclassificador por correlação. As entradas deste multiclassificador são $f \in F u n[F, K]$ e um conjunto de kernels $\mathcal{G} \subset F u n[G, K]$, e a saída é uma função $\Gamma_{\mathcal{G}}(f)$ contendo um conjunto de rótulos distintos em níveis de cinza para cada um dos objetos a serem rotulados.

Seja $t \in K$. Seja $\Xi_{t}: F u n[F, K] \rightarrow F u n[F, K]$ uma função de limiarização, dada por, $\forall f \in F u n[F, K], \forall x \in F$,

$$
\Xi_{t}(f)(x)=\left\{\begin{array}{l}
f(x), \text { se } f(x) \geq t \\
0, \text { caso contrário }
\end{array} .\right.
$$

Seja $b \in K$. Seja $\Omega_{b}: F u n[F, K] \rightarrow F u n[F, K]$ uma função definida por, $\forall f \in F u n[F, K]$, $\forall x \in F$,

$$
\Omega_{b}(f)(x)=\left\{\begin{array}{l}
b, \text { se } f(x)=\max \{f(x): x \in F\} \\
0, \text { caso contrário }
\end{array}\right.
$$


Seja $n$ o número de objetos a serem segmentados em $f$. Para cada objeto $i, i \in[1, n]$, há um classificador por correlação $\Upsilon_{i}$ com um kernel $g_{i} \in \mathcal{G}$. Este classificador é dado por

$$
\Upsilon_{g_{i}, t_{i}, v_{i}}(f)=\Omega_{v_{i}}\left(\Xi_{t_{i}}\left(f \circ g_{i}\right)\right)
$$

Para cada objeto $i$, o classificador computa a correlação entre $f$ e $g_{i}$ e define o marcador tomando os pontos cujo valor de correlação é próximo do valor de correlação máximo. Então, é atribuído o rótulo $v_{i}$ a estes pontos. Se $\max \left\{\left(f \circ g_{i}\right)(x): x \in F\right\}<t_{i}$, nenhum marcador é imposto. Isto é feito para evitar a imposição de marcadores por $\Upsilon_{g_{i}, t_{i}, v_{i}}$ em uma partícula $j, j \neq i$, já que pode ocorrer que pontos altamente correlacionados com a partícula $i$ sejam altamente correlacionados com a partícula $j$ também.

O resultado da multiclassificação é um conjunto de rótulos distintos atribuídos a cada objeto a ser segmentado, dados pela aplicação de $\Upsilon_{g_{i}, t_{i}, v_{i}}(f), v_{i} \neq v_{j}$ quando $i \neq j, i, j \in[1, n]$. O multiclassificador por correlação $\Gamma_{\mathcal{G}}: F u n[F, K] \rightarrow F u n[F, K]$ é dado por, $\forall f \in F u n[F, K]$,

$$
\Gamma_{\mathcal{G}}(f)=\bigvee_{i \in[1, n]} \Upsilon_{g_{i}, t_{i}, v_{i}}(f)
$$

onde $g_{i}$ é o kernel de correlação para o objeto $i, t_{i}$ é o valor de limiarização associado a $i$ e $v_{i}$ é o valor do rótulo atribuido ao objeto $i, v_{i} \neq v_{j}, i, j \in[1, n]$. Os valores $t_{i}$ e $v_{i}$ são parâmetros dados ao multiclassificador.

\subsubsection{Multiclassificação por Módulo da Diferença}

Uma outra operação, similar à correlação, foi utilizada para projetar um outro multiclassificador. O módulo da diferença entre duas funções discretas $f \in F u n[F, K]$ e $g \in F u n[G, K]$ é definida por, $\forall x \in[0,|F|-1]$,

$$
(f \bullet g)(x)=\sum_{m=0}^{|F|-1}|f(m)-g(x+m)| .
$$

O projeto do multiclasificador por módulo da diferença é similar ao do multiclassificador por correlação. Ambos têm a mesma entrada de dados. Como saída, o multiclassificador por módulo da diferença tem a função $\Gamma_{\mathcal{G}}^{\bullet}(f)$ contendo um conjunto de rótulos distintos em níveis de cinza para os objetos a serem marcados. Este multiclassificador é definido da mesma maneira que o multiclassificador por correlação, porém, dados $t, b \in K$, os operadores $\Xi_{t}$ e $\Omega_{b}$ são trocados, respectivamente, por $\Xi_{t}^{\bullet}: F u n[F, K] \rightarrow F u n[F, K]$ e $\Omega_{b}^{\bullet}: F u n[F, K] \rightarrow F u n[F, K]$. Ambos são dados por, $\forall f \in F u n[F, K], \forall x \in F$,

$$
\Xi_{t}^{\circ}(f)(x)=\left\{\begin{array}{l}
f(x), \text { se } f(x) \leq t \\
k-1, \text { caso contrário }
\end{array} .\right.
$$

and

$$
\Omega_{b}^{\bullet}(f)(x)=\left\{\begin{array}{l}
b, \text { se } f(x)=\min \{f(x): x \in F\} \\
0, \text { caso contrário }
\end{array}\right.
$$




\subsubsection{Experimentos Realizados}

Os experimentos de comparação entre os dois multiclassificadores propostos nas Sub-seções anteriores e o multiclassificador aperture foram realizados usando a sequência Simulação de Sistema de Partículas (veja a Seção 6.2). Os multiclassificadores $\Gamma_{\mathcal{G}}$ e $\Gamma_{\mathcal{G}}^{\circ}$ foram projetados para gerar cinco marcadores que são produzidos por cinco classificadores $\Upsilon_{g_{i}, t_{i}, v_{i}}, i \in[1,5]$, um para cada partícula. Para cada classificador foi utilizado um kernel $g_{i}$ que consiste em um quadrado extraído do centro da partícula $i$. Os valores $t_{i}$ para as limiarizações $\Xi_{t_{i}}$ foram escolhidos bem próximos de $\max \left(g_{i} \circ g_{i}\right)$, e os valores $t_{i}$ para as limiarizações $\Xi_{t_{i}}^{\bullet}$ foram escolhidos bem próximos de $\min \left(g_{i} \bullet g_{i}\right)$. Para os rótulos foram escolhidos os valores: $v_{1}=120, v_{2}=100$, $v_{3}=80, v_{4}=60, v_{5}=40$.

A aplicação da metodologia para segmentação com os multiclassificadores $\Gamma_{\mathcal{G}}$ e $\Gamma_{\mathcal{G}}^{\bullet}$ é basicamente a mesma que a aplicada com o multiclassificador aperture. Assim como no multiclassificador aperture, a partícula a ser perseguida e segmentada é a que apresenta textura similar a uma impressão digital. A etapa de tracking inicia com a partícula desejada já segmentada manualmente no primeiro quadro. O multiclassificador é aplicado a partir do segundo quadro dentro da máscara de restrição $R$. A única diferença entre as aplicações dos multiclassicadores $\Gamma_{\mathcal{G}}$ e $\Gamma_{\mathcal{G}}^{\bullet}$ e o multiclassificador aperture é que os marcadores gerados pelos dois primeiros multiclassificadores não são filtrados, ao contrário dos marcadores gerados pelo multiclassificador aperture.

\section{Categorias de Experimentos}

Foram realizados 21 experimentos para comparação dos multiclassificadores por correlação com o multiclassificador aperture. Estes experimentos podem ser divididos em cinco categorias, descritas abaixo:

\section{- Multiclassificação por Operadores Aperture}

Neste único experimento realizado com um multiclassificador aperture, o operador foi treinado através da observação de 10 pares de imagens, usando uma janela $3 \times 3 \times 21$. A máscara de restrição também foi utilizada na etapa de treinamento. O conjunto de treinamento foi coletado apenas da região dada pela máscara de restrição em cada par do conjunto.

\section{- Multiclassificação por Correlação Normalizada}

Nestes 5 experimentos, que chamaremos de $c n_{i \times i}$, onde $i \times i$ são as dimensões do kernel $g_{i}$, foi usado o multiclassificador por correlação normalizada. O Paradigma de Beucher-Meyer recebe como entradas de dados os marcadores obtidos pela aplicação deste multiclassificador dilatados por um disco e a imagem original $f$.

\section{- Multiclassificação por Módulo da Diferença}




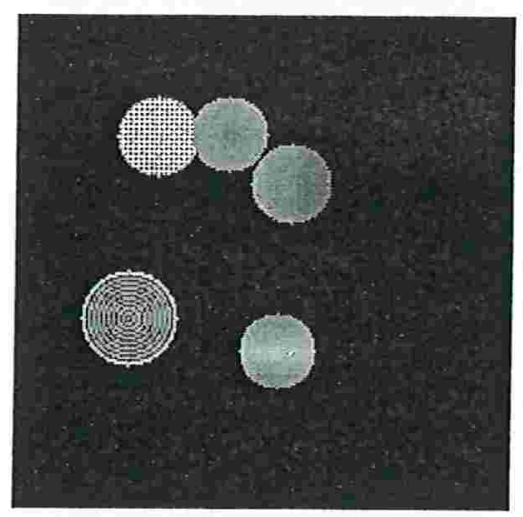

(a)

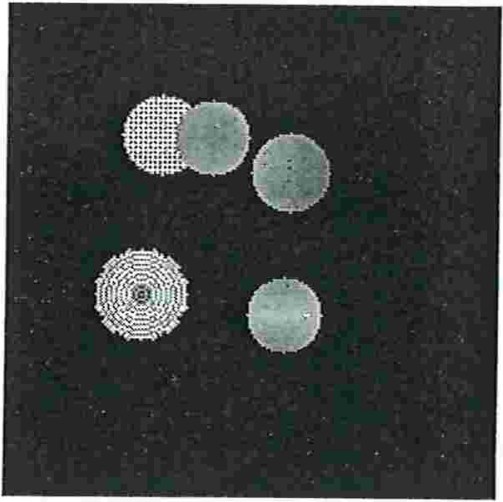

(b)

Figura 6.6: Resultados do Algoritmo de Watershed. (a) Resultado Apropriado. (b) Resultado Não Apropriado.

Nos 5 experimentos realizados nesta categoria, foi usado o multiclassificador por módulo da diferença e, como na categoria descrita anteriormente, o Paradigma de Beucher-Meyer recebe como entradas os marcadores obtidos pela aplicação deste multiclassificador dilatados por um disco e a imagem original $f$. Chamaremos os experimentos contidos nesta categoria de $c d_{i \times i}$.

\section{- Multiclassificação por Correlação Normalizada e Simplificação de Textura por Operadores Levelings}

Os 5 experimentos realizados nesta categoria são semelhantes aos da segunda categoria descrita, apresentando duas diferenças. A primeira delas é que o Paradigma de Beucher-Meyer recebe por entrada o leveling da $f$. Esta substituição foi realizada objetivando-se uma melhora no resultado na segmentação visto que o algoritmo de watershed, desenvolvido por Lotufo e Falcão [30], utilizado na segmentação dos objetos não apresentou resultados adequados em alguns quadros da seqüência original (Figura 6.6 (b)).

Outra diferença é que, nestes experimentos, os marcadores obtidos pela multiclassificação não são dilatados.

Chamaremos de $c n L e v_{i \times i}$ os experimentos contidos nesta categoria.

- Multiclassificação por Módulo da Diferença e Simplificação de Textura por Operadores Levelings

Estes 5 últimos experimentos, que serão denotados por $c d L e v_{i \times i}$, são os mesmos descritos na categoria anterior, porém, nesta categoria é utilizado o multiclassificador por correlação pelo módulo da diferença.

Denotemos por $\Lambda_{\Pi}(f)$ o operador que calcula o leveling de $f$ usando um operador $\Pi$ para representar o conjunto de marcadores. (para maiores detalhes, consulte a Seção 3.4). Em cada um dos dez experimentos contidos nas duas últimas categorias descritas, o leveling $l$ de $f$ é dado 
por

$$
l=\Lambda_{\Pi\left(\Lambda_{\Pi(f)}(f)\right)}\left(\Lambda_{\Pi(f)}(f)\right),
$$

onde $\Pi$ é uma filtragem de $f$ por um filtro alternado sequencial, dado por

$$
\Pi(f)=\psi_{3, B}^{2}(f)
$$

onde $B$ é um elemento estruturante disco de raio 3 (veja Seção 2.3 para maiores detalhes).

\section{Kernels Utilizados}

Com exceção do multiclassificador aperture, as categorias descritas acima consistem em cinco experimentos realizados. Cada um destes cinco experimentos foi realizado escolhendo-se as dimensões $k \times k$ do kernel $g_{i}$, onde $i$ é um índice para cada uma das partículas que aparecem no quadro. As dimensões escolhidas para $g_{i}$ em cada um dos experimentos foi $5 \times 5,7 \times 7,9 \times 9$, $11 \times 11$ e $13 \times 13$.

Quando nos referirmos ao experimento $c n_{7 \times 7}$, estaremos nos referindo ao experimento que utiliza multiclassificação por correlação normalizada onde o multiclassificador utiliza kernels $g_{i}$ de dimensão $7 \times 7$.

O kernel $g_{i}$ utilizado pelo classificador para impor um marcador para a partícula $i$ é um pedaço recortado do centro da partícula. O centro de $g_{i}$ corresponde ao centro da partícula $i$.

\section{Limiarização}

Como foi visto anteriormente, os valores de limiarização são utilizados para que o classificador de uma partícula $i$ imponha marcadores somente para esta partícula, ignorando os marcadores impostos erroneamente nas demais partículas. Os limiares para $\Gamma_{\mathcal{G}}$ e $\Gamma_{\mathcal{G}}^{\bullet}$ foram escolhidos próximos aos valores de $\max \left(g_{i} \circ g_{i}\right)$ e $\min \left(g_{i} \bullet g_{i}\right)$, respectivamente.

As Tabelas 6.1 e 6.2 apresentam os limiares utilizados pelos classificadores. Cada valor destas tabelas apresenta um limiar $t_{i}$ utilizado pelo classificador da partícula $i$ que utiliza um kernel de dimensões $k \times k$.

A Tabela 6.1 apresenta os limiares utilizados pelos classificadores por correlação normalizada, seja com simplicação de textura ou não, enquanto a Tabela 6.2 apresenta os limiares utilizados pelos classificadores por módulo da diferença (com e sem simplificação de textura).

Note que a partícula 1 não possui limiares pois o classificador que impõe marcadores para esta partícula é o único que não aplica limiarização. Isto se deve ao fato de que a partícula 1 é a que desejamos segmentar. 


\begin{tabular}{|l|c|c|c|c|c|}
\hline & $5 \times 5$ & $7 \times 7$ & $9 \times 9$ & $11 \times 11$ & $13 \times 13$ \\
\hline Partícula 1 & - & - & - & - & - \\
\hline Partícula 2 & 1180 & 1540 & 2100 & 2460 & 3020 \\
\hline Partícula 3 & 720 & 1020 & 1330 & 1650 & 1970 \\
\hline Partícula 4 & 740 & 1040 & 1340 & 1640 & 1950 \\
\hline Partícula 5 & 1150 & 1590 & 2010 & 2430 & 2820 \\
\hline
\end{tabular}

Tabela 6.1: Correlação Normalizada - Limiares Utilizados

\begin{tabular}{|c|c|c|c|c|c|}
\hline & $5 \times 5$ & $7 \times 7$ & $9 \times 9$ & $11 \times 11$ & $13 \times 13$ \\
\hline Partícula 1 & - & - & - & - & - \\
\hline Partícula 2 & 60 & 220 & 300 & 400 & 700 \\
\hline Partícula 3 & 175 & 400 & 600 & 700 & 900 \\
\hline Partícula 4 & 75 & 200 & 330 & 480 & 620 \\
\hline Partícula 5 & 50 & 175 & 235 & 400 & 600 \\
\hline
\end{tabular}

Tabela 6.2: Módulo da Diferença - Limiares Utilizados

\section{Implementações}

Os experimentos foram realizados em ambiente Linux utilizando-se ferramentas do sistema Khoros [29]. Foram utilizadas ferramentas da toolbox MMach [15], bem como foram criadas algumas ferramentas que foram incorporadas à já existente toolbox tracking. Esta toolbox contém várias ferramentas para o tratamento de seqüências de imagens, divididas em categorias. Uma delas, intitulada Correlation, contém as ferramentas utilizadas nestes experimentos. São três ao todo.

A primeira ferramenta, intitulada $K$ Corr $M s k$, recebe como entradas a imagem $f$, o kernel $g$, a máscara de restrição $R$ e a operação desejada (correlação normalizada ou módulo da diferença). $K C o r r M s k$ retorna $(f \circ g)$ ou $(f \bullet g)$, dada a máscara de restrição $R$.

A segunda ferramenta, chamada KCorrThres, recebe uma imagem $h$, o tipo da operação da qual $h$ é o resultado (correlação normalizada ou módulo da diferença) e um limiar $t$. KCorrThres retorna $\Xi_{t}(h)$ ou $\Xi_{t}^{\bullet}(h)$.

A terceira ferramenta, intitulada KMaxCorr, recebe uma imagem $h$, uma opção $a$ que representa a operação que foi aplicada (correlação normalizada ou módulo da diferença) e um rótulo $b \in K$. Retorna $\Omega_{b}(h)$ ou $\Omega_{b}^{\bullet}(h)$.

De posse destas ferramentas, foi desenvolvido em Perl um script que recebe como entradas a seqüência de imagens e um kernel para cada partícula da seqüência. Por fim, o script retorna duas imagens. A primeira é a composição do watershed com a imagem original. A segunda é a composição dos marcadores com a imagem original. 


\section{Resultados Obtidos}

Apresentamos em seguida os resultados de aplicação dos multiclassificadores segundo diversos critérios de erro. Os multiclassificadores foram comparados segundo os seguintes critérios:

1. Número de partículas mal classificadas em um quadro. Uma partícula foi mal classificada se foi classificada como outra partícula.

2. Número de quadros onde ocorre má classificação.

3. Número de partículas que foram mal segmentadas. Este erro ocorre devido ao mal posicionamento do marcador na partícula, ou à falta de robustez do algoritmo de watershed, ou se a partícula for perdida, segmentando assim a partícula errada.

4. Instante em que a partícula 1 é perdida, deixando de ser perseguida. Este instante é dado pelo índice do quadro em que a partícula é perdida. Se a partícula é perseguida até o final da seqüência, este valor é indicado com um " - ".

A Tabela 6.3 apresenta quantitativamente os resultados de cada um dos experimentos realizados. As linhas representam os experimentos, enquanto as colunas representam os critérios descritos acima. Em seguida, estes resultados são comentados com exemplos.

Vale ressaltar que o multiclassificador aperture, comparado com os demais multiclassificadores por correlação, utiliza uma janela $3 \times 3$.

A Tabela 6.4 apresenta as porcentagens de erro de cada multiclassificador e as porcentagens de erro de segmentação. A porcentagem de erro do Critério 1 foi calculada em relação ao total de partículas contidas nos 50 frames da seqüência (250 ao todo). A porcentagem de erro do Critério 2 foi calculada em relação ao total de frames contidos na sequêencia (50). E a porcentagem de Erro de Segmentação (Critério 3) foi calculda em relação ao total de partículas 1 que deviam ter sido segmentadas nas seqüências (50).

Umas das causas do erro analisado pelo Critério 1 ocorre quando o multiclassificador confunde as partículas. Houveram muitos casos em que um classificador associado a uma partícula $i$ impôs um marcador também em outras partículas $j$. O erro decorre do fato de que $\left(P_{i} \circ g_{i}\right) \simeq\left(P_{j} \circ g_{i}\right)$, onde $P_{i}$ e $P_{j}$ são duas partículas e $g_{i}$ é o kernel usado para classificar a partícula $P_{i}$.

Observe na Figura 6.7 (c) que o multiclassificador confunde a partícula 3 (com textura clara à esquerda e escura à direita) com a partícula 4 (com textura clara nas bordas e escura no centro). $\mathrm{O}$ classificador associado à partícula 3 impõe um marcador corretamente à mesma, porém o classificador associado à partícula 4 também impõe um marcador. As partículas $3 \mathrm{e}$ 4 apresentam alta correlação e como os valores de limiarização para estas partículas são muito próximos (vejas as Tabelas 6.1 e 6.2).

Outra causa do erro analisado pelo Critério 1 ocorre quando a partícula está parcialmente oclusa. Observe na Figura 6.8 (c) que a partícula 1 (com textura semelhante a uma impressão digital) está parcialmente oclusa pela partícula 3 . O multiclassificador impôs o marcador próximo da partícula 1 porém na borda da partícula 3 . 


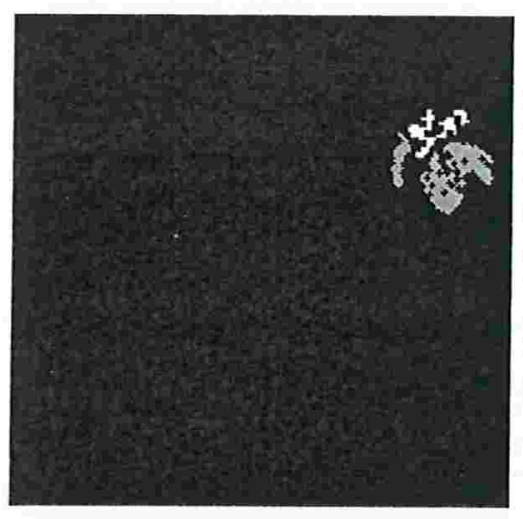

(a)

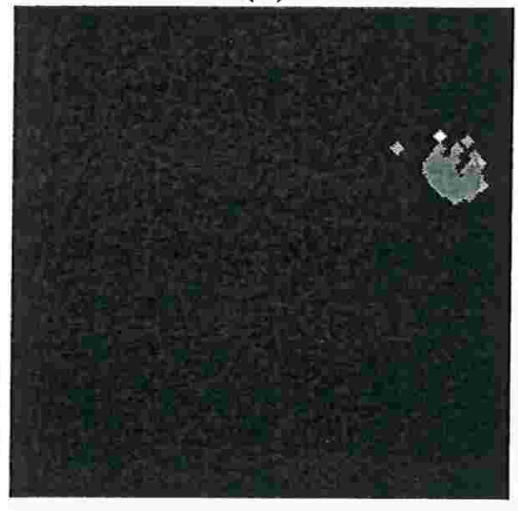

(c)

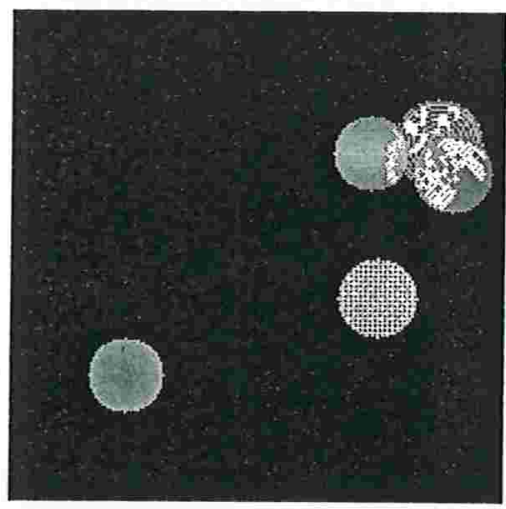

(b)

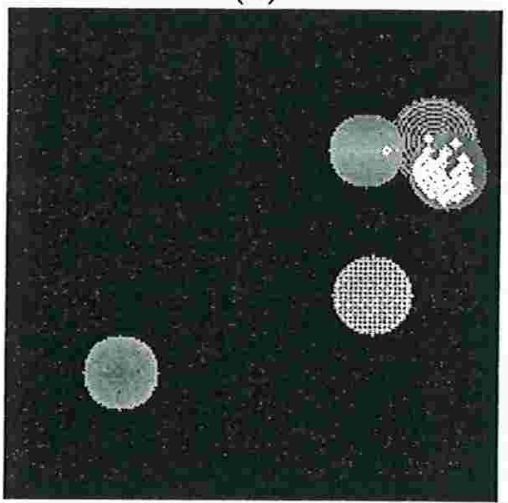

(d)

Figura 6.7: Resultados dos Multiclassicadores: (a) Marcadores gerados pelo Aperture. (b) Composição dos Marcadores gerados pelo Aperture com Imagem Original. (c) Marcadores gerados por Correlação. (d) Composição dos Marcadores gerados por Correlação com Imagem Original. 


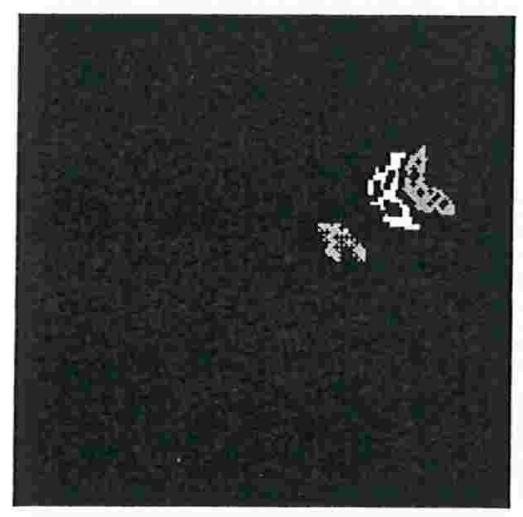

(a)

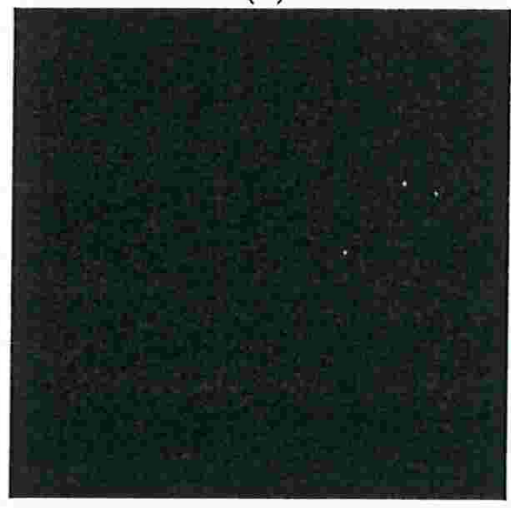

(c)

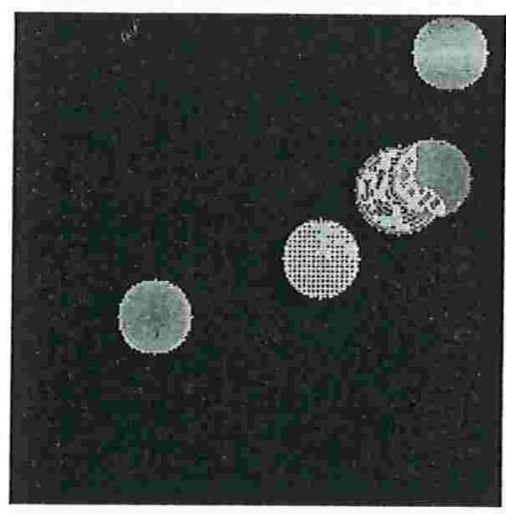

(b)

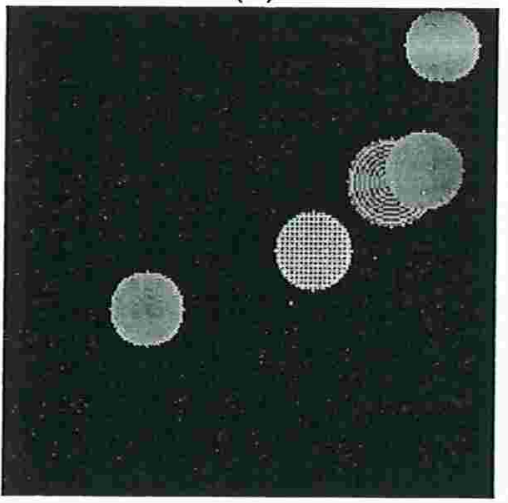

(d)

Figura 6.8: Resultados dos Multiclassicadores: (a) Marcadores gerados pelo Aperture. (b) Composição dos Marcadores gerados pelo Aperture com Imagem Original. (c) Marcadores gerados por Correlação. (d) Composição dos Marcadores gerados por Correlação com Imagem Original. 


\begin{tabular}{|c|c|c|c|c|}
\hline & Critério 1 & Critério 2 & Critério 3 & Critério 4 \\
\hline$c n_{5 \times 5}$ & 35 & 25 & 19 & - \\
\hline$c n_{7 \times 7}$ & 42 & 30 & 25 & 42 \\
\hline$c n_{9 \times 9}$ & 34 & 30 & 25 & 42 \\
\hline$c n_{11 \times 11}$ & 18 & 18 & 25 & 42 \\
\hline$c n_{13 \times 13}$ & 24 & 24 & 25 & 42 \\
\hline & & & & \\
\hline$c d_{5 \times 5}$ & 11 & 11 & 22 & - \\
\hline$c d_{7 \times 7}$ & 13 & 13 & 20 & - \\
\hline$c d_{9 \times 9}$ & 1 & 1 & 22 & - \\
\hline$c d_{11 \times 11}$ & 2 & 2 & 22 & - \\
\hline$c d_{13 \times 13}$ & 2 & 2 & 22 & - \\
\hline & & & & \\
\hline$c n L e v_{5 \times 5}$ & 35 & 25 & 13 & - \\
\hline$c n L e v_{7 \times 7}$ & 43 & 30 & 20 & 42 \\
\hline$c n L e v_{9 \times 9}$ & 34 & 30 & 20 & 42 \\
\hline$c n L e v_{11 \times 11}$ & 11 & 10 & 13 & - \\
\hline$c n L e v_{13 \times 13}$ & 18 & 17 & 14 & - \\
\hline & & & & \\
\hline$c d L e v_{5 \times 5}$ & 12 & 12 & 16 & - \\
\hline$c d L e v_{7 \times 7}$ & 13 & 13 & 16 & - \\
\hline$c d L e v_{9 \times 9}$ & 1 & 1 & 16 & - \\
\hline$c d L e v_{11 \times 11}$ & 2 & 2 & 16 & - \\
\hline$c d L e v_{13 \times 13}$ & 2 & 2 & 16 & - \\
\hline & & & & \\
\hline$a p e r t u r e$ & 0 & 0 & 0 & - \\
\hline & & & & \\
\hline
\end{tabular}

Tabela 6.3: Resultados Obtidos

São vários as causas de erro analisadas pelo Critério 3. Uma delas é a qualidade da segmentação da partícula 1 em alguns quadros da seqüência, onde o algoritmo de watershed utilizado não apresentou resultados adequados. Isto se deve ao fato de que a partícula em questão apresenta duas zonas planas entrelaçadas e, dependendo do posicionamento e tamanho do marcador, o algoritmo de watershed não funciona adequadamente (veja Figura 6.9 (b)). Esta é a motivação de terem sido feitos experimentos com a aplicação de operadores leveling para contornar este problema. Porém, apesar do resultado ter melhorado, o algoritmo ainda apresenta alguns resultados indesejados (Figura 6.9 (c)).

Outra causa de erro de segmentação é o mal posicionamento dos marcadores. Nos casos em que o multiclassificador impõe o marcador para a partícula 1 dentro de outra partícula, as linhas de partição de águas invadem o outro objeto. Observe na Figura 6.9 (d) que as linhas de partição de águas envolvem a partícula 1 e um pedaço da partícula 3. 


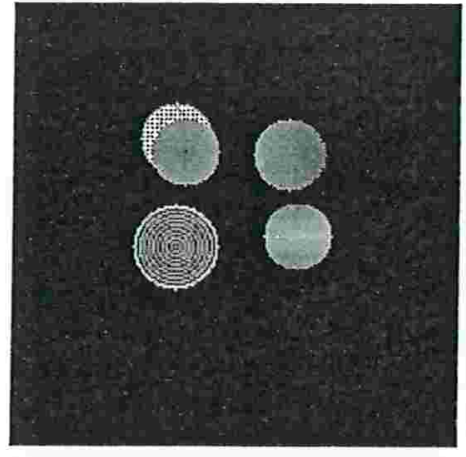

(a)

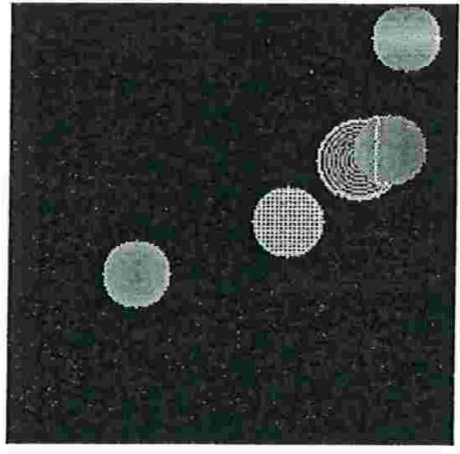

(d)

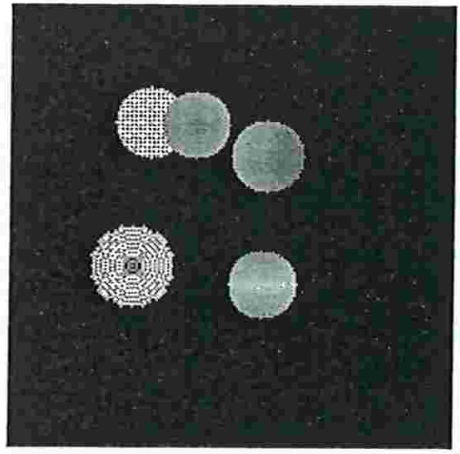

(b)

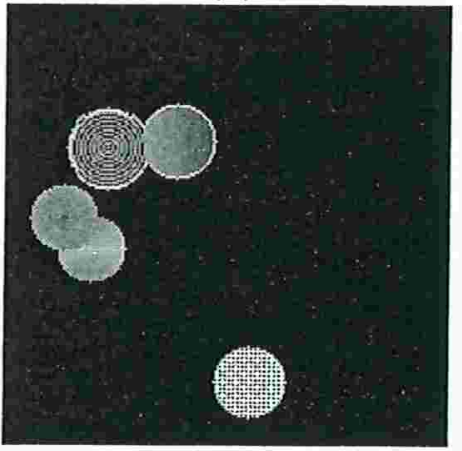

(e)

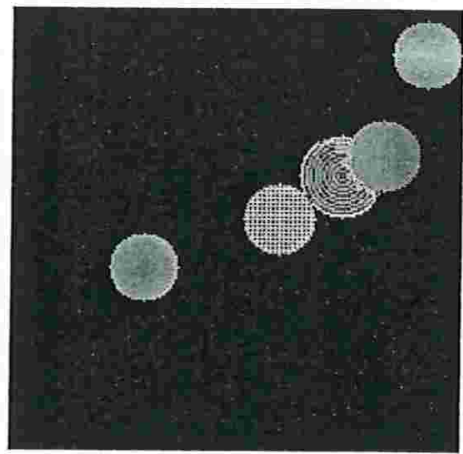

(c)

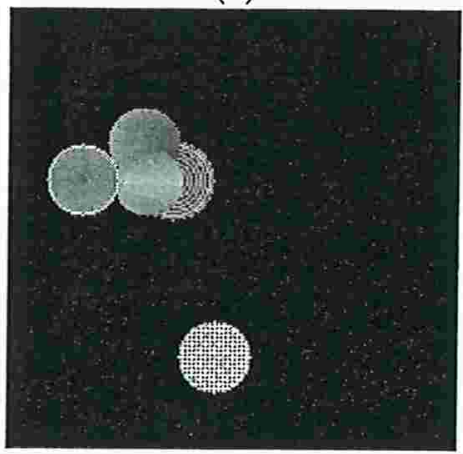

(f)

Figura 6.9: Resultados de Segmentação. (a) Segmentação Correta (b) Erro do Algoritmo de Watershed (c) Redução do Erro do Algoritmo de Watershed (d) Invasão da Linha de Partição de Águas (e) Segmentação de Duas Partículas (f) Perda da Partícula 


\begin{tabular}{|c|c|c|c|}
\hline & Critério 1 (\% Erro) & Critério 2 (\% Erro) & Critério 3 (\% Erro) \\
\hline$c n_{5 \times 5}$ & 14,0 & 50,0 & 38,0 \\
\hline$c n_{7 \times 7}$ & 16,8 & 60,0 & 50,0 \\
\hline$c n_{9 \times 9}$ & 13,6 & 60,0 & 50,0 \\
\hline$c n_{11 \times 11}$ & 7,2 & 36,0 & 50,0 \\
\hline$c n_{13 \times 13}$ & 9,6 & 48,0 & 50,0 \\
\hline & & & 44,0 \\
\hline$c d_{5 \times 5}$ & 4,4 & 22,0 & 40,0 \\
\hline$c d_{7 \times 7}$ & 5,2 & 26,0 & 44,0 \\
\hline$c d_{9 \times 9}$ & 0,4 & 2,0 & 44,0 \\
\hline$c d_{11 \times 11}$ & 0,8 & 4,0 & 44,0 \\
\hline$c d_{13 \times 13}$ & 0,8 & 4,0 & 26,0 \\
\hline & & & 40,0 \\
\hline$c n L e v_{5 \times 5}$ & 14,0 & 50,0 & 40,0 \\
\hline$c n L e v_{7 \times 7}$ & 17,2 & 60,0 & 26,0 \\
\hline$c n L e v_{9 \times 9}$ & 13,6 & 60,0 & 28,0 \\
\hline$c n L e v_{11 \times 11}$ & 4,4 & 20,0 & 32,0 \\
\hline$c n L e v_{13 \times 13}$ & 7,2 & 34,0 & 32,0 \\
\hline & & & 32,0 \\
\hline$c d L e v_{5 \times 5}$ & 4,8 & 24,0 & 32,0 \\
\hline$c d L e v_{7 \times 7}$ & 5,2 & 26,0 & 32,0 \\
\hline$c d L e v_{9 \times 9}$ & 0,4 & 2,0 & 0,0 \\
\hline$c d L e v_{11 \times 11}$ & 0,8 & 4,0 & \\
\hline$c d L e v_{13 \times 13}$ & 0,8 & 4,0 & \\
\hline & & 0,0 & \\
\hline$a p e r t u r e$ & 0,0 & & \\
\hline & & & \\
\hline
\end{tabular}

Tabela 6.4: Porcentagem de Erro

Um erro semelhante ao descrito no parágrafo anterior ocorre quando o multiclassificador não impõe marcadores às partículas adjacentes à partícula 1 . O algoritmo de watershed entende que a partícula 1 e a partícula adjacente são a mesma partícula e segmenta as duas (Figura 6.9 (e)).

Em algumas situações ocorrem erros de segmentação porque a partícula 1 é perdida, sendo perseguida outra partícula. Como apresentado na Tabela 6.3 , em todos os experimentos onde houveram perda da partícula 1 , a perda ocorreu no $42^{\circ}$ quadro (Figura 6.9 (f)). Isto ocorreu porque o multiclassificador para a partícula 1 impôs o marcador em outra partícula, perseguindoa desde então.

Outro fato observado foi o comportamento de cada multiclassificador no quadro 41 da sequiência. Neste quadro, a partícula 1 foi fragmentada pela sobreposição de duas outras partículas. Sob esta circunstância, o multiclassificador aperture ainda conseguiu impor um marcador para cada uma dos fragmentos da partícula 1, possibilitando ainda segmentá-la (Figura $6.10(a))$. 


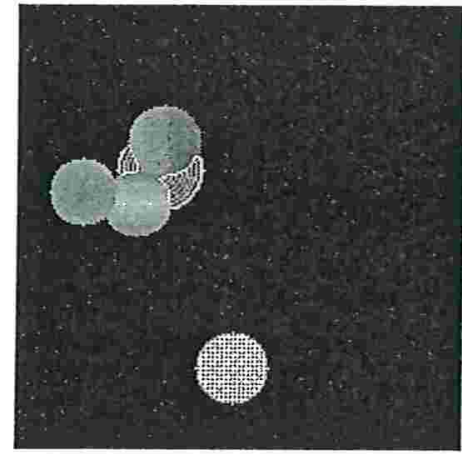

(a)

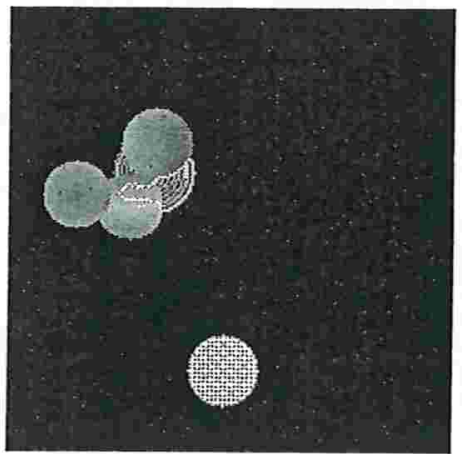

(b)

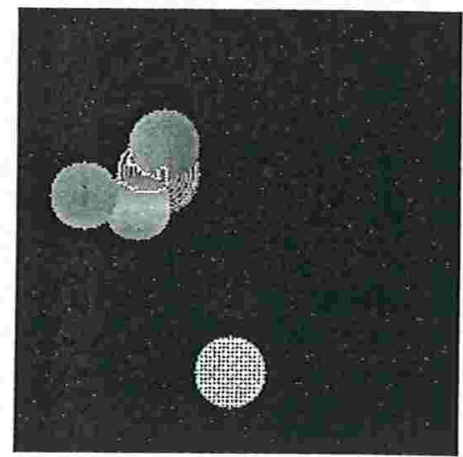

(c)

Figura 6.10: Segmentação da Partícula Fragmentada. (a) Segmentação Total. (b-c) Segmentação Parcial.

Com relação aos demais experimentos, nenhum dos demais multiclassificadores impôs marcadores para os dois fragmentos da partícula. Foi observado que os multiclassificadores por correlação e por módulo da diferença impuseram marcadores ou no fragmento da direita ou no fragmento da esquerda, segmentando somente o que foi marcado (Figura 6.10 (b-c)). E mais, nos experimentos em que a partícula foi perdida (veja Tabela 6.1), esta perda se sucedeu após a tentativa de segmentar a partícula no quadro 41.

\section{Conclusões}

Foi observado através dos 21 experimentos realizados que o multiclassificador aperture mostrouse mais adequado do que demais multiclassificadores apresentados para encontrar marcadores para segmentação. A multiclassificação por operadores aperture foi correta em todas as partículas. Além disto, o multiclassificador aperture impôs marcadores bem definidos e bem posicionados. Ao receber tais marcadores, o algoritmo de watershed segmentou corretamente e adequadamente todas as partículas.

Os operadores aperture aplicados à multiclassificação se mostraram mais eficazes que os demais multiclassificadores porque é uma classe mais genérica de operadores do que os multiclassificadores apresentados nesta Seção. Outras comparações de performance dos operadores aperture foram apresentadas em [9]. 
72 CAPÍTULO 6. SEGMENTAÇÃO MORFOLÓGICA DE SEQÜÊNCIAS DE IMAGENS 


\section{Capítulo 7}

\section{Aplicações}

$\hat{O}$ cride, fala pra mãe

Que tudo que a antena captar

Meu coração captura

Titãs "Televisão"

Apresentamos aqui resultados experimentais da aplicação da metodologia proposta para segmentação de seqüências de imagens $[2,3]$. O primeiro experimento descrito foi realizado com uma seqüência de imagens real em níveis de cinza [2]. A Seção 7.2 apresenta a extensão da metodologia proposta para segmentação de seqüências de imagens coloridas, e emm seguida são descritos dois outros experimentos, onde esta extensão foi aplicada em duas outras sqüência de imagens reais [3].

Todos os resultados apresentados neste capítulo, inclusive os resultados da aplicação da metodologia na seqüência "Simulação do Sistema de Partículas" podem ser conferidos no $c d$ rom que acompanha este texto e no web site http://www.vision.ime.usp.br/demos.

\subsection{Seqüência Real : Jogador de Tênis de Mesa}

A seqüência do jogador de tênis de mesa é composta de 120 frames com dimensões $480 \times 421$. Ela apresenta um tenista rebatendo uma bolinha de tênis duas vezes. A câmera se afasta lentamente da mesa e do tenista; as duas rebatidas ocorrem com o tenista em distâncias diferentes da câmera. Foram feitos dois experimentos. Um deles objetiva segmentar a bola de tênis de mesa, o outro, segmentar a raquete. 


\subsubsection{Segmentação da Bola}

$\mathrm{O}$ problema de segmentar a bola é resolvido adequando-se a metodologia proposta às suas características. A bola está no quadro inicial e permanece na seqüência até o $16^{\circ}$ quadro. A bola, então, deixa a cena, retornando somente no $97^{\circ}$ quadro, onde permanece até o penúltimo quadro.

O treinamento do operador aperture foi realizado utilizando-se oito pares de imagens. Das imagens de observação retiradas da seqüência, quatro são amostras do início da seqüência, enquanto as demais são amostras do instante em que a bola volta à cena. A imagem ideal associada com cada imagem de observação representa o marcador para a raquete.

A bola já está segmentada para o primeiro quadro e para o $97^{\circ}$, que é quando a bola retorna à seqüência. Aplica-se o operador aperture no quadro $i+1$ na área restrita pela bola segmentada no quadro $i$. O resultado da aplicação é um marcador pulverizado para a bola.

A filtragem consiste na aplicação de operadores de erosão, areaopen e areamerge. Finalmente, aplica-se o Paradigma de Beucher-Meyer utilizando-se o resultado do operador aperture filtrado. A Figura 7.1 mostra a bola em composição com a linha de partição de águas, cuja cor é branca.

\subsubsection{Segmentação da Raquete}

O problema de segmentar a raquete apresenta algumas características diferentes, com relação ao problema de segmentar a bola. O resultado do operador aperture é mais definido, pois a raquete é bem maior que a bola. No entanto, no final da seqüência, a raquete fica "borrada" (Figura 7.2) quando o tenista rebate a bola pela segunda vez. Neste caso, a raquete é mais difícil de segmentar, já que suas bordas não estão definidas. Como no caso da bola, a raquete deixa a seqüência quando o tenista prepara-se para rebater novamente a bola, retornando em seguida.

A raquete foi segmentada por abordagem similar à utilizada para segmentar a bola, com algumas alterações. A mais significativa foi a introdução da técnica para encontrar levelings na abordagem utilizada. Os levelings simplificaram as imagens onde a raquete estava borrada, pois, além de reduzirem o número de padrões utilizados para a estimação do aperture, elas definem uma "borda" para a raquete (Figura 7.2).

Para segmentar a raquete, foram treinados dois operadores aperture para encontrar o marcador para a raquete. O primeiro deles foi treinado com seis pares de imagens, onde quatro das imagens de observação são do início da seqüência e as outras duas ilustram o instante em que a raquete se choca com a bola pela primeira vez. O segundo aperture foi treinado com três pares, onde as três imagens de observação são os levelings das imagens da raquete quando esta volta ao filme. Cada uma destas nove imagens de observação formam o par com uma imagem ideal que contém um marcador para a raquete.

O aperture é aplicado sobre o leveling de cada quadro, porém, em uma área restrita, como nos experimentos descritos anteriormente. A filtragem é feita através de uma composição de uma erosão com um operador areaopen. Finalmente aplica-se o Paradigma de Beucher com o marcador filtrado e com a leveling do quadro. O resultado pode ser conferido na Figura 7.3, onde a linha de partição de águas (mais uma vez em branco) foi composta com a imagem original. 


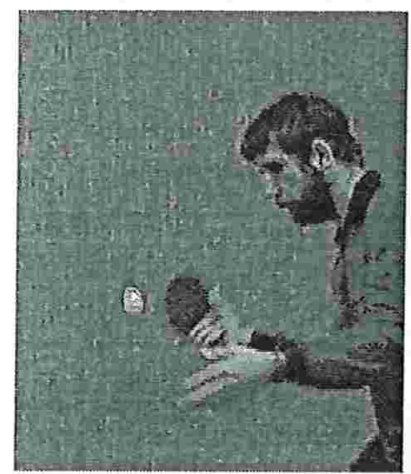

8

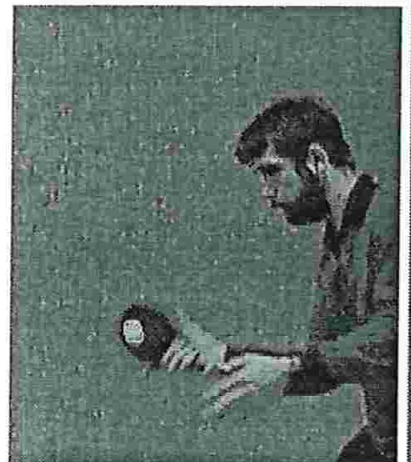

11

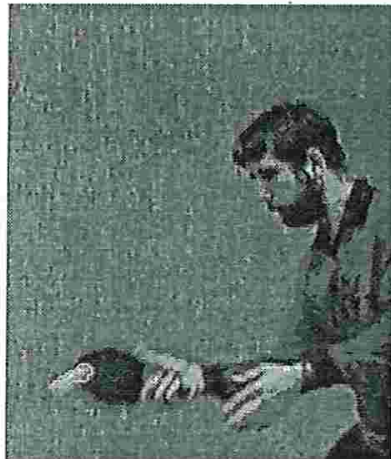

14

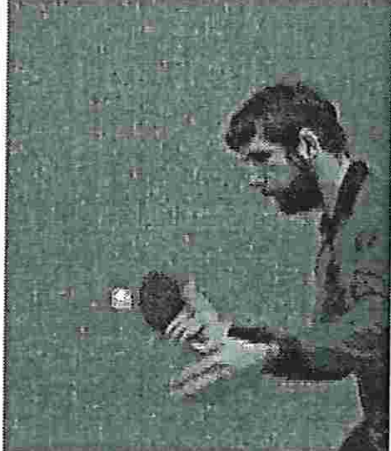

9

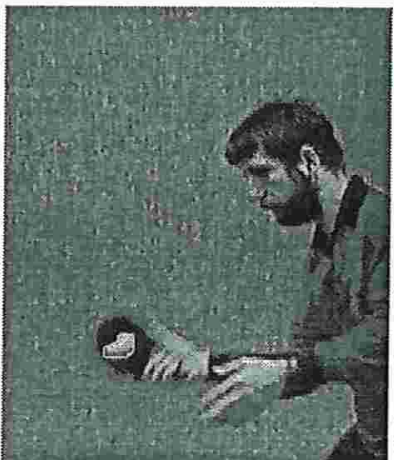

12

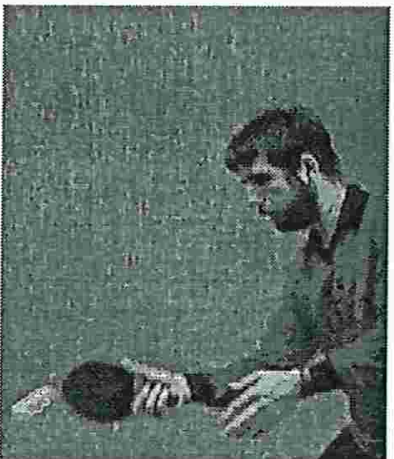

15

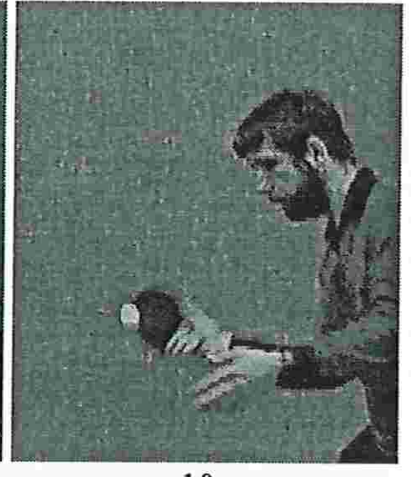

10

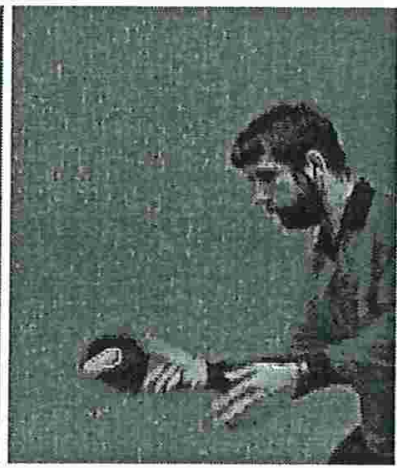

13

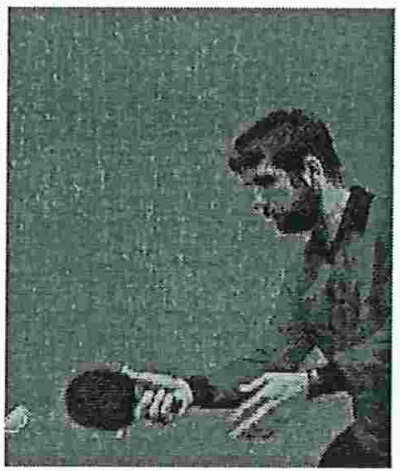

16

Figura 7.1: Bola Segmentada na Seqüência Jogador de Tênis de Mesa. quadros 8-16 da seqüência. 


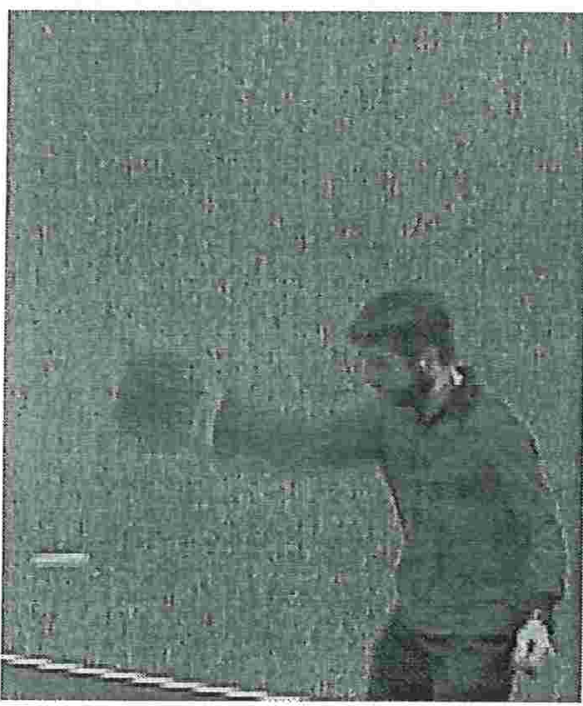

(a)

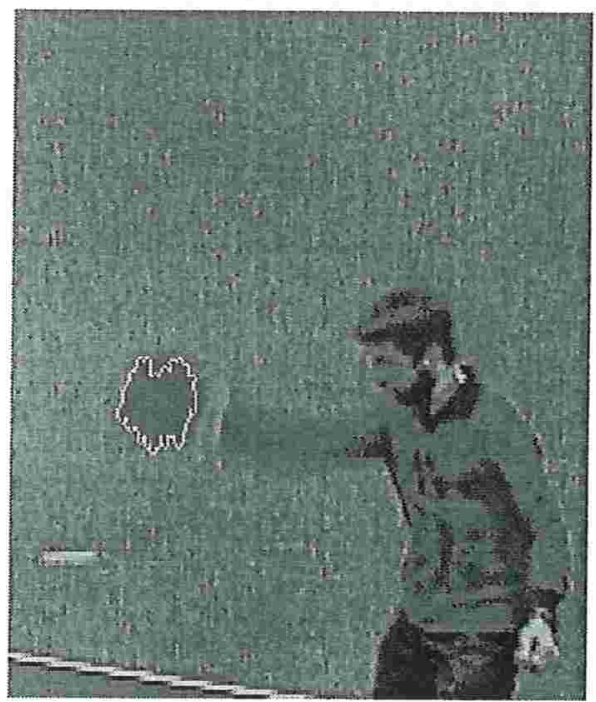

(b)

Figura 7.2: (a) Raquete com Borda Não Definida. (b) Segmentação da Raquete.

\subsection{Segmentação de Seqüências de Imagens Coloridas}

Apresentamos nesta Seção a extensão da metodologia para a segmentação de objetos em seqüências de imagens coloridas [3]. Esta extensão apresenta algumas características que a diferem da metodologia aplicada em seqüências em níveis de cinza:

- Foram utilizados vários modelos de representação de cores [20, 19]. Em cada um deles, uma cor é representada unicamente por um ponto num espaço tridimensional finito e discreto: o sistema RGB (Red, Green, Blue), onde cada dimensão é definida por um vetor relacionado a uma cor - vermelho, verde ou azul; o sistema IHS (Intensity, Hue, Saturation), onde as dimensões representam a cor pura e suas variações de luminosidade e adição de luz branca; e o sistema YIQ (padrão N.T.S.C. para televisão colorida), semelhante ao sistema IHS. Chamamos de banda um vetor que define o espaço de cores.

- Existe mais informação em uma imagem colorida do que em uma imagem em níveis de cinza com as mesma dimensões. Enquanto que nas imagens em níveis de cinza um pixel guarda somente a informação de intensidade, nas imagens coloridas a cor de um pixel é dada por uma terna de valores. Esta terna representa um ponto no espaço de cores; cada ponto desta terna é uma projeção em uma das bandas da imagem.

- Uma das entradas do Paradigma de Beucher-Meyer é o gradiente de uma imagem em níveis de cinza. Fez-se necessário o estudo de vários métodos para o cálculo do gradiente de imagens coloridas [21] (veja a Seção 2.4). 


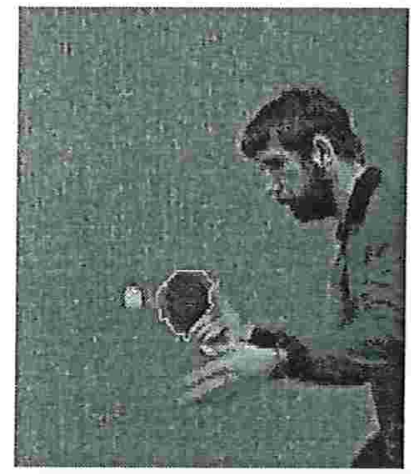

8

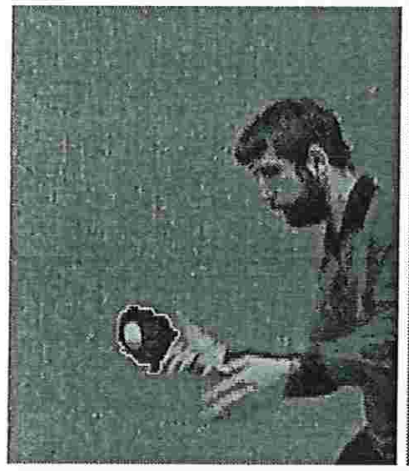

11

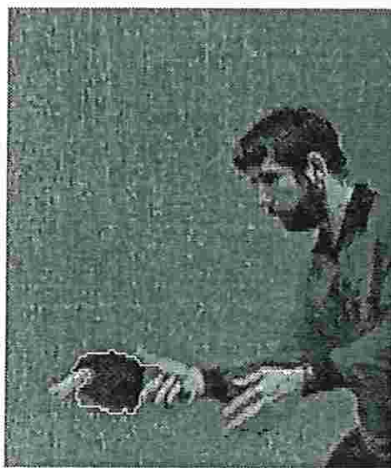

14

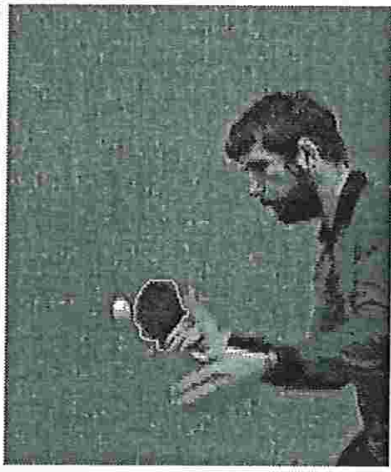

9

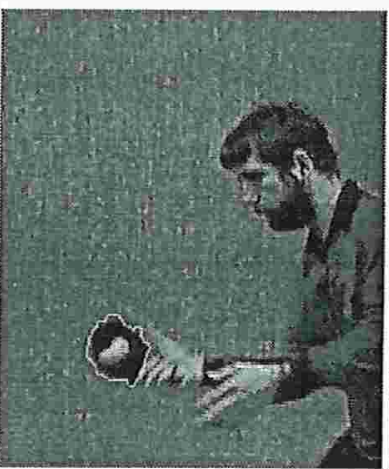

12

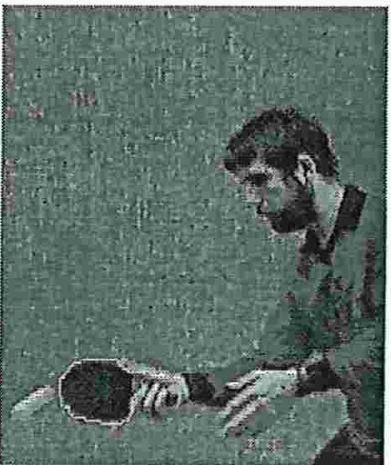

15

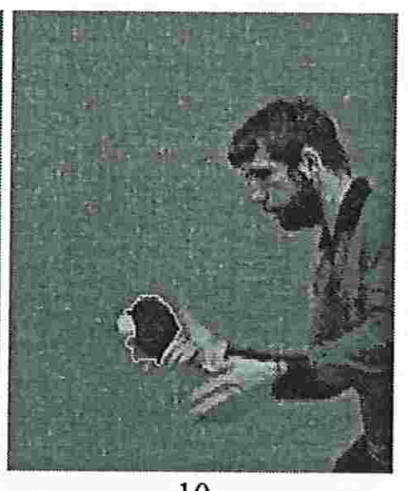

10

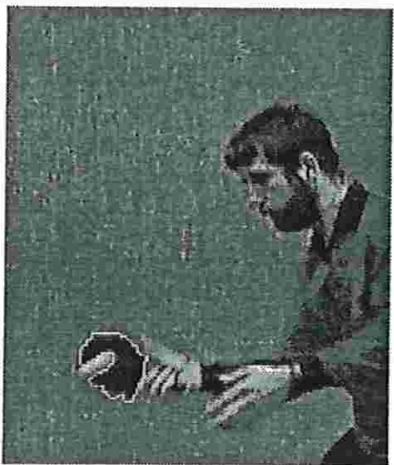

13

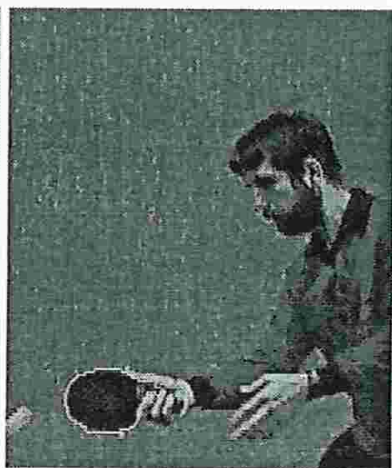

16

Figura 7.3: Raquete Segmentada na Seqüência Jogador de Tênis de Mesa. quadros 8-16 da seqüência. 


\subsubsection{Metodologia Aplicada em Seqüências de Imagens Coloridas}

A metodologia aplicada na segmentação de seqüências de imagens coloridas é basicamente a mesma para imagens em níveis de cinza.

- Na etapa de treinamento do multiclassificador, são fornecidos $n$ pares de imagens $\left(X_{i}, Y_{i}\right)$, $i=1, \ldots, n$, onde $X_{i}$ é uma imagem colorida (quadro) de observação retirada da seqüência, e $Y_{i}$ é uma imagem ideal, contendo os marcadores para os objetos a serem segmentados em $X_{i}$ (Figura 5.4). Como no caso das seqüências em níveis de cinza, não é necessário que $X_{i}$ e $X_{i+1}$ sejam consecutivos na seqüência, porém cada uma das imagens deve representar todas as situações em que os objetos de interesse se encontram.

Como na metodologia aplicada em níveis de cinza, os exemplos de treinamento $(\mathbf{x}, y)$ são coletados somente de uma região da imagem restrita aos objetos de interesse e às suas vizinhanças. Esta região é dada por uma máscara de restrição $R$ que é construída em função da velocidade em que os objetos se movimentam na seqüência.

Um dos problemas levantados na Seção 5.2 foi o número de configurações da janela $W$ que comporão a tabela a ser preenchida na etapa de coleta de dados. Os dados contidos nesta tabela podem estar distribuídos esparsamente por ela. Faz-se necessária uma redução na quantidade de configurações observadas na imagem. Através da redução do número de zonas planas, pode-se diminuir o número de configurações observadas. Reduzindo-se a estatística da imagem, aumenta-se a confiabilidade nos dados observados.

Foram utilizados vários filtros para a redução da estatística da imagem. Estes filtros mostraram uma grande eficácia para este objetivo, visto que estes reduziram o número de zonas planas na imagem e, ao mesmo tempo, preservaram a estrutura da imagem.

Observe na Figura 7.4 que apesar de haver uma redução no número de zonas planas, as imagens filtradas ainda mantêm os objetos. A Figura 7.4 (a) não está filtrada. A Figura 7.4 (b) apresenta o resultado da filtragem por abertura e fechamento coloridos, utilizando-se um elementos estruturante cruz. A Figura 7.4 (c) apresenta o resultado da filtragem por area merging colorido, eliminando zonas planas com área inferior a 40 . Finalmente a Figura 7.4 (d) apresenta o resultado da composição dos filtros supracitados, utilizando os mesmos parâmetros. A Tabela 7.1 mostra o número de zonas planas e o número de cores restantes após a aplicação da filtragem para um determinado quadro.

\begin{tabular}{|c|c|c|}
\hline Filtragem & N $^{\mathbf{O}}$ Flat Zones & N $^{\mathrm{O}}$ Cores \\
\hline Sem Filtragem & 27356 & 2695 \\
\hline Abertura / Fechamento Colorido & 4594 & 1321 \\
\hline Area Merging Colorido & 516 & 250 \\
\hline Abertura / Fechamento Colorido e Area Merging Colorido & 472 & 204 \\
\hline
\end{tabular}

Tabela 7.1: Comparação da Performance dos Filtros na Redução de Zonas Planas e Cores.

- A etapa de tracking também é similar à respectiva etapa na metodologia aplicada em seqüências em níveis de cinza. Seja $f_{i}$ o $i$-ésimo quadro da seqüência. Seja $M_{i}$ a imagem que 


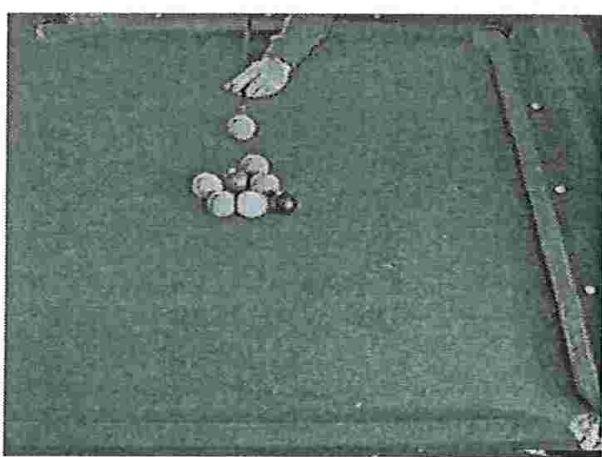

(a)

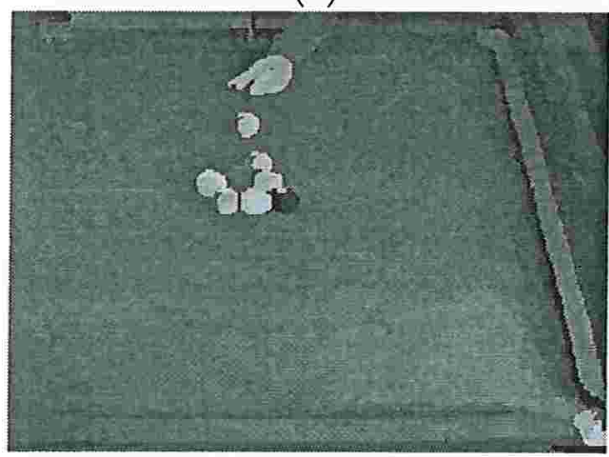

(c)

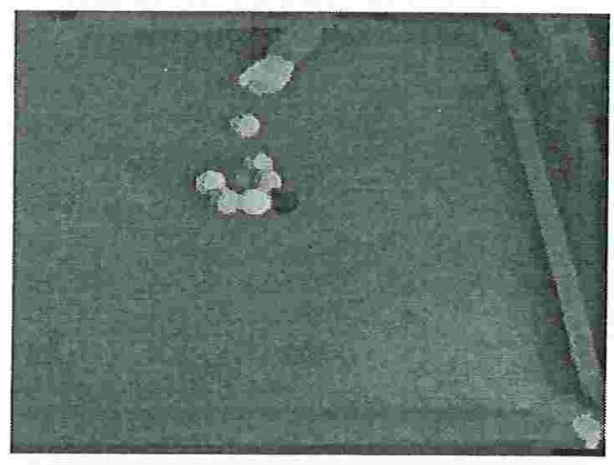

(b)

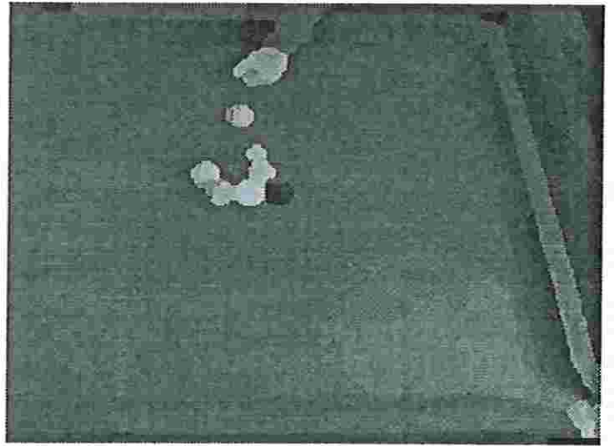

(d)

Figura 7.4: Comparação da Redução de Zonas Planas Após Filtragem. (a) Sem Filtragem. (b) Abertura e Fechamento Coloridos. (c) Area Merging Colorido. (d) Composição de Abertura e Fechamento Coloridos com Area Merging Colorido. 


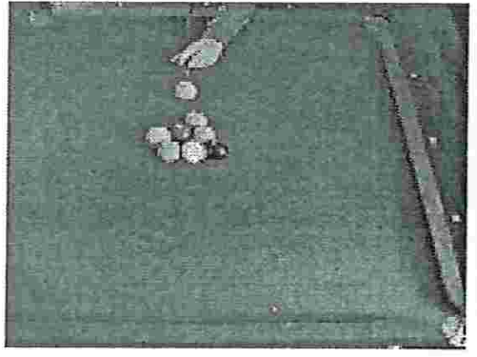

(a)

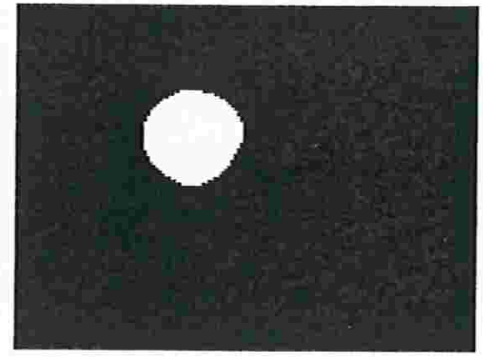

(b)

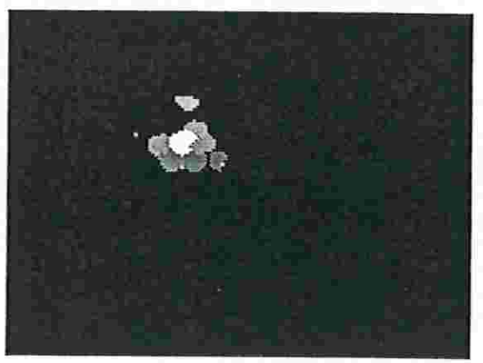

(c)

Figura 7.5: Aplicação do Operador Aperture. (a) quadro $f_{i}$. (b) Restrição $M_{i}$. (c) Resultado da aplicação do Operador.

contém a máscara de restrição $R$ de aplicação do W-operador, dada pelo objeto segmentado no quadro $f_{i-1}$ (Figura 7.5 (b)). Com exceção do frame $f_{1}$, onde o objeto de interesse é segmentado manualmente, o W-operador é aplicado em $f_{i}$ restrito a $R$. O resultado é um conjunto de rótulos, um para cada objeto contido em $f_{i}$ (Figura 7.5 (c)).

Após a obtenção dos marcadores, seleciona-se, através de uma limiarização e filtragem, os marcadores associados aos objetos a serem segmentados (Figura 7.6 (b)). Em seguida, calcula-se o gradiente da imagem colorida (Figura 7.6 (a)) e, de posse deste gradiente e dos marcadores desejados aplica-se o Paradigma de Beucher-Meyer para segmentar os objetos desejados. A Figura 7.6 (c) mostra a Linha de Partição De Águas para o objeto que está sendo perseguido na seqüência e a Figura 7.6 (d) mostra a linha de partição de águas dilatada e composta com a imagem original.

\subsubsection{Estudo Comparativo Entre os Gradientes Coloridos Propostos}

Foram realizados vários experimentos de comparação entre os gradientes apresentados na Seção 2.4. Foram avaliados visualmente dois critérios de qualidade: (a) o quanto as linhas de partição de águas se estendem além das bordas dos objetos e (b) o quanto o objeto é segmentado, por inteiro ou parcialmente.

O primeiro experimento consiste na segmentação de uma bola vermelha posicionada entre várias outras bolas. Para segmentar este objeto, foram impostos os marcadores internos e externos apresentados na primeira coluna da esquerda para a direita na Figura 7.7. As demais colunas apresentam os resultados dos gradientes (invertidos para melhor visualização) e seus respectivos resultados de segmentação, após a aplicação do Paradigma de Beucher-Meyer. Os gradientes comparados são introduzidos na Seção 2.4 .

O Gradiente $I$ provê um bom realce de bordas, porém em alguns casos, algumas bordas importantes não são realçadas, como aconteceu no exemplo da Figura 7.7. Este mesmo problema ocorreu com o Gradiente $I V$. O Gradiente $I I$ dá um resultado melhor que o Gradiente $I$, porém, as linhas de partição de águas se estenderam para fora do objeto. Os Gradientes $I I I$ e $V I$ apresentaram bons resultados, mas algumas sombras pequenas ainda aparecem.

O Gradiente $V$ apresentou o mesmo problema que o Gradiente $I$. Ao aplicar o Gradiente 


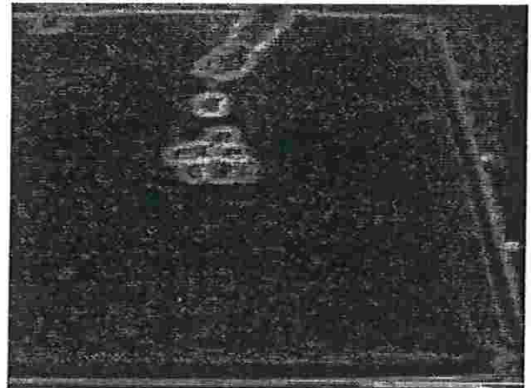

(a)

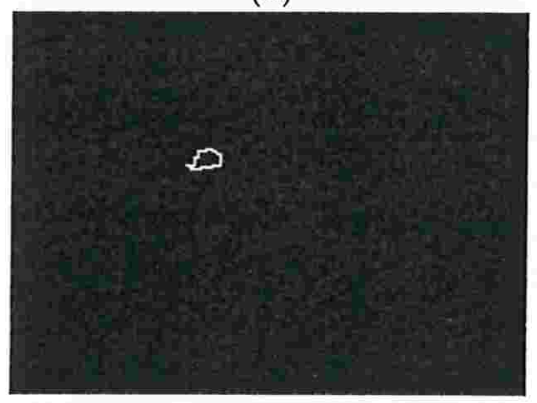

(c)

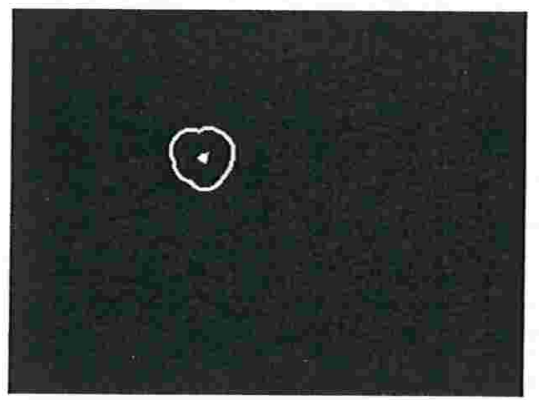

(b)

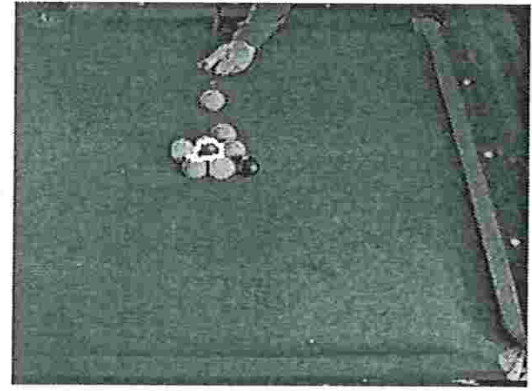

(d)

Figura 7.6: Aplicação do Paradigma de Beucher-Meyer. (a) Gradiente do quadro Colorido. (b) Marcadores. (c) Objeto Segmentado (Watershed). (d) Composição do Watershed com o quadro.

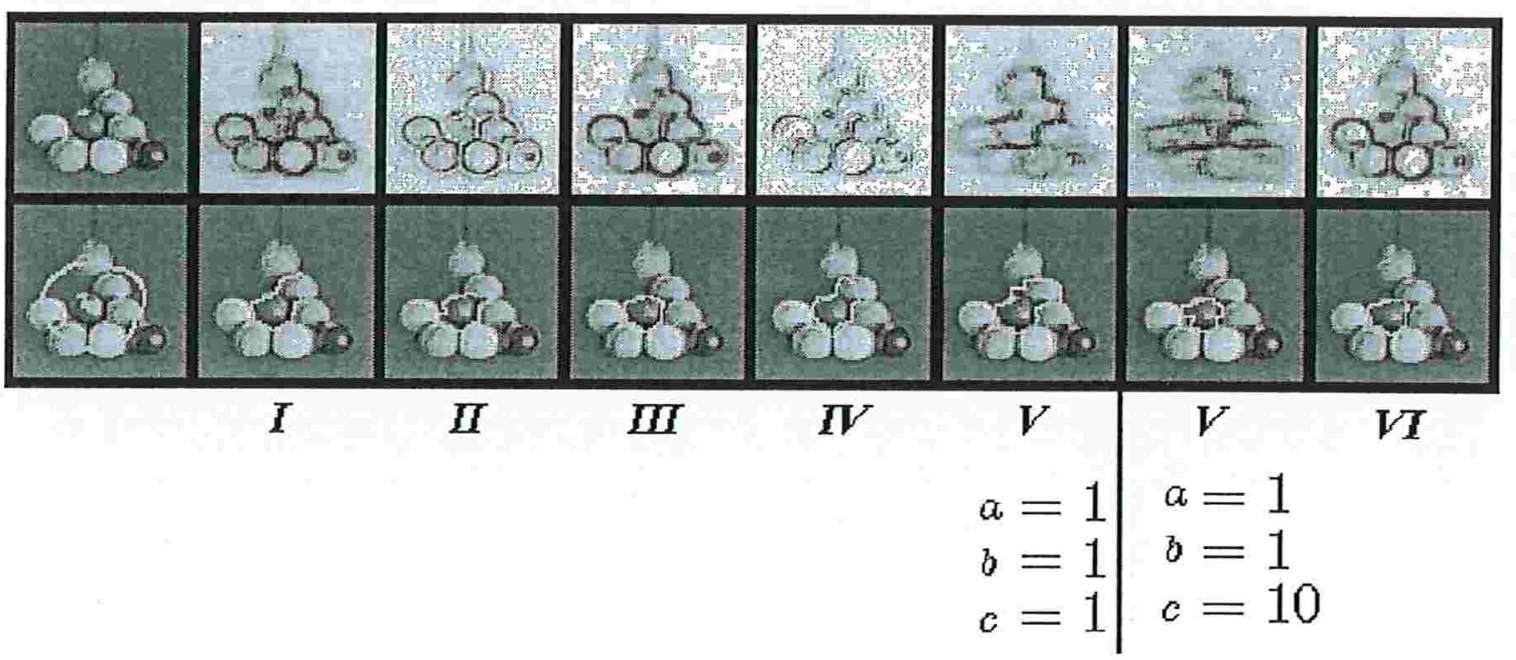

Figura 7.7: Resultados do Primeiro Experimento de Comparação entre os Gradientes Coloridos. 


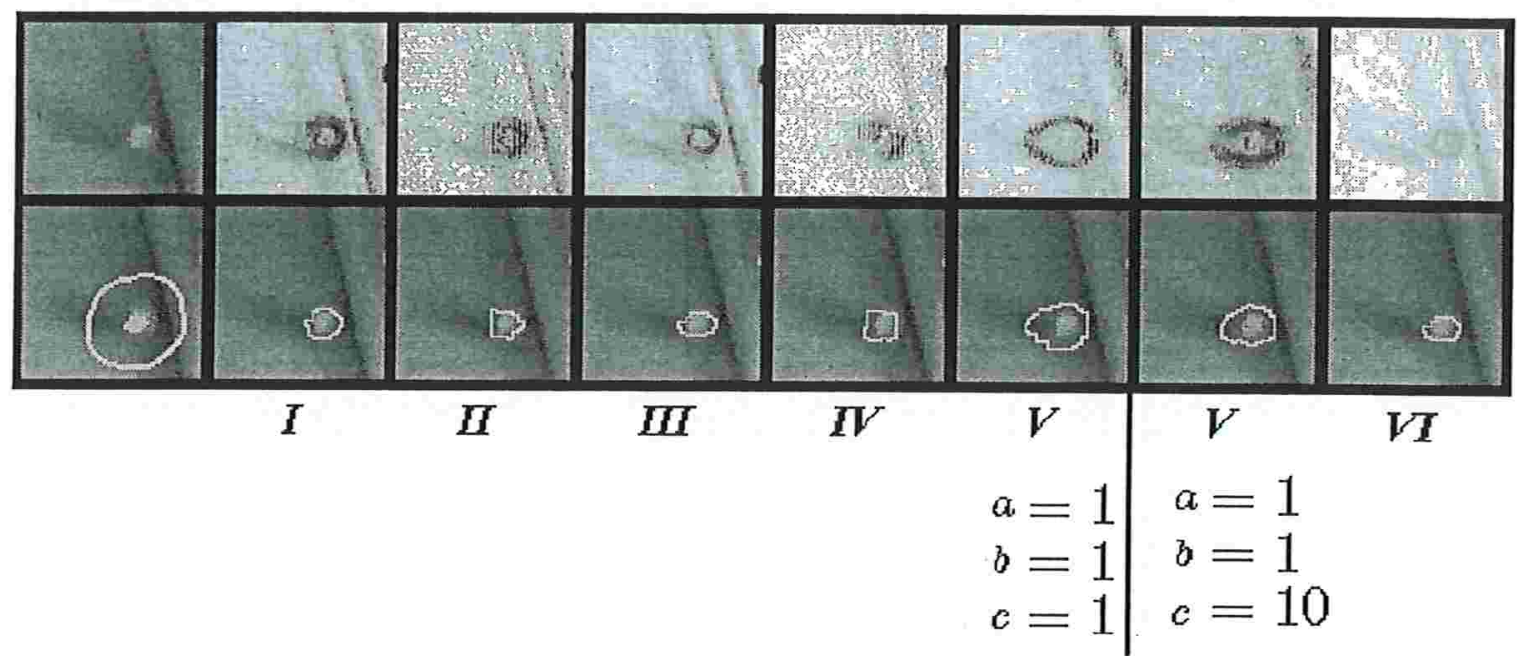

Figura 7.8: Resultados do Segundo Experimento de Comparação entre os Gradientes Coloridos.

$V$ atribuindo-se os pesos $a=b=c=1$ para os gradientes, a informação de cada um deles não foi suficiente para realçar a bordas entre a bola vermelha e a laranja, e estas duas bolas são segmentadas como se fossem um único objeto. Isto ocorre porque apesar da informação de cor ser a mais importante no processo de segmentar a bola vermelha, esta informação não é suficiente, visto que as bolas vermelha e laranja tem informações de cores similares. Ao ajustarse os pesos atribuindo um peso maior à informação de saturação $(a=b=1$ e $c=10)$, as bordas realçadas definem melhor os objetos e a segmentação é corrigida.

O experimento acima foi repetido com uma outra imagem, desta vez, contendo somente a bola vermelha (Figura 7.8). No entanto, além da imagem estar borrada, existem duas regiões sombreadas. A primeira coluna da esquerda para a direita apresenta a imagem utilizada, bem como os marcadores impostos para a segmentação.

Mesmo estando a bola localizada em uma região borrada, todos os Gradientes deram bons resultados, provendo uma boa segmentação. Os melhores resultados de segmentação, porém, foram atingidos utilizando-se os dois Gradientes $V$ testados, que realçaram melhor as bordas dos objetos. O primeiro deles utilizou pesos $(a=b=c=1)$ e o segundo, $(a=b=1$ e $c=10)$.

Os testes foram realizados com mais trinta e três imagens similares e o Gradiente $V$ apresentou muito menos erros de segmentação com relação aos demais gradientes coloridos. No entanto, uma dificuldade com relação ao Gradiente $V$ é o ajuste de pesos ideal para um determinado problema. Este ajuste ainda não é feito de maneira sistemática.

\subsection{Seqüência Real : Bolas de Bilhar}

O objetivo deste experimento foi segmentar uma bola de bilhar vermelha através de uma seqüência de 80 quadros com dimensões $320 \times 240$, onde os pixels são representados no modelo de cores RGB. Além da bola vermelha, há mais sete bolas, de cores distintas, movendo-se sobre 
a mesa de bilhar. Alguns dos problemas encontrados na resolução deste problema foram: a variação de luminosidade na seqüência, a falta de foco da câmera no fim da seqüência, e a já citada grande quantidade de informação em imagens coloridas, que pode interferir na qualidade do operador a ser projetado estatisticamente.

Foram utilizadas duas seqüências neste experimento, a original e uma filtrada. A seqüência filtrada foi utilizada para o treinamento e para a aplicação do operador, já que esta é estatisticamente mais simples que a original. O filtro utilizado para gerar tal seqüência foi uma composição de area opening e area closing aplicada em cada uma das bandas da imagem.

O multiclassificador foi treinado para associar um rótulo distinto a cada uma das bolas de bilhar. Na etapa de treinamento, foram utilizados dez pares de imagens para treinar o multiclassificador. As imagens de observação foram tomadas da seqüência filtrada de modo a cobrir todas as situações as quais a bola vermelha se encontra. As imagens ideais continham um rótulo distinto para cada uma das bolas. O multiclassificador treinado foi utilizado na segmentação da bola vermelha mas poderia ser utilizado para segmentar também qualquer uma das demais bolas, bastando um pequeno ajuste na etapa de treinamento para um novo multiclassificador. O multiclassificador é um W-operador e a cardinalidade da janela utilizada neste problema é 1 (ou seja, foi utilizada uma janela de um ponto).

A etapa de tracking é realizada como descrito na Seção anterior. A segmentação da primeira bola é dada manualmente e o Paradigma de Beucher-Meyer é aplicado nos demais quadros. Após a aplicação do multiclassificador, é feita uma limiarização seguida de uma filtragem conexa para separar o marcador para a bola vermelha dos demais marcadores e para ajustar o marcador desejado ao objeto. O marcador externo foi imposto calculando-se o gradiente morfológico do marcador para a bola vermelha dilatado por um disco com um diâmetro grande, objetivando manter o marcador externo próximo das bordas da bola vermelha. O gradiente utilizado foi a soma dos gradientes ponderados, utilizando-se principalmente a informação de cor com um pequeno ajuste da informação de saturação.

A Figura 7.9 apresenta a segmentação da bola vermelha. A linha de partição de águas foi dilatada e composta com a imagem original.

\subsection{Seqüência Real : Mãos em Movimento}

Esta seqüência de 60 quadros, com dimensões $640 \times 480$, representados no modelo de cores RGB, apresenta um par de mãos se movendo sobre uma superfície de cortiça. Este problema é mais difícil que o anterior porque, além de apresentar alguns dos problemas já combatidos no outro problema, esta experimento ainda lida com mais dois problemas: as duas mãos devem ser segmentadas e cada uma delas é composta por vários objetos, como a própria mão, as unhas e um anel na mão direita. A Figura 7.10 (a) mostra um dos quadros da seqüência.

Novamente foi produzida uma seqüência simplificada por filtragem para ser utilizada para treinamento e aplicação do classificador. Esta seqüência, filtrada por uma composição de area opening e area closing coloridos, também é utilizada para a aplicação do gradiente colorido. A Figura 7.10 (b) mostra um desses quadros filtrados. 

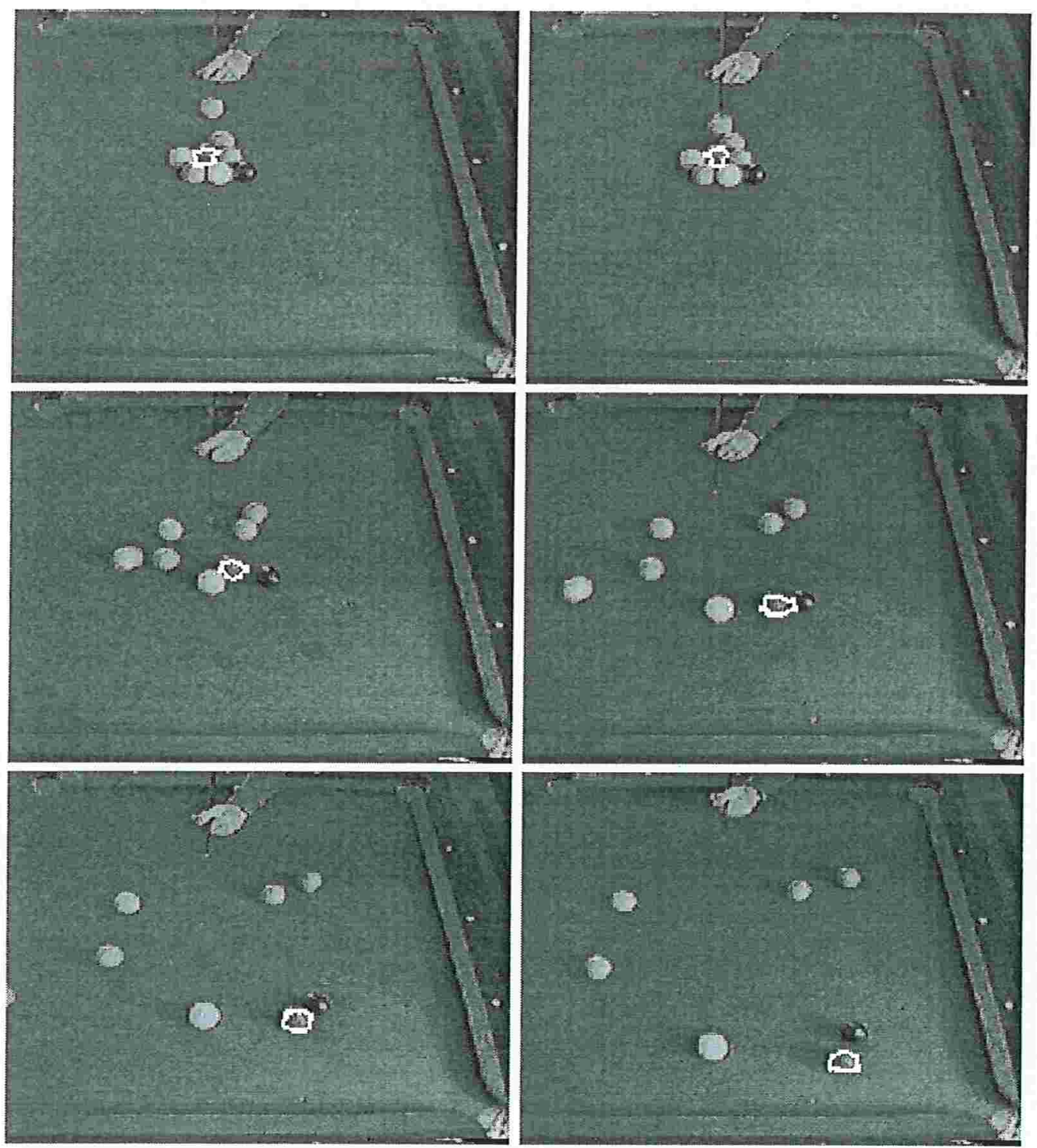

Figura 7.9: Seqüência Bolas de Bilhar Segmentada 


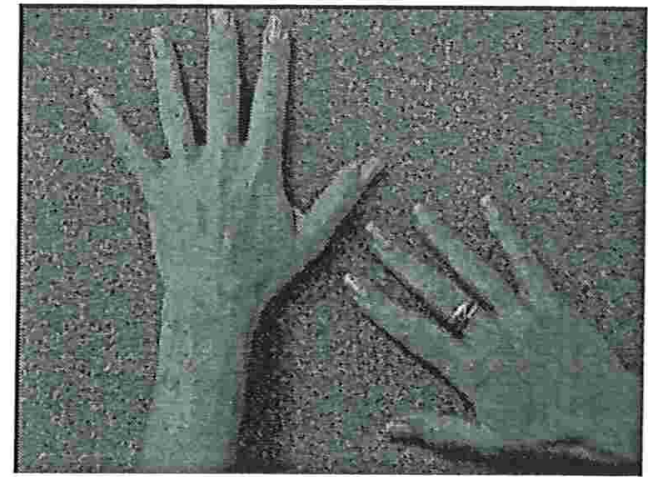

(a)

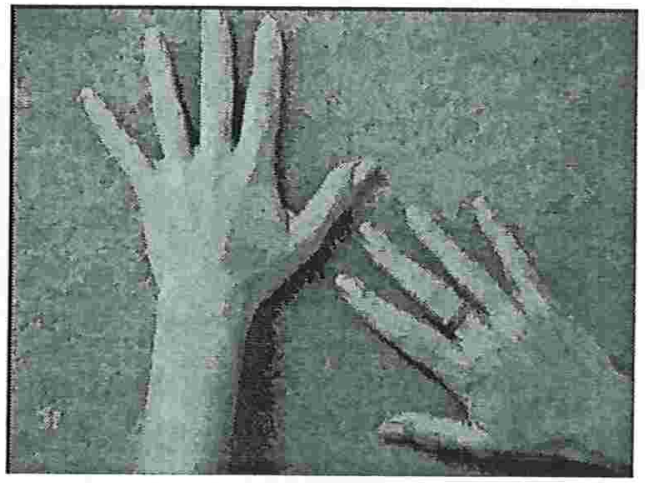

(b)

Figura 7.10: Mãos em Movimento. (a) Quadro da Seqüência. (b) Imagem Filtrada.

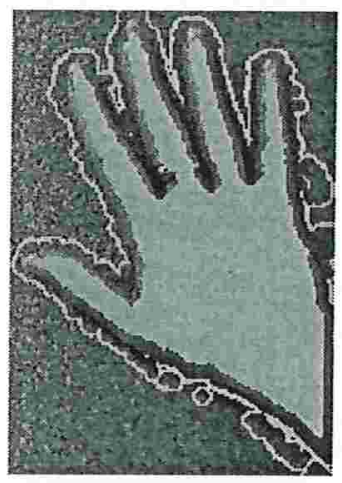

(a)

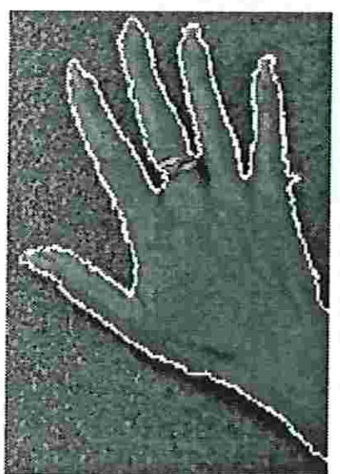

(b)

Figura 7.11: Segmentação da Mão. (a) Marcadores. (b) Linha de Partição de Águas.

Foram utilizados dez pares de imagens para treinar o operador aperture. O conjunto de imagens de observação foi tomado de vários instantes da seqüência simplificada e suas respectivas imagens ideais são imagens binárias que associam o valor 1 aos pixels das mãos e 0 aos demais pixels da imagem. Como no problema das bolas de bilhar, o classificador é um W-operador e, como naquele problema, foi utilizada uma janela de um ponto.

O primeiro par de mãos é segmentado manualmente na etapa de tracking. Nos demais quadros, o classificador é aplicado e seu resultado é filtrado por um filtro morfológico composto por filtros conexos (para filtrar pequenas zonas planas) e operadores de afinamento [14] (para ajustar os marcadores dentro das mãos). Os marcadores externos foram impostos dilatando-se o resultado do classificador e computando-se o seu gradiente. A Figura 7.11 (a) mostra o marcador resultante para uma das mãos em composição com a mesma.

O gradiente utilizado para a aplicação do Paradigma de Beucher-Meyer foi a soma dos gradientes ponderados. Por ser pouco relevante, a informação de cor foi ignorada, enquanto que as informações de intensidade e saturação foram realçadas. Após o cálculo do gradiente, e de 
posse dos marcadores, foi aplicado o operador watershed para segmentar as mãos. A Figura 7.11 (b) mostra o resultado da segmentação da mão direita utilizando-se os marcadores mostrados na Figura 7.11 (a). A Figura 7.12 mostra a composição do resultado de segmentação com a imagem original. As linhas de partição de águas foram dilatadas para uma melhor visualização. 

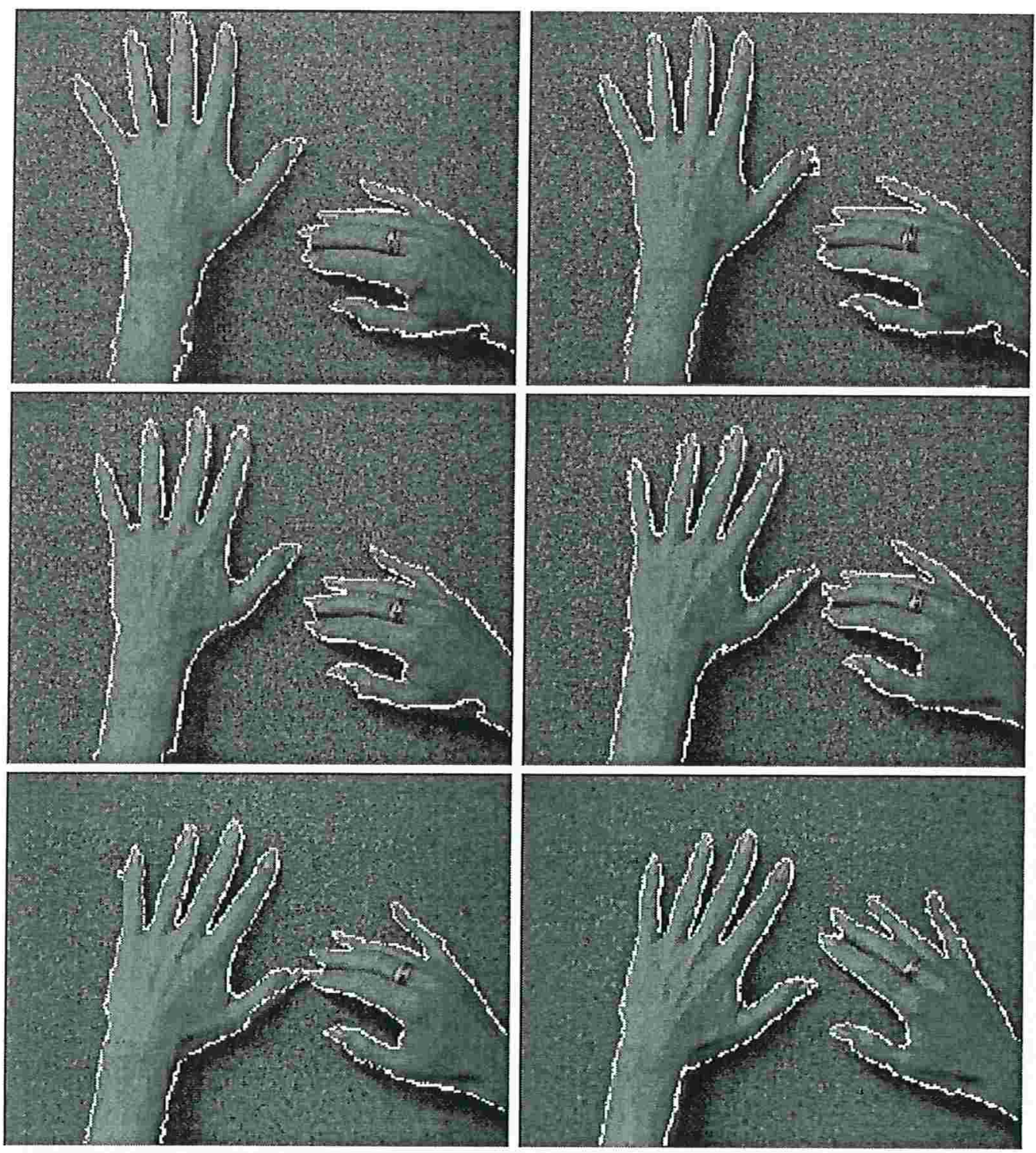

Figura 7.12: Seqüência Mãos em Movimento Segmentada. 


\title{
Capítulo 8
}

\section{Conclusão}

Se sou eu ainda jovem

Passando por cima de tudo

Se hoje canto esta canção

$O$ que cantarei depois?

Ira! "Dias de Luta"

\begin{abstract}
Atualmente, a segmentação de objetos em seqüências de imagens é feita manualmente em edições de vídeo. Esta técnica pode não ser aplicável em algumas situações quando a seqüência é composta por centenas ou milhares de quadros. Algumas técnicas de edição de vídeo, como o Chroma Key, utilizadas na resolução deste problema, requerem que a seqüência seja produzida com alguns cuidados a priori, como pintar os objetos a serem segmentados com uma cor neutra de modo a substituir automaticamente os objetos pintados através da aplicação de técnicas clássicas de reconhecimento de padrões. Este procedimento, além de eventualmente ter alguns "efeitos colaterais", restringe a aplicação da técnica às seqüências que tenham sido preparadas para tal.
\end{abstract}

O objetivo deste trabalho foi a apresentação de uma metodologia de segmentação de seqüências de imagens. Esta metodologia consiste na aplicação do Paradigma de Beucher-Meyer em cada quadro, utilizando marcadores impostos por aplicação de operadores aperture projetados através de aprendizado computacional no espaço destes operadores. Esta metodologia pode ser aplicada tanto em imagens em níveis de cinza como em imagens coloridas. Esta metodologia foi implementada através de operadores representados como operadores morfológicos.

A Morfologia Matemática é uma poderosa teoria algébrica muito aplicada em Processamento Digital de Imagens e Visão Computacional, que estuda a decomposição de operadores entre reticulados completos em termos de operadores e operações elementares. Operadores entre imagens podem ser decompostos em termos de erosões e dilatações e em termos das operações 


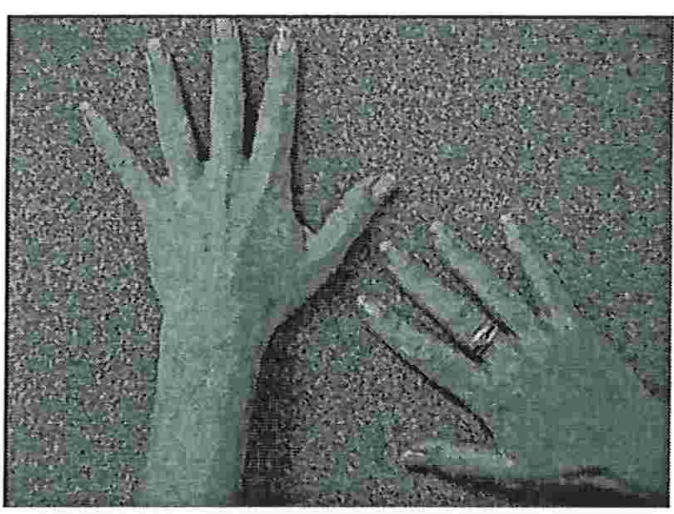

(a)

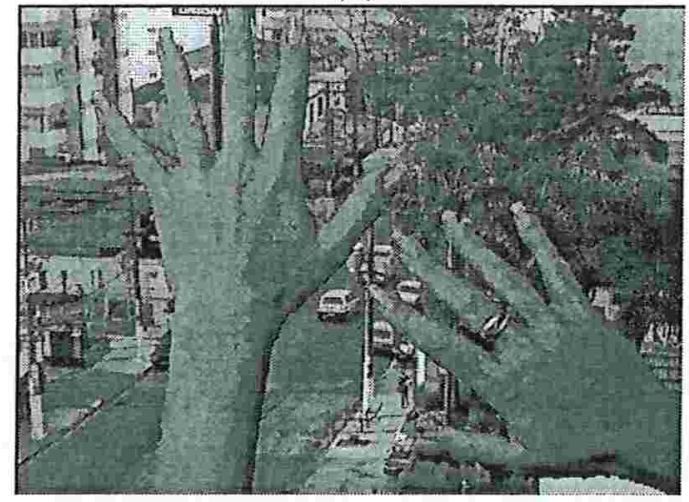

(c)

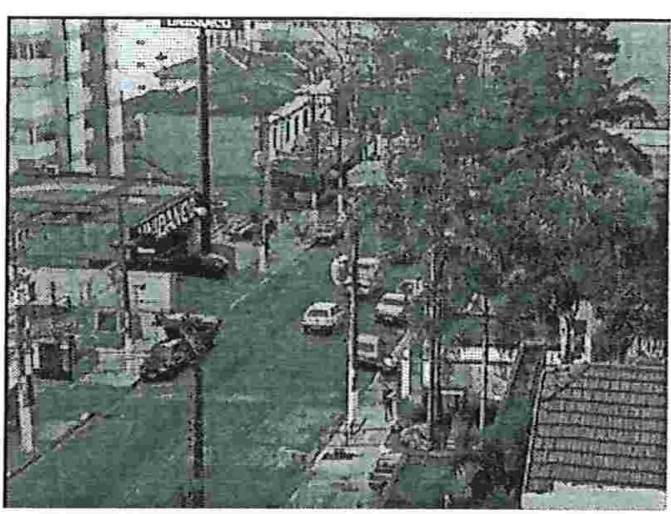

(b)

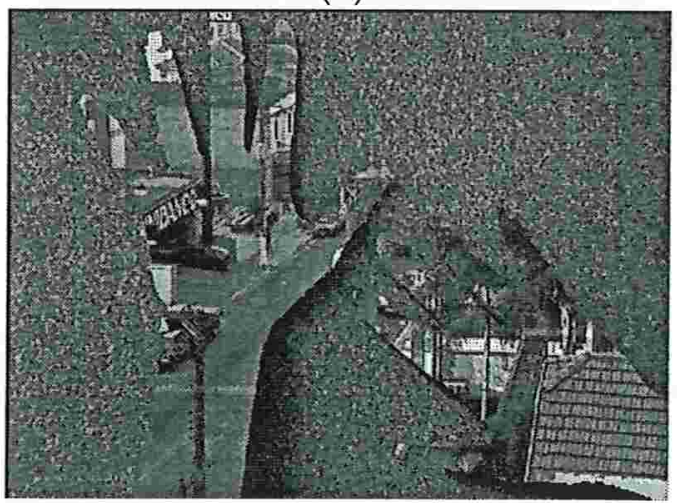

(d)

Figura 8.1: Combinação de Vídeo realizado após Segmentação das Mãos. (a-b) Imagens a serem mixadas (c-d) Combinação de Vídeo. 
de supremo, ínfimo, negação e composição.

Filtros Conexos foram utilizados na simplificação da imagem sob dois aspectos: redução da variedade da configurações observadas em uma janela no projeto do multiclassificador; redução do número de objetos na imagem, objetivando a eliminação de bordas indesejadas, ou até uma melhora na definição de bordas.

O operador watershed é uma poderosa técnica utilizada em detecção de bordas. Normalmente aplicado em gradientes de imagens, este operador detecta exatamente os contornos dos objetos. O Paradigma de Beucher-Meyer consiste na aplicação do operador watershed em um gradiente filtrado por um filtro homotópico, que preserva somente as bordas dos objetos apontados por um conjunto de marcadores.

O gradiente de imagens em níveis de cinza é calculado simplesmente pela aplicação de um operador gradiente, por exemplo, o gradiente morfológico. Esta tarefa porém, não é simples para imagens coloridas. Foram explorados diversos espaços de cores e diversas métricas para o cálculo de gradientes coloridos. A técnica que se mostrou mais eficiente dentre as testadas foi a soma ponderada dos gradientes.

Os marcadores para os objetos a serem segmentados são impostos via aplicação de operadores aperture projetados por aprendizado computacional no espaço destes operadores. Tais operadores têm por característica serem invariantes por translação e localmente definidos por uma restrição dada por uma janela, tanto espacialmente como no conjunto de níveis de cinza. Além disso, operadores aperture são caracterizados unicamente por uma função K-computacional. O projeto de um operador com as características apontadas consiste em, dado um conjunto de observações em uma imagem, estimar uma partição do espaço que represente o operador ótimo. $\mathrm{Na}$ metodologia proposta, os dados utilizados no projeto do detector de marcadores são coletados dos objetos a serem segmentados e da vizinhança dos mesmos, e esta vizinhança é uma área calculada em função da velocidade em que os objetos de interesse se movem na seqüência. Esta restrição visa reforçar a estatística das configurações observadas ao redor dos objetos de interesse.

A metodologia foi testada em seqüências de imagens em níveis de cinza e coloridas, e foram obtidos resultados excelentes, com poucos erros. Para fins de comparação com os operadores aperture projetados estatisticamente, foram projetados outros dois multiclassificadores, um deles baseado em correlação e o outro no módulo da diferença entre duas imagens. Os operadores aperture tiveram performance muito superior aos outros multiclassificadores testados.

A técnica de segmentação de seqüências de imagens apresentada neste trabalho mostra-se como uma promissora técnica a ser utilizada em edições de vídeo (Figura 8.1). Ao invés dos editores de vídeo segmentarem manualmente centenas de quadros, eles simplesmente segmentam manualmente uns poucos quadros para projetarem o operador responsável pela perseguição do objeto através da seqüência.

Outra vantagem que esta técnica oferece é a sua aplicação em seqüências produzidas sem cuidados a priori. Por exemplo, a seqüência Jogador de Tênis de Mesa é uma seqüência real que não foi produzida com cuidados adicionais, e mesmo assim, foi possível a escolha dos objetos que queríamos segmentar (nos exemplos apresentados, a bolinha e a raquete). 
Outra contribuição deste trabalho foi a extensão apresentada do Paradigma de BeucherMeyer para imagens coloridas. A extensão é dada pela aplicação de técnicas de cálculo do gradiente colorido reduzindo o problema de detecção de bordas de objetos coloridos ao problema já resolvido para imagens em níveis de cinza. No entanto, outras métricas podem ainda ser estudadas para melhorar os resultados de segmentação de imagens coloridas.

Para dar continuidade a este trabalho, podemos vislumbrar vários tópicos de pesquisa:

- O estudo de um modelo de representação computacional da capacidade de discriminação de cores do sistema visual humano.

- A introdução de um modelo de continuidade de movimento para melhorar os resultados de segmentação, visto que ao assistirmos a seqüência, as bordas detectadas parecem tremular.

- A aplicação de operadores aperture, projetados por aprendizado computacional, para a deteç̧ão de corte seco em seqüências de imagens.

- O estudo de operadores adaptativos para deteç̧ão de marcadores. Em cada instante da seqüência, é feita uma avaliação quantitativa do resultado do operador. Se a qualidade em um dado momento começa a cair, devido à mudança do contexto estatístico, por exemplo, o operador é reprojetado, tomando-se como imagens de observação as $m$ últimas imagens onde houveram quedas na qualidade do resultado do operador. 


\section{Apêndice A}

\section{Abordagem Clássica}

No apêndice A apresentamos algumas técnicas utilizadas em segmentação de imagens e em vídeo digital $[31,32,33,34,35,36,37,38,39,40]$. Algumas destas técnicas têm como propósito edição de vídeo, codificação, etc.

\section{A.1 Chroma Key}

Uma técnica de edição de vídeo há muito utilizada é a Chroma Key [1]. Esta técnica é utilizada para combinar duas seqüências de imagens; uma delas contém alguns objetos que aparecerão na seqüência final, enquanto que os demais objetos serão substituídos. A técnica de Chroma Key é dividida em duas etapas. Na primeira, a seqüência é produzida com os objetos a serem substituídos cobertos ou pintados por uma cor. Na segunda etapa, em cada quadro da seqüência, as regiões que contém a cor utilizada para cobrir os objetos são segmentadas e substituídas por outros objetos.

$\mathrm{Na}$ etapa de produção da seqüência, ela é filmada com os objetos cobertos. Por exemplo, dançarinos podem ser filmados dançando em frente a uma parede pintada de azul, ou ainda um objeto como um vaso pode ser pintado com a mesma cor. Os objetos contidos na seqüência de imagens resultante podem ser usados como "carimbos"; tais objetos poderão ser "carimbados" em uma seqüência que possui o novo background.

Este processo de "carimbo" é realizado na segunda etapa da aplicação da técnica. Atualmente, porém, são utilizadas técnicas clássicas de reconhecimento de padrões na etapa de segmentação e substituição dos objetos. Algumas das técnicas utilizadas são a classificação por distância mínima e classificação por correlação [20]. Os atributos utilizados pelos classificadores são compostos pelos valores dos pixels contidos na imagem, objetivando classificar a cor utilizada para cobrir os objetos a serem substituídos.

A Figura A.1 mostra o exemplo de um estúdio onde se filma uma seqüência a ser utilizada no "video mixing". A Figura A.2 mostra o resultado da aplicação de Chroma Key, onde os músicos "estão tocando em frente a Torre de Piza". Apesar de Chroma Key ser amplamente usada, ela apresenta algumas desvantagens. Uma delas é a necessidade de certos cuidados a priori, como 


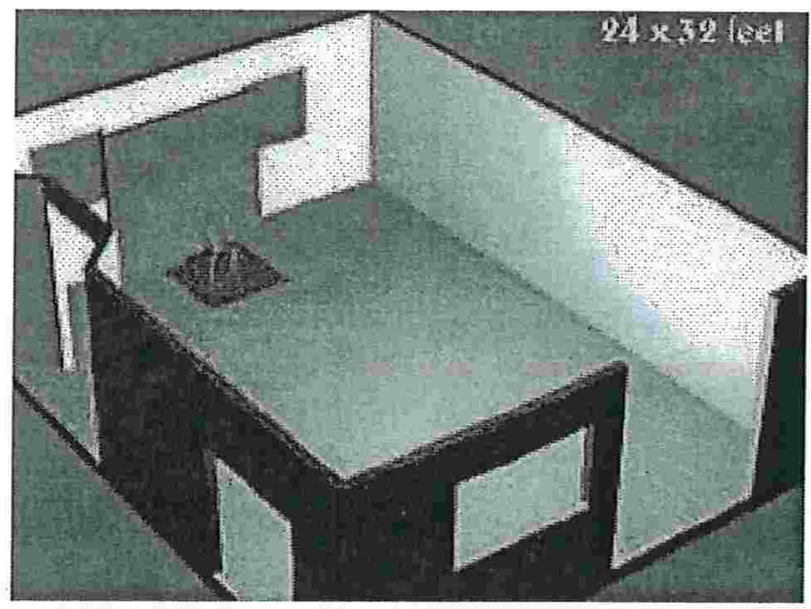

Figura A.1: Estúdio de filmagem para seqüências onde será aplicada a Chroma Key

justamente cobrir os objetos a serem substituídos. Outra desvantagem é que objetos que não devem ser substituídos mas que sejam da cor que cobre aqueles objetos, ou que possuam ao menos partes com esta cor, também serão substituídos.

\section{A.2 Segmentação Hierárquica Baseada em Contorno}

Westberg [32] apresenta um algoritmo de segmentação de regiões em movimento. Este algoritmo faz uso de uma estrutura de dados piramidal, que representa a hierarquia de classificação dos objetos. $\mathrm{O}$ algoritmo recebe como entrada uma seqüência de imagens e devolve uma seqüência contendo os contornos do(s) objeto(s) contidos em cada cena da seqüência original. A segmentação em cada frame é obtida a partir do contorno do(s) objetos(s) contidos no mesmo.

Este contorno é obtido através do refinamento da borda composta pela diferença simétrica entre dois frames. Esta diferença é uma imagem onde as regiões em que ocorreram movimento possuem pixels com intensidade não-nula e as demais regiões valem zero. Normalmente a borda de um objeto representado na diferença entre dois frames é composta pela união da borda do mesmo contido em cada um dos frames. A idéia é encontrar esta borda através de um processo hierárquico de segmentação. É importante observar que a borda de um objeto a ser segmentada corresponderá à borda do mesmo em ambos os frames utilizados para segmentá-la. Em outras palavras, haverão pequenas diferenças entre a borda do objeto e a segmentada, mas esta última será externa ao objeto em ambos os frames.

Este processo consiste na divisão da imagem em blocos e na classificação dos mesmos. Um bloco pode ser classificado como Interno (bloco contido em um objeto), Externo (bloco não contido em nenhum objeto) ou Borda (bloco que contém um pedaço da borda). Esta classificação é feita por uma função de limiarização. Quando um bloco é classificado como Interno (ou Externo) o processamento para este bloco cessa, pois quaisquer sub-blocos deste bloco também seriam classificados como Internos (ou Externos). E quando o bloco é classificado como Borda, 


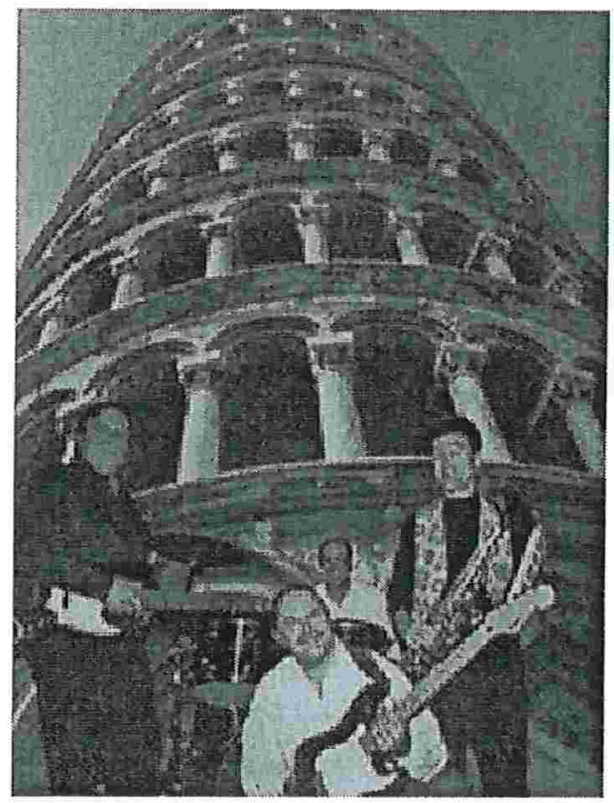

Figura A.2: Resultado de aplicação de Chroma Key.

este é subdividido em quatro sub-blocos (de modo semelhante à estrutura de uma quadtree), e cada um destes sub-blocos também é classificado no próximo nível da hierarquia. O bloco inicial é a própria imagem (que é classificada como Borda, a menos que não hajam objetos em movimento. Desta forma, a imagem é classificada como um bloco Externo e o processamento cessa). Quando os blocos classificados como Borda tiverem o tamanho mínimo (um pixel), a borda será localizada.

O algoritmo proposto inicia o processamento no nível mais baixo $(i=0)$, considerando a imagem inteira como um bloco, e se este não for classificado como um bloco de Borda o algoritmo pára.

Ao chegar ao nível $i$, todos os blocos que foram classificados como Borda no nível $i-1$ serão divididos em quatro sub-blocos e estes serão classificados como Temporariamente Internos ou Temporariamente Externos. Os blocos Temporariamente Internos mais externos serão classificados como Borda e os Temporariamente Internos restantes serão classificados como Internos, e os restantes, então, serão classificados como Externos.

O motivo de se classificar os sub-blocos que não estão contidos no objeto em Temporariamente Externos ao invés de Externos é devido ao processo de refinamento da borda, onde alguns blocos Temporariamente Externos ficam dentro do objeto. Isto é corrigido através de um passo adicional de reclassificação, que classifica todos os blocos Temporariamente Externos como Internos quando necessário.

O algoritmo além das características descritas acima tem como características: a restrição de que deve haver uma área coerente de movimento; e o critério de classificação que faz uso de uma limiarização que varia de acordo com o nível em que o processo se encontra. 


\section{A.3 Segmentação Morfológica Hierárquica para Codificação}

Uma outra proposta de segmentação morfológica aplicada à codificação de imagens, apresentada por Salembier e Pardàs [34], extende resultados anteriores aplicados em imagens estáticas para seqüências de imagens. Os autores apresentam algumas soluções para problemas relacionados ao modelo proposto como complexidade computacional e como considerar tal modelo com relação ao sinal.

O algoritmo é hierárquico no sentido de repetir o algoritmo de segmentação de modo que a cada repetição a segmentação é aprimorada. Este algoritmo de segmentação é dividido em quatro partes: simplificação, extração de marcadores, passo de decisão e estimação da qualidade.

A função do passo de simplificação é a de controlar o tipo e a quantidade de informação que é mantida para a segmentação. A noção de hierarquia deve-se a este passo. No primeiro nível a simplificação é muito forte, descartando a maior parte da informação, e nos níveis subseqüentes a simplificação é reduzida, aumentando a precisão dos resultados. Isto ocorre porque inicialmente, o elemento estruturante utilizado é grande e seu tamanho diminui na execução deste passo nos próximos níveis.

Dois operadores apropriados à utilização no passo de simplificação são a abertura por reconstrução e o fechamento por reconstrução. O primeiro elimina regiões de alta intensidade que não se ajustem ao elemento estruturante e o segundo trata da mesma maneira as regiões de baixa intensidade. Além disto, ambos os operadores restauram os contornos dos objetos que restaram na imagem. Porém, os autores apontam que ao aplicarem a abertura-fechamento por reconstrução em uma seqüência de três frames utilizando como elemento estruturante um paralelepípedo, algumas regiões pertencentes ao fundo da imagem que estão na trajetória dos objetos têm os pontos de textura conectados. Os autores apresentam como solução, a aplicação de uma abertura (fechamento) por reconstrução parcial, definido(s) por:

$$
\begin{aligned}
& \gamma^{(r e c)}\left(\varepsilon_{n}(f), \gamma_{k}(f)\right) \\
& \varphi^{(r e c)}\left(\delta_{n}(f), \varphi_{k}(f)\right)
\end{aligned}
$$

onde $\varepsilon_{n}$ e $\delta_{n}$ são, respectivamente, os operadores morfológicos de erosão e dilatação, e $k$ é um parâmetro que controla a suavização na reconstrução. Esta suavização varia desde a reconstrução completa $(k=0)$ até nenhuma reconstrução $(k=n)$.

O passo seguinte é o de extração de marcadores, que consiste na localização de regiões homogêneas. Este passo devolve um conjunto de marcadores rotulados, que marcam as regiões homogêneas. Estes rótulos consistem em regiões onde o nível de cinza é constante. Junto com os marcadores rotulados, o passo de extração de marcadores também devolve as áreas de incerteza, que são áreas que não foram rotuladas.

Existem várias técnicas para a extração de tais marcadores. Os autores apresentam duas destas técnicas: a primeira extrai marcadores de regiões planas, rotulando as funções no espaço onde os níveis de cinza são constantes. Isto é feito através de um algoritmo de busca em largura; a segunda extrai os marcadores através de extração de contraste, através da aplicação de um operador $c$,

$$
c=\left|I d-\operatorname{Min}\left\{\gamma_{n} \varphi_{n}, \operatorname{Max}\left\{\varphi_{n} \gamma_{n}, I d\right\}\right\}\right|
$$


onde $I d$ é a identidade (imagem original). Um detalhe muito importante é que não é objetivo deste passo detectar as bordas mas sim do passo seguinte, o de decisão.

O passo de decisão recebe como entradas a imagem original e o conjunto de marcadores definindo os objetos a serem segmentados e devolve uma seqüência de rótulos como resultado da segmentação. Este passo consiste basicamente na aplicação do algoritmo de watershed para a obtenção dos contornos dos objetos marcados. Porém, os autores apontam o gradiente da imagem como ineficaz para se encontrar tais contornos. Isto ocorre porque, ao contrário de imagens estáticas onde a espessura do gradiente é estreita (um ou dois pixels), o gradiente de imagens em movimento é mais espesso e é muito dificil encontrar as bordas somente com o gradiente. Os autores então apresentam uma versão modificada do algoritmo de watershed [34] que é aplicado diretamente sobre a imagem.

O último passo é o de estimação da qualidade da segmentação. É este passo que indica ao próximo nível hierárquico onde a segmentação deve ser aprimorada. Esta estimação pode ser feita reconstruíndo o frame e calculando a diferença entre o frame original e o reconstruído. As áreas que possuírem muitas diferenças são as áreas que precisam ser melhoradas. Esta diferença é chamada de resíduo e guarda a informação sobre a qualidade atual da segmentação.

\section{A.4 Algoritmos Occam para Estimação de Movimento}

De maneira geral, as técnicas utilizadas em estimação de movimento utilizam-se principalmente da correspondência entre os pixels. Isto normalmente é feito através da identificação de características locais em cada frame e depois computa um matching entre as mesmas. Como conseqüência, o custo computacional das mesmas pode crescer exponencialmente no número de características estudadas. Uma aproximação utilizada então foi a de considerar a estimação de movimento como um problema de otimização. Este problema é definido em termos de restrições impostas pela correspondência entre os pixels e em termos de restrições do modelo real.

Schweitzer [36] propõe uma aproximação para estimação de movimento. A idéia é considerar uma seqüência de vídeo como um conjunto de parâmetros e, através deste conjunto, gerar uma função que prediga frames desconhecidos.

Um dos objetivos da técnica apresentada é compactar a codificação de preditores de frames. A complexidade de um preditor é definida pela codificação de todos os preditores possíveis. Se esta codificação for quase ótima, os preditores também serão quase ótimos.

Antes de apresentar as idéias básicas deste trabalho, faz-se necessária uma introdução à notação utilizada. Uma seqüência de vídeo digital é uma função de intensidade definida no tempo e no espaço $I(x, y, t)$. Um frame é definido pela função $I(x, y, t)$ quando $t$ é constante. Um pixel é definido pela mesma função quando os valores de $x, y$ e $t$ são constantes.

Existe uma correspondência entre dois frames $I\left(x_{1}, y_{1}, t_{1}\right)$ e $I\left(x_{2}, y_{2}, t_{2}\right)$ se $t_{1} \neq t_{2}$ e se $\left(x_{1}, y_{1}\right)$ e $\left(x_{2}, y_{2}\right)$ forem projeções do mesmo ponto 3D. Esta correspondência é definida em termos de duas funções $U_{x}$ e $U_{y}$. Podemos então dizer que existe uma correspondência entre os pixels $I\left(x+U_{x}\left(x, y, t_{1}, t_{2}\right), y+U_{y}\left(x, y, t_{1}, t_{2}\right), t_{1}\right)$ e $I\left(x, y, t_{2}\right)$, para todo $x, y, t_{1}$ e $t_{2}$. 
Seja $I_{0}(x, y)=I(x, y, 0)$ um frame de referência. O movimento em uma imagem é definido pela correspondência entre os pixels $I_{0}\left(x+U_{x}(x, y, t), y+U_{y}(x, y, t)\right)$ e $I(x, y, t)$. Podemos ainda especificar a seqüência inteira em termos do frame de referência e do movimento como

$$
I(x, y, t) \approx I_{0}\left(x+U_{x}(x, y, t), y+U_{y}(x, y, t)\right) .
$$

Finalmente, definimos uma função $P$ como preditor da seqüência $I(x, y, t)$ se

$$
I(x, y, t) \approx P(x, y, t) .
$$

O erro de predição no instante $t$ é definido por $E=\sum_{x, y}\|P(x, y, t)-I(x, y, t)\|$.

Os algoritmos Occam são uma estratégia aplicada na resolução de problemas através de aprendizado computacional onde os preditores são consistentes com o conjunto de exemplos de treinamento, não possuem muitas restrições e são "simples". Estes algoritmos garantem a produção de um preditor preciso com uma codificação que é significantemente menor que os dados originais. O projeto de um algoritmo Occam para estimação de movimento pode ser resumido nos seguintes passos. Após determinar o tipo de preditor que se quer produzir, determina-se um esquema de codificação para todos os preditores do tipo definido. Se este esquema produzir descrições significantemente mais curtas que os dados originais, crie um algoritmo que receba frames como entrada e devolva o preditor de comprimento mínimo.

Schweitzer propõe um algoritmo [36] que segue os passos descritos acima. A codificação proposta é através do particionamento de um frame. O erro de predição é novamente definido como

$$
E=\sum_{r \in R} e_{r}
$$

onde $R$ é uma partição do frame e $e_{r}$, o erro de predição em um segmento $r \in R$, é definido como $e_{r}=\sum\left\|P_{r}(x, y, t)-I(x, y, t)\right\|$. O algoritmo proposto cria a partição $R$ e associa um preditor $P_{r}$ para cada segmento de $R$ de forma a compacțar a representação do preditor.

O particionamento é feito através da divisão dos segmentos que compõem o frame (o frame é o segmento original) em retângulos, e cada um destes retângulos é um novo segmento. Estes retângulos são armazenados em uma estrutura de dados semelhantes a uma quadtree. Este particionamento pode ser considerado como um problema de minimização. Esta minimização pode ser feita em duas situações: dado o erro $E$, minimizar o número de segmentos $n$ (retângulos); e dado $n$, minimizar $E$. Esta minimização pode ser feita, por exemplo, através do seguinte algoritmo: A partir de uma partição original $R$ que cobre o frame inteiro, repetir $n-1$ vezes os seguintes passos:

1. Remova de $R$ o retângulo $r$ que possua o maior erro $e_{r}$.

2. Divida $r$ em dois retângulos $r_{1}$ e $r_{2}$ tal que $e_{r_{1}}+e_{r_{2}}$ seja mínimo.

3. Devolva $r_{1}$ e $r_{2}$ para $R$.

Vale ressaltar que a segmentação do frame em retângulos e a estimação de movimento são feitos simultaneamente. 
Para finalizar, uma das características de um algoritmo Occam é que ele escolhe o preditor mais "simples". O critério de "simplicidade" usado aqui é o comprimento de codificação (ou, o número de retângulos). Assim, um preditor "simples" teria um número mínimo de retângulos.

\section{A.5 Perseguição de Alvo por Comparação de Características}

Um sistema de análise de movimento aplicável em imagens reais para perseguição de veículos é apresentado em [38]. Este sistema é dividido em duas etapas: na primeira delas, os objetos em movimentos são separados do background estático. Na segunda, filtros de Kalman utilizando dois vetores de estado são aplicados à perseguição dos objetos em movimento.

Durante a primeira etapa, uma estrutura de dados piramidal com $L+1$ níveis é construída. Para cada nível da pirâmide, são computadas derivadas temporais, $D_{x, y}^{l}(t), l=0, \ldots, L$, de onde também são extraídas magnitudes e mudanças de sinal. Enquanto as altas magnitudes são encontradas nas bordas dos objetos em movimento, as mudanças significativas de sinal se encontram no interior dos objetos em questão. Estas mudanças definem valores $\in\{0,1\}$ através da função

$$
\Psi_{x, y}^{l}=\left\{\begin{array}{l}
1, \text { se } P_{x, y}^{l}<-\theta_{1} \\
0, \text { caso contrário, }
\end{array}\right.
$$

onde $\theta_{1}$ é um limiar fixo e $P_{x, y}^{l}=D_{x+m, y+n}^{l}(t) D_{x+u, y+v}^{l}(t), m, n, u, v \in\{-1,0,1\}$.

$\mathrm{O}$ operador que estima movimento é definido então como

$$
E_{x, y}^{l}=\max \left\{\left|D_{x, y}^{l}(t)\right|, \Psi_{x, y}^{l}\right\}
$$

Em níveis de resolução mais alta, as mudanças temporais detectadas por $E_{x, y}^{l}$ se concentram nas bordas dos objetos enquanto que nos níveis de resolução mais baixa, cada objeto possui uma máscara compacta. A idéia é propagar estas máscaras dos níveis de resolução mais baixa para os níveis de resolução mais alta. Isto é feito através da combinação da informação na posição $(x, y)$ no nível $l+1$ com as informações nas posições $(2 x+i, 2 y+j), i, j \in\{0,1\}$, no nível $l$ (de resolução maior).

As máscaras encontradas são representações grosseiras dos objetos, e são utilizadas para encontrar as bordas de tais objetos. Isto é feito considerando-se, em cada nível de resolução $l$, uma máscara binária $M_{x, y}^{l}$, contendo $N$ regiões representando os objetos em movimento. Cada região $R_{i} \in M_{x, y}^{l}, i=1 \ldots N$, é usada como uma janela de busca por um polígono convexo $P_{i}$, onde cada um destes polígonos é definido por um conjunto de pontos $\left\{\left(x_{1}^{i}, y_{1}^{i}\right), \ldots,\left(x_{m}^{i}, y_{m}^{i}\right)\right\}$. O processo de propagação dos contornos detectados para os níveis de resolução maiores é semelhante ao processo de propagação dos marcadores na etapa anterior; quanto maior a resolução, mais refinados serão os contornos detectados.

Na segunda etapa do sistema, os objetos em movimento são perseguidos através da aplicação de filtros de Kalman. Estes filtros estimam consistentemente, a partir de um vetor de estado $\mathrm{x}_{k}$, um vetor $\widehat{\mathbf{x}}_{k}$ ( $k$ representa aqui um índice de tempo). Os filtros de Kalman são utilizados neste sistema para perseguir um conjunto de $N$ atributos de um objeto em movimento, onde, para 
cada atributo $n=1, \ldots, N$, são usados dois vetores $\mathbf{x}_{k}^{n}$ e $\mathbf{v}_{k}^{n}$ que representam, respectivamente, sua posição e velocidade. $\mathrm{O}$ vetor $\widehat{\mathrm{x}}_{k}=\left(x_{k}^{1}, y_{k}^{1}, x_{k}^{2}, y_{k}^{2}, \ldots, x_{k}^{N}, y_{k}^{N}\right)^{T}$ representa o vetor posição estimado, onde $x_{k}^{i}$ e $y_{k}^{i}$ representam as coordenadas espaciais do atributo $i$. O vetor $\widehat{\mathbf{v}}_{k}=$ $\left(u_{k}, v_{k}, s_{k}\right)^{T}$ representa o vetor velocidade estimado, onde $u_{k}$ e $v_{k}$ representam as translações ao longo dos eixos $x$ e $y$ e $s_{k}$ é um fator de escala.

Os autores propõem, como atributos a serem perseguidos, os contornos dos objetos em movimento e suas próprias regiões. A primeira proposta (contornos dos objetos), apesar de computacionalmente mais viável, encontra problemas quando os contornos não estão bem definidos. Já a segunda proposta (regiões dos objetos) apesar de um custo computacional mais elevado, tem uma detecção mais precisa e não depende do background.

\section{A.6 Informação Vetorial e Critérios de Similaridade}

Radig [40] apresenta também um método de segmentação e perseguição de objetos. A segmentação e a perseguição são executados em etapas distintas, pois a etapa de perseguição depende dos resultados da etapa de segmentação. De posse dos objetos segmentados, os objetos são perseguidos, frame a frame, via critério de similaridade.

A etapa de segmentação inicia-se com um pré-processamento, que consiste em transladar uma máscara sobre a imagem e coletar os valores sob ela. Em cada pixel da imagem, a máscara é considerada como um plano e os valores coletados pela máscara são utilizados para se estimar a equação deste plano. De posse da equação estimada do plano $\widehat{z}(x, y)=\widehat{A} x+\widehat{B} y+\widehat{C}(\mathrm{e}$, conseqüentemente, dos coeficientes do vetor normal ao plano), calcula-se, para cada pixel que se encontra sob o ponto origem do plano (máscara) dois valores: o azimute e a distância polar. O primeiro é o ângulo entre o eixo positivo $x$ e a projeção do vetor normal ao plano. O segundo é o ângulo entre o eixo $z$ e o vetor normal a plano. Ambos são calculados pelas equações

$$
\begin{aligned}
\tan (\text { distância polar }) & =\sqrt{\left(\widehat{A}^{2}+\widehat{B}^{2}\right)} \\
\tan (\text { azimute) } & =-\frac{\widehat{B}}{\widehat{A}}
\end{aligned}
$$

e, de posse destes dois valores, podemos considerar um pixel como uma quíntupla (Gray, Azi, Pol, $Y, X)$, onde $X$ e $Y$ são as coordenadas dos pixels, Gray é seu nível de cinza e $A z i$ e $P o l$ são, respectivamente, o azimute e a distância polar.

O algoritmo de segmentação inicia o processamento criando-se um grafo onde cada nó representa um pixel (Gray, Azi, Pol, $Y, X$ ), e, cada um destes nós inicialmente tem uma aresta ligando-o a cada um de seus oito vizinhos.

Em seguida, os parâmetros de segmentação de regiões são passados via arquivo. Para cada região a ser segmentada, é passado um conjunto de parâmetros, que são intervalos numéricos para cada atributo da quíntupla ( $G r a y, A z i, P o l, Y, X)$. Estes intervalos compõem funções booleanas, onde, verifica-se cada atributo se este está contido em seu intervalo correspondente. 
Todos os pixels são submetidos a estas funções booleanas, e se alguma destas funções retornar o valor falso (ou seja, se algum dos atributos estiver fora do respectivo intervalo passado como parâmetro) para um pixel, todos os arcos que ligam o nó, que representa este pixel, a seus vizinhos serão cortados, isolando este nó. Após esta etapa, o grafo será composto de componentes conexas com pelo menos dois nós.

No passo seguinte, são extraídos novos atributos das regiões remanescentes. Estes atributos são utilizados tanto na seleção de regiões de interesse quanto na perseguição frame a frame destas regiões. Para selecionar regiões de interesse, basta fazer uma limiarização com base nestes atributos. As regiões cujos atributos não se ajustam aos parâmetros escolhidos são descartadas.

Como resultado da aplicação das operações acima, temos regiões segmentadas baseadas em um conjunto de parâmetros. A próxima etapa é a de perseguição de cada região, frame a frame. Isto é feito basicamente calculando-se a similaridade entre as regiões e depois, criando-se pares entre as mesmas.

O primeiro passo é do cálculo de similaridade entre as regiões, duas a duas. Para cada atributo regional, calcula-se um valor entre 0.0 (se as regiões forem completamente diferentes) e 1.0 (se as regiões forem idênticas). O valor mínimo encontrado entre duas regiões é o valor de similaridade entre elas. No entanto, estes cálculos só podem ser feitos para regiões que foram extraídas baseadas no mesmo conjunto de parâmetros. Caso contrário, o valor de similaridade entre estas regiões é zero. Ainda sobre o cálculo de similaridade, para cada região $i$ contida em um frame no instante $t$, são calculados os valores de similaridade entre a região $i$ e todas as regiões contidas nos frames nos instantes $t-1$ e $t+1$.

Após calcular estes valores de similaridade, são criadas, para cada uma das regiões, duas listas ordenadas pelos valores de similaridade: uma com relação ao frame seguinte e outra para o frame anterior. Duas regiões formam um par se uma aparece na lista apropriada da outra (no caso de ambigüidade, o valor mais alto de similaridade é o critério de desempate. Isto quer dizer que, dadas duas regiões, $A$ contida num frame no instante $t$, e $B$ contida num frame no instante $t+1$, se $A$ pertencer à lista da região $B$ relativa ao frame $t$ e se $B$ pertencer à lista da região $A$ relativa ao frame $t+1$, então $A$ e $B$ formam um par.

Como base nestes critérios de similaridade e paridade, pode-se construir uma lista de descritores para cada região, possibilitando a construção de uma seqüência para cada uma destas regiões. 


\section{Apêndice B}

\section{Notação Utilizada}

$E$

Subconjunto retangular finito de pontos de $\mathbb{Z} \times \mathbb{Z}$

$K=[0, k] \quad$ Intervalo Fechado de $\mathbb{Z}$

$f, g \quad$ Funções de $E$ em $K$

$X, Y \quad$ Subconjuntos de $E$

$\mathcal{X}, \mathcal{Y} \quad$ Coleções de Subconjuntos de $E$

$a, b \quad$ Elementos de $\Re$

$|X| \quad$ Cardinalidade de um conjunto $X$

$x, y \quad$ Pontos em $E$

Fun $[X, Y] \quad$ Conjunto de todas as funções $f: X \rightarrow Y$

$X_{y} \quad$ Translação do conjunto $X$ pelo vetor $y$

$f_{y} \quad$ Translação da função $f$ pelo vetor $y$

$\leq \quad$ Relação de Ordem "Menor ou Igual"

$\subseteq \quad$ Relação de Ordem "Está Contido em"

$(\mathcal{L}, \leq) \quad$ Conjunto parcialmente ordenado 


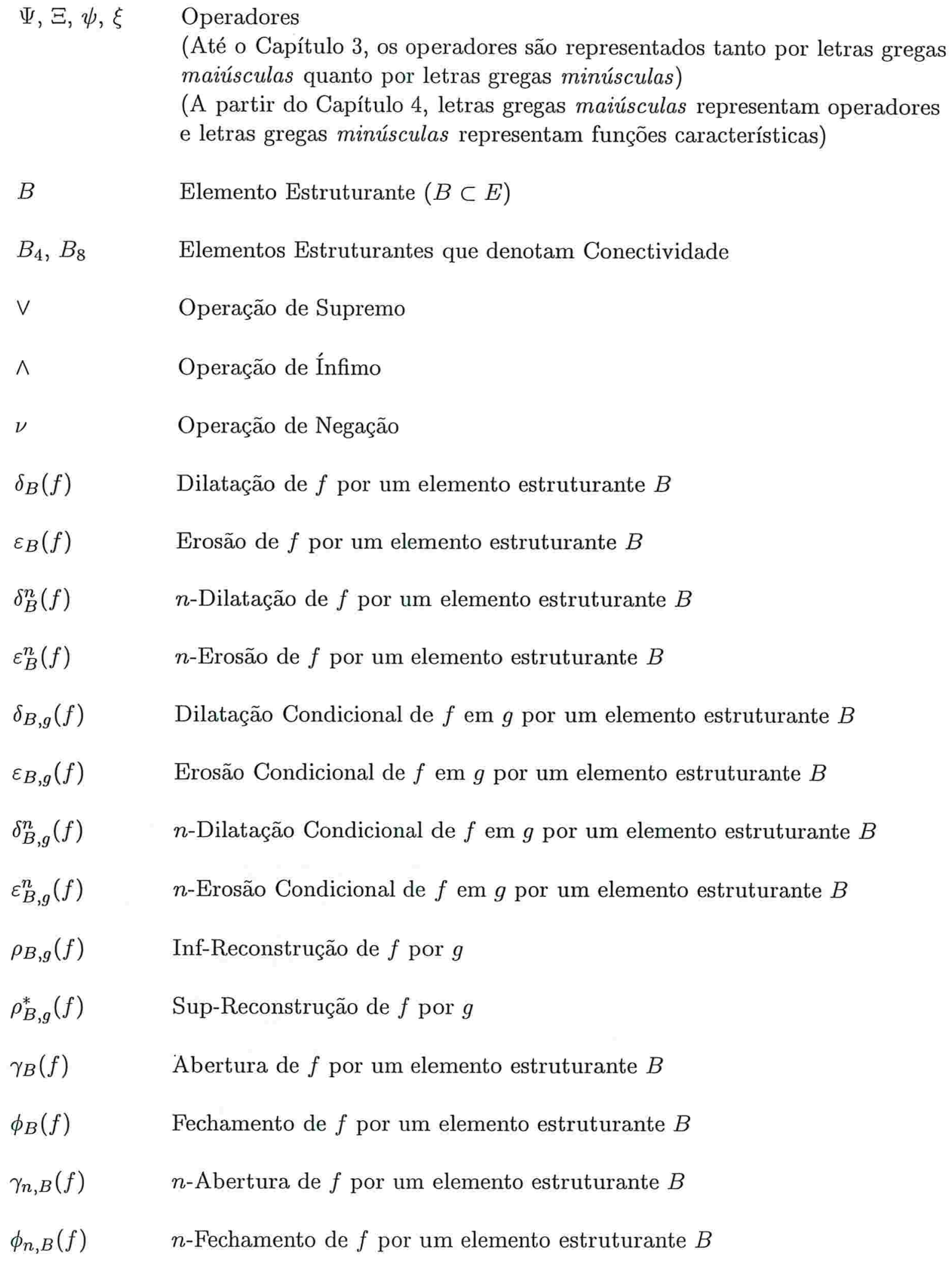


$\psi_{n, B}^{i}(f) \quad$ Filtro Alternado Sequencial

$\tau_{B}^{a b e}(f) \quad$ Top-Hat por Abertura

$\tau_{B}^{f e c}(f) \quad$ Top-Hat por Fechamento

$\nabla_{B}(f), \nabla_{B}^{i}(f)$

$\nabla_{B}^{e}(f) \quad$ Gradientes Morfológicos de $f$

$N_{G}(x) \quad$ Vizinhança de $x \in E$

$C=\left\{p_{0}, p_{1}, \cdots, p_{m}\right\}$

Caminho de $p_{0}$ a $p_{m}, p_{0}, p_{m} \in E$

$\theta(f) \quad$ Mudança de Homotopia de $f$

$\Phi_{Y}^{X}(f) \quad$ Leveling $\operatorname{de} f$

$\gamma_{a}^{\text {área }}(f) \quad$ Area Opening Binário

$\Gamma_{a}^{\text {área }}(f) \quad$ Area Opening em Níveis de Cinza

$\Phi_{a}^{\text {área }}(f) \quad$ Area Closing em Níveis de Cinza

$\mathcal{F} \quad$ Conjunto de todas as Zonas Planas de uma Imagem

$\mathcal{N}(F) \quad$ Conjunto de todas as Zonas Planas Adjacentes a Zona Plana $F$

$\mu_{a}(f) \quad$ Area Merging

$\theta_{A}\left(B_{i}\right) \quad$ Zona de Influência Geodésica de $B \subset A$

$\Theta_{A}(B) \quad$ União das Zonas de Influência Geodésica de todas os Subconjuntos de $B$

$\Sigma_{h}(f) \quad$ Conjunto de todos os Mínimos Regionais de $f$ com Altitude $h$

$\xi(f) \quad$ Conjunto de todas as Bacias de Captação de $f$

$\Xi(f) \quad$ Linhas de Partição de Águas de $f$

$\bar{f}, \bar{g} \quad$ Funções (ou imagens) Multibanda 
$\bigvee\{\bar{f}, \bar{g}\} \quad$ Supremo entre duas Funções Multibanda

$\bigwedge\{\bar{f}, \bar{g}\} \quad$ Ínfimo entre duas Funções Multibanda

$\delta_{B}(\bar{f}) \quad$ Dilatação de uma imagem multibanda $\bar{f}$ por um elemento estruturante $B$

$\varepsilon_{B}(\bar{f}) \quad$ Erosão de uma imagem multibanda $\bar{f}$ por um elemento estruturante $B$

$\nabla_{B}^{I}(f), \nabla_{B}^{I I}(f)$

$\nabla_{B}^{I I I}(f), \nabla_{B}^{I V}(f)$,

$\nabla_{B}^{V}(f), \nabla_{B}^{V I}(f)$ Gradientes Coloridos

$\Gamma_{a}^{\text {área }}(\bar{f}) \quad$ Area Opening Multibanda

$X^{m} \quad$ Produto Cartesiano entre $m$ Conjuntos $\left(X^{m}=X_{1} \times X_{2} \times \cdots \times X_{m}\right)$

$\mu_{a}(\bar{f}) \quad$ Area Merging Multibanda

$W \quad$ Janela definida Espacialmente $(W \subset E)$

$f / W \quad$ Restrição de $f$ em $W$

$\mathcal{F}_{f / W} \quad$ Classe de Restrição $W$ em $f$

$K=\left\{-\frac{k-1}{2}, \ldots,-1,0,1, \ldots, \frac{k-1}{2}\right\}$

Janela nos Níveis de Cinza

$f / K_{y} \quad$ Enjanelamento de $f$ por uma Janela $K$ em $y$

$\mathrm{X}, \mathrm{Y} \quad$ Conjuntos Aleatórios Discretos

$\mathrm{x}, \mathrm{y} \quad$ Realizações de um Conjunto Aleatório Discreto

$\Psi_{W K} \quad$ Espaço de todos os Operadores Aperture definidos por uma Janela $W$

e uma Janela $K$.

$\epsilon[\mathrm{X}, \mathrm{Y}] \quad$ Função de Erro, usada como Critério de Proximidade entre X e Y

$\Psi_{R} \quad$ Operador $\Psi$ aplicado somente dentro de uma Máscara de Restrição $R$ 
$(f \circ g) \quad$ Correlação entre $f$ e $g$.

$(f \bullet g) \quad$ Módulo da Diferença entre $f$ e $g$.

$\Xi_{t}(f), \Xi_{t}^{\bullet}(f) \quad$ Funções de Limiarização, dado $t \in K$

$\Omega_{b}(f), \Omega_{b}^{\bullet}(f) \quad$ Funções de Atribuição de Rótulos, dado $b \in K$

$\mathcal{G} \quad$ Conjunto de Kernels de Correlação

$\Upsilon_{g_{i}, t_{i}, v_{i}}(f) \quad$ Classificador

$\Gamma_{\mathcal{G}}(f) \quad$ Multiclassificador

$\Lambda_{\Pi}(f) \quad$ Operador Conexo Utilizado para Calcular Levelings

em um dos Experimentos Realizados 


\section{Apêndice $\mathrm{C}$}

\section{Artigos Publicados}

O trabalho apresentado nesta dissertação também resultou na publicação de diversos artigos, em várias conferências.

- R. Hirata Jr., J. Barrera, F. C. Flores and R. A. Lotufo. Automatic Design of Morphological Operators for Motion Segmentation. In J. Stolfi and C. L. Tozzi, editors, In Proceedings of Sibgrapi'99, pages 283-292, Campinas, SP, Brazil, 1999.

- F. C. Flores, R. Hirata Jr., J. Barrera, R. A. Lotufo and F. Meyer. Morphological Operators for Segmentation of Color Sequences. In Proceedings of Sibgrapi'2000, pages 300-307, Gramado, Brazil, October 2000.

- R. Hirata. Jr., F. C. Flores, J. Barrera, R. A. Lotufo and F. Meyer. Color Image Gradients for Morphological Segmentation. In Proceedings of Sibgrapi'2000, pages 316-322, Gramado, Brazil, October 2000.

- F. C. Flores and J. Barrera. Computational Learning Applied to Image Sequence Segmentation. In L. N. Barros, R. M. Cesar Jr., et al, editors, Proceedings of IBERAMIA/SBIA 2000 - Workshop on Artificial Intelligence and Computer Vision, pages 162-166, November 2000.

Em breve, um outro artigo será redigido e submetido, desta vez, para uma revista. 


\section{Referências Bibliográficas}

[1] C. Finch. Special Effects: Creating Movie Magic. Abbeville Press, 1984.

[2] R. Hirata Jr., J. Barrera, F. C. Flores, and R. A. Lotufo. Automatic Design of Morphological Operators for Motion Segmentation. In J. Stolfi and C. L. Tozzi, editors, Proc. of Sibgrapi'99, pages 283-292, Campinas, SP, Brazil, 1999.

[3] F. C. Flores, R. Hirata Jr., J. Barrera, R. A. Lotufo, and F. Meyer. Morphological Operators for Segmentation of Color Sequences. In Proceedings of SIBGRAPI'2000, pages 300-307, Gramado, Brazil, October 2000.

[4] F. C. Flores and J. Barrera. Computational Learning Applied to Image Sequence Segmentation. In L. N. Barros, R. M. César Jr., and et al, editors, Procedings of IBERAMIA/SBIA 2000 - Workshop on Artificial Intelligence and Computer Vision, pages 162-166, November 2000.

[5] F. Meyer and S. Beucher. Morphological Segmentation. Journal of Visual Communication and Image Representation, 1(1):21-46, September 1990.

[6] S. Beucher and F. Meyer. Mathematical Morphology in Image Processing, chapter 12. The Morphological Approach to Segmentation: The Watershed Transformation, pages 433-481. Marcel Dekker, 1992.

[7] R. Hirata Jr. Segmentação de Imagens por Morfologia Matemática. Master's thesis, Instituto de Matemática e Estatística - USP, março 1997.

[8] J. Barrera and E. R. Dougherty. Representation of Gray-Scale Windowed Operators. In Henk J.A.M. Heijmans and Jos B.T.M. Roerdink, editors, Mathematical Morphology and its Applications to Image and Signal Processing, volume 12 of Computational Imaging and Vision, pages 19-26. Kluwer Academic Publishers, Dordrecht, May 1998.

[9] R. Hirata Jr., E. R. Dougherty, and J. Barrera. Aperture Filters. Signal Processing, 80(4):697-721, April 2000.

[10] R. Hirata Jr., E. R. Dougherty, and J. Barrera. Some Applications of Aperture Filters. In J. Goutsias, L. Vincent, and D. S. Bloomberg, editors, Mathematical Morphology and its Applications to Image and Signal Processing, volume 18, pages 119-128. Kluwer Academic Publishers, 2000. Fifth ISMM. 
[11] J. Serra. Image Analysis and Mathematical Morphology. Academic Press, 1982.

[12] J. Serra. Image Analysis and Mathematical Morphology. Volume 2: Theoretical Advances. Academic Press, 1988.

[13] H. J. A. M. Heijmans. Morphological Image Operators. Academic Press, Boston, 1994.

[14] G. J. F. Banon and J. Barrera. Bases da Morfologia Matemática para Análise de Imagens Binárias. IX Escola de Computação, Pernambuco, Julho 1994.

[15] J. Barrera, G. J. F. Banon, R. A. Lotufo, and R. Hirata Jr. MMach: a Mathematical Morphology Toolbox for the Khoros System. Electronic Imaging, 7(1):174-210, 1998.

[16] R. M. Haralick, S. R. Sternberg, and X. Zhuang. Image Analysis Using Mathematical Morphology. IEEE Transactions on Pattern Analysis and Machine Intelligence, PAMI9(4):532-550, July 1987.

[17] J. Facon. Morfologia Matemática: Teoria e Exemplos. Editora Universitária Champagnat da Pontifícia Universidade Católica do Paraná, 1996.

[18] F. Preparata and R. Yeh. Introduction to Discrete Structures for Computer Science and Engineering. Computer Science and Information Processing. Addison-Wesley, 1973.

[19] W. K. Pratt. Digital Image Processing. John Wiley and Sons, 1991.

[20] R. C. Gonzalez and R. E. Woods. Digital Image Processing. Addison-Wesley Publishing Company, 1992.

[21] R. Hirata Jr., F. C. Flores, J. Barrera, R. A. Lotufo, and F. Meyer. Color Image Gradients for Morphological Segmentation. In Proceedings of SIBGRAPI'2000, pages 316-322, Gramado, Brazil, October 2000.

[22] T. H. Cormen, C. E. Leiserson, and R. L. Rivest. Introduction to Algorithms. McGraw-Hill, 1990.

[23] H. J. A. M. Heijmans. Introduction to Connected Operators. In E. R. Dougherty and J. T. Astola, editors, Nonlinear Filters for Image Processing, pages 207-235. SPIE-The International Society for Optical Engineering, 1999.

[24] F. Meyer. From Connected Operators to Levelings. In H.J.A.M. Heijmans and J.B.T.M. Roerdink, editors, Mathematical Morphology and its Applications to Image and Signal Processing, Proc. ISMM'98, pages 191-198. Kluwer Academic Publishers, 1998.

[25] N. S. Tomita. Programação Automática de Máquinas Morfológicas Binárias baseada em Aprendizado PAC. Master's thesis, Instituto de Matemática e Estatística - Universidade de São Paulo, São Paulo, SP - Brasil, março 1996.

[26] J. Barrera, E. R. Dougherty, and N. S. Tomita. Automatic Programming of Binary Morphological Machines by Design of Statistically Optimal Operators in the Context of Computational Learning Theory. Electronic Imaging, 6(1):54-67, January 1997. 
[27] N. S. Tomita. Programação Automática de Máquinas Morfológicas Binárias baseada em Aprendizado PAC. In Anais do XXIII Seminário Integrado de Software e Hardware - IX Concurso de Teses e Dissertações - XV Concurso de Trabalhos de Iniciação Científica, pages 517-525, Recife, PE, Agosto 1996. XVI Congresso da SBC, Sociedade Brasileira de Computação.

[28] J. Goutsias. Morphological Analysis of Discrete Random Shapes. Journal of Mathematical Imaging and Vision, 2:193-215, 1992.

[29] J. Barrera, G. J. F. Banon, and R. A. Lotufo. A Mathematical Morphology Toolbox for the KHOROS System. In Image Algebra and Morphological Image Processing V, Proc. of SPIE, California, July 1994.

[30] R. Lotufo and A. Falcao. The Ordered Queue and the Optimality of the Watershed Approaches. In J. Goutsias, L. Vincent, and D. S. Bloomberg, editors, Mathematical Morphology and its Applications to Image and Signal Processing, volume 18, pages 341-350. Kluwer Academic Publishers, 2000. Fifth ISMM.

[31] V. Kruger and G. Sommer. Affine Real-Time Face Tracking Using a Wavelet Network. In ICCV'99 Workshop Recognition, Analysis and Tracking of Faces and Gestures in Real-Time Systems. Corfu, Greece, September 1999.

[32] L. Westberg. Hierarquical Contour-Based Segmentation of Dynamic Scenes. IEEE Transactions on Pattern Analysis and Machine Intelligence, 14(9):946-952, September 1992.

[33] S. McKenna Y. Raja and S. Gong. Tracking and Segmenting People in Varying Lighting Conditions Using Colour. In Proceedings of IEEE Face and Gesture Recognition. Nara, Japan, April 1998.

[34] P. Salembier and M. Pardàs. Hierarchical Morphological Segmentation for Image Sequence Coding. IEEE Transactions on Image Processing, 3(5):639-651, September 1994.

[35] S. Birchfield. Elliptical Head Tracking Using Intensity Gradients and Color Histograms. In Proceedings of IEEE CVPR, pages 232-237. Santa Barbara, California, June 1998.

[36] H. Schweitzer. Occam Algorithms for Computing Vision Motion. IEEE Transactions on Pattern Analysis and Machine Intelligence, 17(11):1033-1042, November 1995.

[37] T. Maurer and C. Malsburg. Tracking and Learning Graphs and Pose on Image Sequences of Faces. In Proceedings of International Conference on Artificial Neural Networks. Bochum, 1996.

[38] S. Gil, R. Milanese, and T. Pun. Comparing Features for Target Tracking in Traffic Scenes. Pattern Recognition, 29(8):1285-1296, August 1996.

[39] G. Hager and P. Belhumeur. Efficient Region Tracking with Parametric Models of Geometry and Illumination. IEEE Transactions on PAMI, 10(20):1025-1039, October 1998.

[40] B. M. Radig. Image Sequence Analysis, chapter Chapter 5 : Image Region Extraction of Moving Objects, pages 311-354. Springer-Verlag, 1981. 